A CASE STUDY OF IMPLEMENTING RESPONSE TO INTERVENTION IN HIGH SCHOOL

\author{
A Dissertation \\ Presented to \\ The Faculty of the Department of Educational Leadership \\ At the University of Missouri - Columbia \\ In Partial Fulfillment \\ Of the Requirements for the Degree of \\ Doctor of Education
}

ANDREW D. MCCARTHY

Dr. Lisa Dorner, Dissertation Supervisor

MAY 2019 
(C) Copyright by Andrew D. McCarthy, 2019 All Rights Reserved 
The undersigned, appointed by the dean of the Graduate School, have examined the dissertation entitled

\title{
A CASE STUDY OF IMPLEMENTING RESPONSE TO INTERVENTION IN HIGH SCHOOL
}

\author{
Presented by Andrew D. McCarthy, \\ a candidate for the degree of Doctor of Education, \\ and hereby certify that, in their opinion, it is worthy of acceptance
}

Dr. Lisa Dorner, Dissertation Chair

Dr. Erica Lembke, Committee Member

Dr. James Sebastian, Committee Member

Dr. Chris Belcher, Committee Member 


\section{DEDICATION}

I dedicate this dissertation to those that have influenced my life and still continue to impact my life to this day.

God, you led me into this world and put me here to work with and for your people. I had a different plan for myself, and through your leadership, I have found my passion and mission in life through the field of education. I hope to inspire and lead others in your direction.

Rachel, you are my rock and our life can get pretty hectic at times. However, you are still there and remain my lifetime partner. You encourage, inspire, and love me to be a better person. When I have needed the time to work you have supported me the entire way. I am so thankful I met you and get to spend the rest of my life with you. I love you!

Mom and Dad, you both have modeled what it truly means to be parents. You have sacrificed so much for our family over the years and I do not know how to thank you enough. If I can only be half the parent you were, I will have achieved greatness! Thank you for your encouragement and love!

Grandma and Grandpa, you were lifetime educators and helped raise my brother and me. You taught us manners at the table, how to cook, sew, play the piano, build fence, mow the yard, haul hay, plant soybeans, harvest the crop, etc. I will be forever grateful for the life lessons you taught me. As I reflect on my past years of education, it is because of both of you I am in the field of education. I hope to serve others and be as friendly to all as you both were!

Eliyah, Brookson, David, and Samuel, you are so special to me! Since you have entered my life, I have only hoped to be the best dad life can give you. Thank you for 
allowing me to complete this degree and the many nights I was unable to tuck you in before bed. I hope I have modeled the way and proven to you that an education at the highest level is what you should demand of yourselves and your future life partners!

Joe and Linda, we could not raise our family if it were not for your continued support and leadership. Thank you for taking care of our children while Rachel and I needed a night together or spent late night hours completing our dissertations. You help our family tick and for that we are so grateful! 


\section{ACKNOWLEDGEMENTS}

I would like to acknowledge Dr. Lisa Dorner, my advisor and dissertation chair. At times when I wanted to quit, you were there to encourage me. At times when I thought I was not meeting a deadline, you gave me grace and allowed an extension. When I needed you most, you were there to say "keep going" or "this is great work," or "this is coming along nicely.” For these things, I am so grateful. You agreed to take me under your wing not knowing much about me. But from our first interactions we clicked and have been able to share many personal stories to get to know each other even that much more. Thank you for all you have done for me!

Dr. Erica Lembke, thank you for taking the time to brainstorm and meet with me several times over the course of my academic career. From just a guy wanting information about RTI to critiquing and offering suggestions for my work, your expertise in your field has been invaluable to my work. Thanks for stepping outside the box and working on my committee to add a little more research to the work of intervention.

Dr. James Sebastian, thank you for being my critical friend. I needed you on my committee to offer a different perspective and make me think outside my comfort zone. Thanks for posing the tough questions that challenged my thinking and made me question if what I was writing was accurate and added to the body of literature.

Finally, I would like to thank Dr. Chris Belcher for his passion and commitment to PK-20 education. Whether I worked under your leadership or you served on my committee, you always brought the practical application of education to the forefront. Our field is better because you are in it and challenging the thinking of future leaders every day. 


\section{TABLE OF CONTENTS}

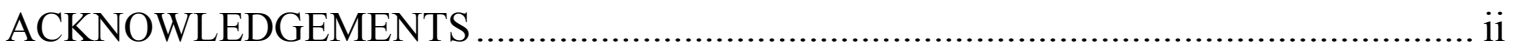

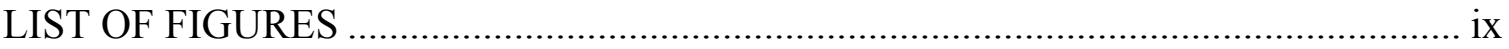

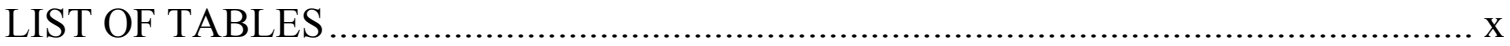

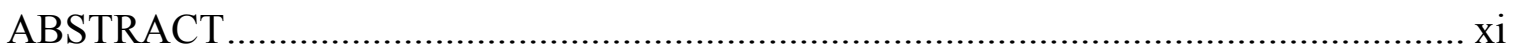

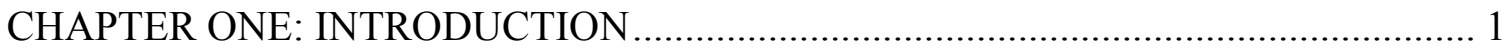

Conceptual Underpinnings \& Review of Literature ......................................... 3

RTI in Primary Schools .................................................................. 5

RTI in Secondary Schools ........................................................... 7

RTI at the High School Level (The Specific Problem).................................... 8

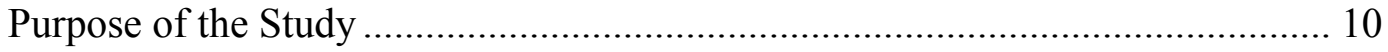

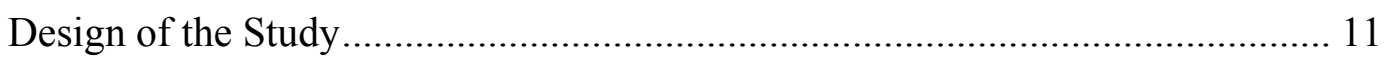

Qualitative Case Study ............................................................. 11

Research Questions ...................................................................... 11

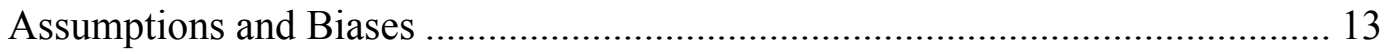

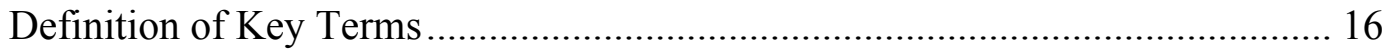

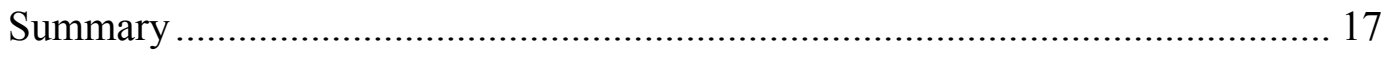

CHAPTER TWO: LITERATURE REVIEW …....................................................... 19

The Importance of Addressing High School Academics Through RTI .............. 19

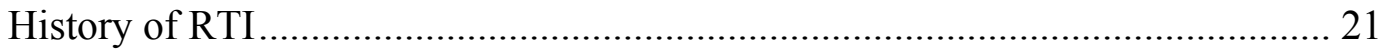

Health Prevention Model \& Prevention Science Framework................. 21

Discrepancy Model in Special Education ......................................... 23

RTI Outside of Special Education ................................................... 24 


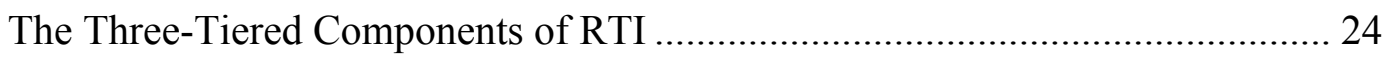

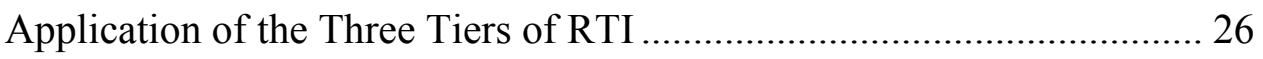

Three tiers of RTI in academics................................................... 26

Three tiers of RTI in behavior ................................................... 27

RTI at Elementary versus Secondary Levels .................................................... 28

Results of Research on RTI in Elementary Schools ................................. 29

Challenges with RTI in Secondary Schools.............................................. 30

Policy Briefs and "How To" Manuals on RTI in Secondary Schools ...... 32

Barriers to RTI Implementation in Secondary Schools ........................................ 33

Barrier to Implementation - Scheduling/Structure .................................. 33

Barrier to Implementation - Curriculum Issues.......................................... 35

Barrier to Implementation - Fidelity .................................................... 36

Barrier to Implementation - Staff Capacity/Professional Development .. 37

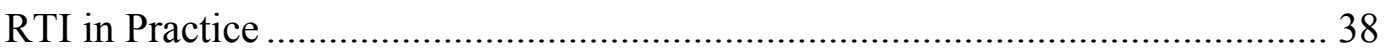

Summary: The Four Essential Elements of RTI ................................................ 40

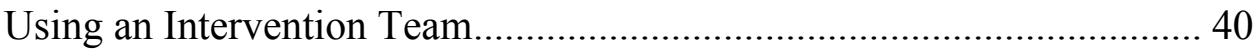

Universal Screening of All Students ......................................................... 41

Progress Monitoring of Student Data .................................................... 43

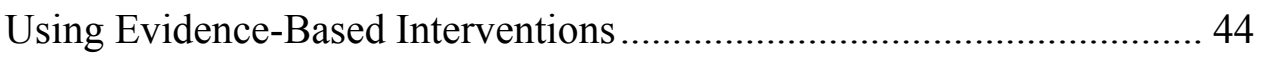

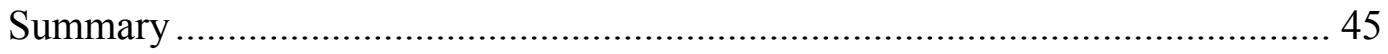

CHAPTER THREE: RESEARCH DESIGN AND METHODOLOGY ........................... 46

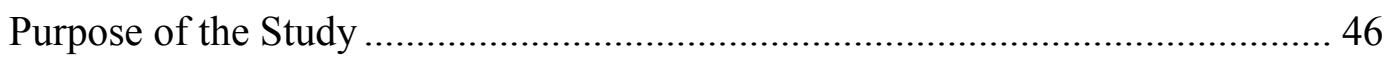

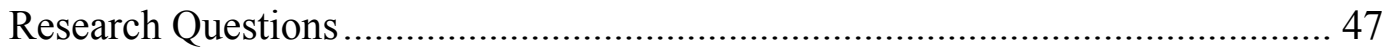




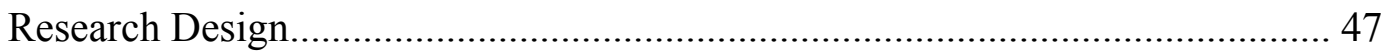

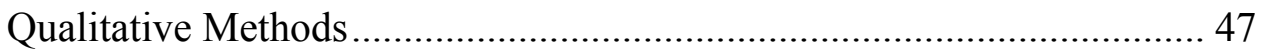

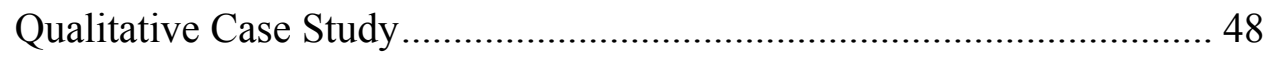

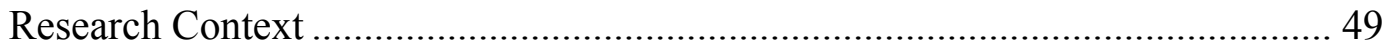

The Context of Character School District.................................................. 49

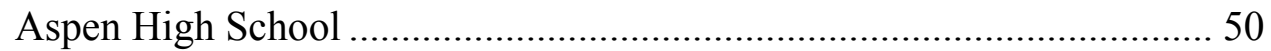

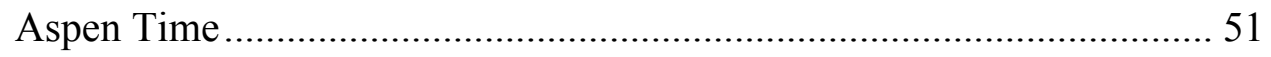

Data Gathering Tools and Procedures ............................................................. 53

Participants and Sampling Procedures............................................................... 57

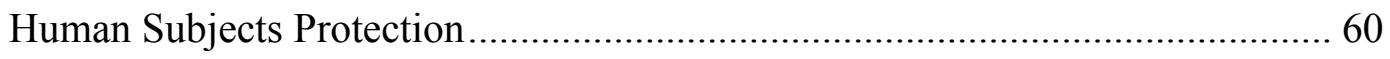

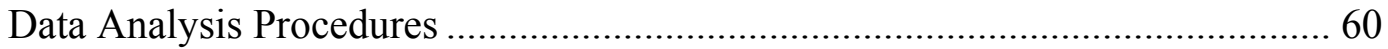

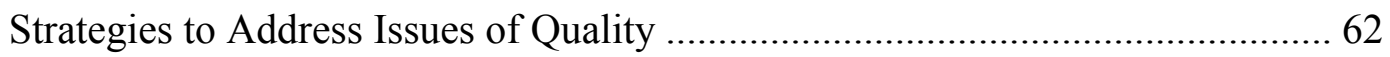

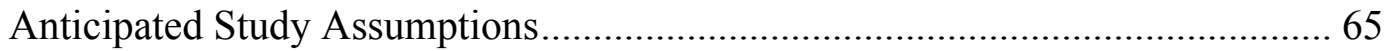

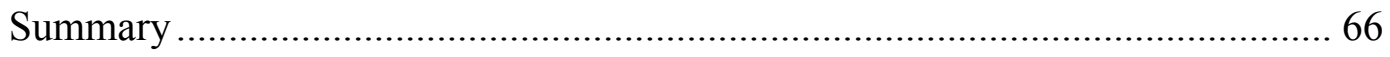

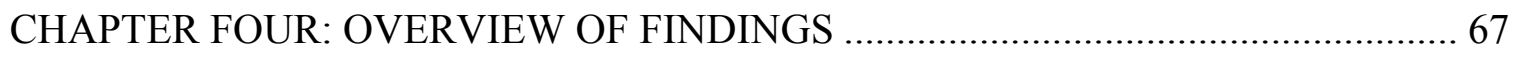

Presence or Absence of Four Essential Elements of RTI ..................................... 68

Lack of Thoughtful Intervention Teams Meeting to Discuss Academic

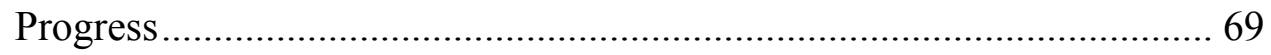

Lack of Purposeful Universal Screening Process \& Tool ......................... 76

Absence of Progress Monitoring Tool for Students Outside of Algebra 1

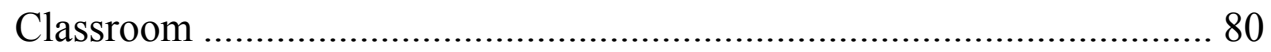

Strong Presence of Evidence-Based Interventions Inside the Algebra 1

Aspen Time Intervention ...................................................................... 85 
Summary of Four Essential Elements ...................................................... 90

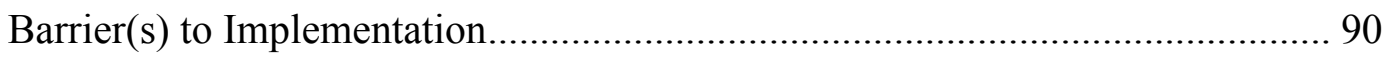

Barrier to Implementation - Scheduling/Structure .................................... 91

Barrier to Implementation - Curriculum Issues......................................... 94

Barrier to Implementation - Fidelity ....................................................... 96

Barrier to Implementation - Staff Capacity ............................................... 97

Barrier to Implementation - Others Noted .............................................. 99

Summary of Barriers to Implementation ............................................... 100

Stakeholders' View of Aspen Time ................................................................ 101

Stakeholders' View I - Logistics Behind Aspen Time........................... 102

Stakeholders' View II - Supervision of Students .................................... 104

Stakeholders' View III - Teams Could be More Effective ..................... 107

Stakeholders' View IV - Ineffective Screening Tool............................. 110

Summary of Stakeholders' View ........................................................ 112

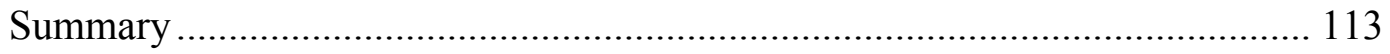

CHAPTER FIVE: DISCUSSION, IMPLICATIONS, AND CONCLUSIONS ............. 114

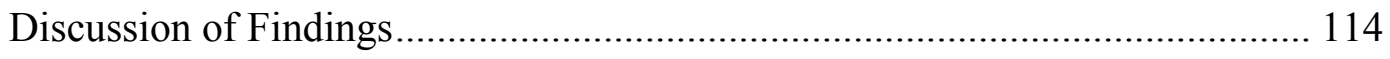

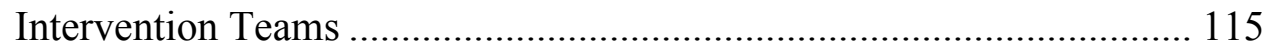

Universal Screening Process.................................................................. 117

Progress Monitoring .......................................................................... 120

Evidence-Based Interventions ............................................................ 123

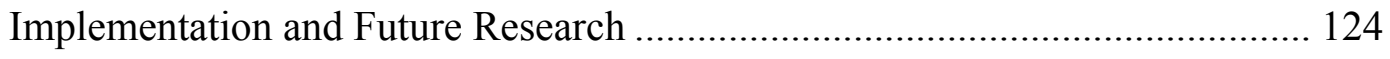

Theoretical Implementation ................................................................ 125 
Future Research Opportunities 126

Limitations of the Study. 127

Implications and Recommendations

General Recommendations for High Schools. 129

Specific Recommendations for High Schools 130

Recommendation One - Change Universal Screening Tool \& Empower Teams 130

Recommendation Two - Logistics Behind Aspen Time 133

Recommendation Three - Transition From Grade to Proficiency

Scale 135

Summary 136

REFERENCES 138

APPENDIX A: TABLE 1. MODEL OVERVIEWS 147

APPENDIX B: TABLE 2. INTERVENTION FEATURES BY TIER 148

APPENDIX C: STEPS TO RUN REPORTS FOR ASPEN TIME INTERVENTION . 150 APPENDIX D: TOOL USED TO TAKE FIELD NOTES IN CLASSROOM SETTING ..

APPENDIX E: TOOL USED TO TAKE FIELD NOTES IN SST MEETING. 156

APPENDIX F: FOCUS GROUP QUESTIONS FOR ASPEN SCHEDULING

COMMITTEE MEMBERS (TEACHERS).

APPENDIX G: FOCUS GROUP QUESTIONS FOR ASPEN LEADERSHIP TEAM 159 APPENDIX H: INFORMED CONSENT FORM 161

APPENDIX I: TRIANGULATION OF DATA BASED ON STUDY QUESTIONS... 163 
APPENDIX J: TRIANGULATION - ABSENCE OF ELEMENT, BARRIERS TO

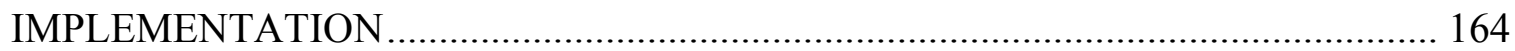

APPENDIX K: TRIANGULATION OF DATA BASED ON BARRIERS IN

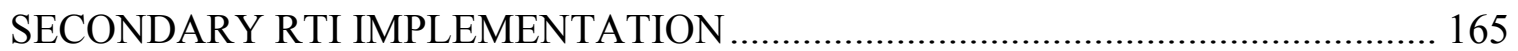

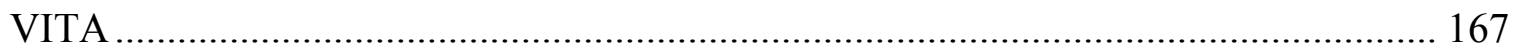




\section{LIST OF FIGURES}

Figure 1. RTI Academic Levels ............................................................................ 4-5 


\section{LIST OF TABLES}

Table 1. Characteristics of Members of the Aspen Scheduling Committee ..................... 9

Table 2. Data Collection Methods Associated with Research Questions ....................... 53

Table 3. Characteristics of Members of the Leadership Team Focus Group .................. 58

Table 4. Characteristics of Members of the Scheduling Committee/Teacher Focus Group

Table 5. Teacher Interview Responses to Instructional Strategies Used During Aspen

Time 89 


\begin{abstract}
Many secondary schools pride themselves on having a rigorous academic program for all students. These same schools are excited to share how their students have become more socially responsible after graduation. In fact, many schools provide both ideologies in their mission statements and plaster it throughout their buildings, websites, publications, and letterhead. But what secondary schools should be asking and answering is: how do their teams respond when students do not master the material? Schools that successfully provide student intervention and support student mastery at every level of content attainment should celebrate and promote this product of student growth.

Studies, mostly in elementary schools, highlight that well-implemented response to intervention, or RTI, processes include the following: formation of intervention teams, development of a universal screening process, continual monitoring of students for progress, and use of evidence-based interventions. Previous studies on RTI in secondary school settings have shown some success with reading and math interventions, but various barriers to implementation also existed and were minimally discussed. Seeking to add to the growing body of RTI literature in a high school setting, this qualitative case study explored to what degree the essential elements of response to intervention, or RTI, were implemented in Aspen Time, one high school's uniquely designed, daily, 30minute, student intervention period. Data collection included document review, focus groups, interviews and observations of Aspen Time. Analyses found four barriers to implementation (scheduling/structure, curriculum issues, fidelity, and staff capacity/professional development) and offered recommendations for high schools on RTI implementation.
\end{abstract}




\section{Chapter I: Introduction}

Many schools throughout the United States have reorganized their faculties and staff to operate as Professional Learning Communities (PLCs) (DuFour \& Eaker, 1998). In this model, teachers work together to design curriculum, instruction, and common assessments for students. As teachers work in PLCs, they explore three questions: “(1) What do we expect students to learn? (2) How will we know what students have learned? (3) How will we respond to students who aren't learning?" (Eaker, DuFour, \& DuFour, 2002, p. 12). As Aspen ${ }^{1}$ High School, a $9^{\text {th }}$ through $12^{\text {th }}$ grade school in the midcontinental United States of America, operated as a PLC, the third question became the most important one. Aspen teachers were asking: How do we help students who are failing classes and falling behind in earning credits to graduation?

In turn, Aspen High School developed a system-wide academic intervention to support students at the first indication they were not learning subject material. Specifically, despite potential barriers to implementation, they adapted a popular systemwide approach more commonly used in elementary schools called "Response to Intervention" (RTI) (Johnson, Smith, \& Harris, 2009). Aspen educators called their intervention - a 30-minute daily period where teachers provided individually designed support for academically struggling students_-“Aspen Time.”

Since its development, RTI has emphasized helping students at the first sign of academic failure, but it has rarely been studied at the high school level. The phrase "response to intervention" (RTI) came from language in the Individuals with Disabilities Education Improvement Act (IDEIA) of 2004 (H. Res. 1350, 2004). When that federal

\footnotetext{
${ }^{1}$ All names used in this proposal are pseudonyms and have been changed to protect the actual names of those contained herein.
} 
law was created, local educational agencies were encouraged to "develop and implement coordinated, early intervening services" that "may use a process that determines if the child responds to scientific, research-based intervention as a part of the evaluation procedures" (H. Res. 1350, 2004). The goal was to implement best practices, instructional strategies, and interventions that ensured student success.

Although RTI has been used primarily in the realm of special education to identify and support students with special needs, and especially at the elementary school level, RTI can be "applied more broadly across schools as a diagnostic approach that shapes instruction and informs decisions about intervention" (Duffy, 2007, p. 2). Several schools throughout the nation have created different RTI services for their unique situations (National High School Center, 2010), and research has showed some promise for RTI at the primary level (as reviewed in Chapter 2). However, relatively few studies have examined RTI supports for secondary students. Those that do exist suggest that the compartmentalized structure of secondary schools may impede its implementation for older students. For example, possible barriers include working around the scheduling of courses, issues with curriculum, fidelity of implementation, staff capacity, and opportunities for professional development.

To better understand whether and how RTI can be used at the secondary level, this study examined the program design and implementation of Aspen Time. The research questions of this study were:

\section{- How was RTI implemented at Aspen High School?}

A. To what degree was each of the four essential elements of RTI evident in weekly student support team meetings and the classroom? 
- formation of intervention teams,

- development of a universal screening process,

- continual monitoring of students for progress,

- use of evidence-based interventions

B. When an essential element was not evident, which barrier(s) to implementation limited the presence of the element?

C. How did different stakeholders (administrators and teachers) view Aspen Time?

\section{Conceptual Underpinnings and Review of Literature}

RTI was designed per theoretical frameworks from a public health prevention model (Caplan, 1964); then the RTI approach was later incorporated into school settings (e.g., Klingman, 1986; Klingman \& Ben Eli, 1981). The health prevention model would “assess the population's risk status as a whole and initiate widespread preventive actions to inoculate the population against a disease or condition" (Mellard, McKnight, \& Jordan, 2010, p. 217). The public health prevention model proposed using three levels--primary, secondary, and tertiary--to determine a person's risk to society and then responded to the disease or condition. The action or response that followed was dependent upon where the person was placed in the tier system.

Prevention science was also used as a context to study RTI systems. The National Research Council and the Institute of Medicine (2009) released a report that described the three levels of risk: universal interventions, selective interventions, and indicated interventions prevention cycles. These similarly mirrored the public health prevention model's three levels of risk detailed above in that prevention science worked to pass laws 
for a minimum drinking age that prevented and reduced underage drinking, where the public health prevention model worked to prevent people from obtaining a disease.

Kellam and Langevin (2003) proposed the prevention science research cycle.

This framework contained six themes to understand the meaning of evidence in prevention science research and programs. The third theme that emerged was that prevention programs (like RTI) would address different segments of a population based on the associated risk. A prevention program was directed at the population as a whole, a smaller population at greater risk required additional support, and yet an even smaller subpopulation at a higher risk required yet more support or an entirely different prevention program. More recently, Lembke, McMaster, and Stecker (2010) used prevention science as a context to study reading intervention in a RTI model.

Similarly, with RTI in schools, all students are assessed and then a response team places students into one of three levels, and students are then provided the necessary support. For example, Buffum, Mattos, and Weber (2009) used the three-tiered approach in relation to academics. The authors visually represented their system with a triangle (see Figure 1).

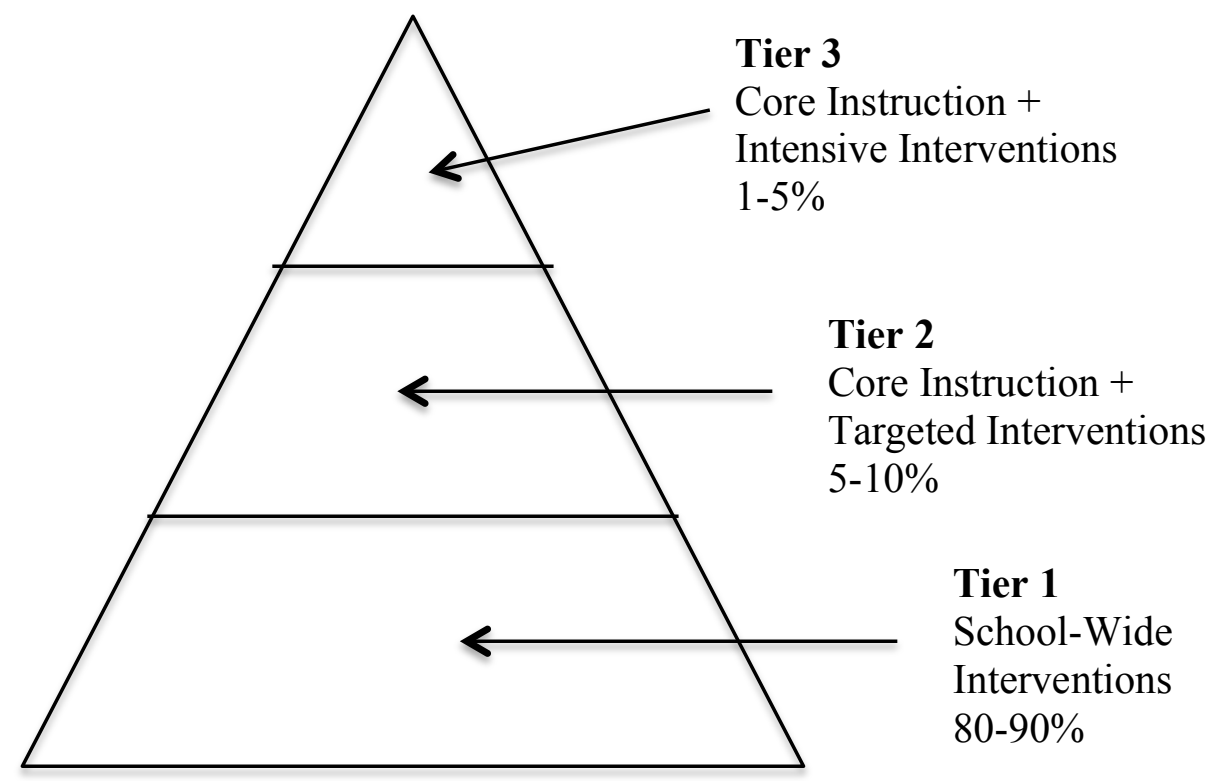


Figure 1. RTI tiers. Figure illustrates the three levels of RTI and approximate percent of students composing each level.

The base of the triangle represents the largest category of students or tier one (primary). Interventions that occur at this level impact all students and are used system-wide. Tier two (secondary) is in the middle of the triangle with a fewer number of students. Finally, a tertiary or third level consisting of more individualized supports that impact fewer students than tiers one and two is at the top. Students classified in tiers two or three of the triangle required more intervention in academic or behavioral supports.

According to this conceptual framework and as shown through the literature review, there are four essential elements needed to implement RTI in a school setting: formation of intervention teams, development of a universal screening process, continual monitoring of students for progress, and use of evidence-based interventions. The following overview of the research, which is expanded in Chapter 2, demonstrates that primary schools have found some success with RTI, but we know less about its implementation at the high school level. Furthermore, there are few studies of the design and implementation of RTI at the secondary level. In short, more research needs to examine how high schools implement RTI in their unique settings.

\section{RTI in Primary Schools}

Since IDEIA of 2004 was passed, RTI has been studied in elementary schools throughout the nation. Several of these studies focused on reading intervention (Al Otaiba \& Fuchs, 2006; McMaster, Fuchs, Fuchs, \& Compton, 2005; Vaughn, LinanThompson, \& Hickman, 2003). Students either improved their reading skills or were not enrolled in remediation programs due to the early identification and interventions 
performed in the studies. Therefore, research suggested that the RTI systems established in these schools worked for the intended purposes.

Several studies also emphasized the difference between the standard treatment protocol (Fuchs, Fuchs, \& Compton, 2004; Vaughn et al., 2003) and problem-solving model (Deno, 2002; Marston, Muyskens, Lau, \& Canter, 2003; Tilly, Reschly, \& Grimes, 1999) of intervention teams. In these studies, the standard treatment protocol was when an "intensive fixed-duration trial... is used, involving a validated standard treatment protocol" (Fuchs et al., 2004, p. 218). All students whom were tested received the same treatment. If the student responded positively to the treatment, she/he returned to the general education setting. However, if the response was negative then further information was needed to determine if a disability existed.

Differing from the standard treatment protocol, a problem-solving model in the referenced studies involved a process whereby the intervention team identified a student's academic challenges and then worked to provide the needed student support. Therefore, not every student received the same initial treatment as in the standard treatment protocol. "Solutions to instructional and behavioral problems are induced by evaluating students' responsiveness to a four-stage process" (Fuchs, Mock, Morgan, \& Young, 2003, p. 160). Students received different treatments based on their need for intervention. A cyclical process was designed until the ultimate treatment worked to resolve the problem.

While these studies examined RTI implementation at the primary level, this study examined RTI implementation at the secondary level to determine barriers and 
stakeholders' views. The next section reviews the extant literature on RTI in secondary schools.

\section{RTI in Secondary Schools}

Literature regarding RTI at the secondary level was limited. Several "briefs" and "how to" manuals existed but at the time of this study, there was little empirical research in school settings. A brief by Duffy (2007) reviewed the implementation issues associated with tiered interventions at the high school level. This brief also included one high school example where RTI was implemented, and it listed resources needed to support such a RTI program. Duffy (2007) advocated that schools determined the intervention model that worked best for the students in their building and also were cognizant of the issues unique to the high school level (such as how students moved through the process and timelines of the intervention period). Another important factor mentioned was the need to train staff and provide continuous professional development that supported them with the intervention process.

In addition, the National High School Center (2010) published a report that defined RTI as a "framework for promoting access to high-quality core instruction and providing increasingly intensive educational interventions in a timely manner for students who struggle in core instruction" and also reviewed the components of an RTI framework at the high school level (p. 1). This report provided a profile of eight high schools and how each one implemented the components of RTI in their buildings (e.g., high quality Tier 1/core instruction, universal screening, ongoing progress monitoring, tiered interventions, and data-based decision making). 
However, we still know very little about how RTI is implemented at the high school level and the barriers to implementation. Few secondary schools have adopted a RTI model, and there was a lack of studies that have been conducted to examine implementation at the older grade levels. The next section explains RTI at Aspen and the specific problem that was studied in this dissertation.

\section{RTI at the High School Level (The Specific Problem)}

Aspen High School's scheduling committee took on the challenge to increase the number of students obtaining credits in a timely fashion towards graduation. They created a system-wide RTI approach called Aspen Time that began the first year Aspen High School opened. This section describes what data led to the school's decisions to create Aspen Time and briefly reviews how Aspen Time worked.

Data about students entering Aspen High School in August 2013 indicated that approximately $9.3 \%$ or $136 / 1467$ students were behind in credits to graduation based on garnering six credits each year to stay on track for graduation. Specifically, 136 students had less than six credits at the end of their freshman year, or less than 12 credits by the end of their sophomore year, or less than 18 credits by the end of their junior year. Aspen faculty wanted to reduce the number of students behind in credits and thus get these 136 students back on track to graduate with their cohort class.

The scheduling committee, which was an ad hoc committee of administrators and

teacher volunteers (see Table 1), designed Aspen Time to address this issue. They created a 30-minute intervention period that occurred within the school day to support students who were falling behind academically. 
Table I

Characteristics of Members of the Aspen Scheduling Committee

\begin{tabular}{llccccc}
\hline & $\begin{array}{c}\text { Pseudonym } \\
\text { Name }\end{array}$ & $\begin{array}{c}\text { Role in } \\
\text { Building }\end{array}$ & Gender & $\begin{array}{c}\text { Years of } \\
\text { Experience }\end{array}$ & $\begin{array}{c}\text { Subject } \\
\text { Taught }\end{array}$ & $\begin{array}{c}\text { Grade } \\
\text { Taught }\end{array}$ \\
\hline 1 & Principal P & Principal & F & 29 & Administration & $9-12$ \\
2 & AP M & Asst. Principal & M & 13 & Administration & $9-12$ \\
3 & AP G & Asst. Principal & F & 27 & Administration & $9-12$ \\
4 & Teacher A & Teacher & F & 25 & Social Studies & 11 \\
5 & Teacher B & Teacher & M & 10 & Mathematics & 9 \\
6 & Teacher C & Teacher & F & 12 & Language Arts & $9-10$ \\
7 & Teacher Ha & Teacher & F & 23 & Language Arts & $9-12$ \\
8 & Teacher He & Teacher & F & 15 & AVID & $9-11$ \\
9 & Teacher L & Teacher & F & 10 & Spanish 1 & $9-12$ \\
10 & Teacher M & Teacher & F & 10 & Special Educ. & $9-12$ \\
11 & Teacher P & Teacher & M & 13 & Mathematics & $10-12$ \\
12 & Teacher R & Teacher & M & 16 & Special Educ. & $9-12$ \\
13 & Teacher S & Teacher & F & 25 & Mathematics & $9-10$ \\
14 & Counselor S & Counselor & F & 23 & Counselor & $9-12$ \\
15 & Teacher P & Teacher & M & 7 & Biology & 10 \\
16 & Teacher T & Teacher & M & 12 & Band & $9-12$ \\
17 & Teacher V & Teacher & F & 13 & Health/PE & $9-12$ \\
\hline
\end{tabular}

During Aspen Time, students met with assigned teachers to enhance academic skills previously missed in the courses in which they were failing or nearly failing. The committee did research to create this intervention; specifically, they read four articles regarding the implementation of RTI. Then, they analyzed which students needed Aspen Time and designed the bell schedule so that those students could work with their teachers on the material that they were not understanding. First, a grade report from the eSchoolPLUS software program was downloaded every other week for all students at Aspen. Students were assigned to attend the courses during this 30-minute period in which they earned a "D" or "F" grade. Students were "directed" to attend the course or courses for the next two weeks until either a new grade report was compiled or the assigned teacher indicated on the students' sheet he/she had increased his/her grade to a 
"C" or higher. Students who had all grades in their courses of a "C," "B," or "A" letter grade earned the right to be on "privilege," and particular areas of the building were established for students to play sports, study in groups, work with teachers on enrichment activities, or communicate with friends. This special study time allowed teachers to work with students in a smaller setting to help them grasp concepts presented in class that they missed the first time, which had earned them the " $D$ " or " $F$ " grade.

The ad hoc scheduling committee at Aspen designed and oversaw Aspen Time in the first few years of operation. The committee continually worked to improve Aspen Time to the best of their ability as they addressed concerns and helped solve problems as they arose. Specifically, they made some programmatic changes about when to begin a new cycle, incorporated Professional Learning Team (PLT) time to group students based on need, and re-designed the reports that were shared with students. In other words, the program was monitored as issues arose. The next step was to return to the research and essential characteristics of RTI to develop future program changes. Given the potential challenges and unique implementation of RTI at a high school, an evaluation was necessary to examine this process: How did RTI work at Aspen High School?

\section{Purpose of the Study}

The purpose of this case study was to explore to what degree the essential elements of RTI as defined by the literature were implemented in Aspen Time. In this case, this study helped clarify the scheduling committee's future work in program design and implementation. The study's findings and a set of recommendations were shared with Aspen administration with the intent they would accept some of these recommendations to make programmatic and procedural changes to Aspen Time. 


\section{Design of the Study}

As a preliminary, theory-building study focused on school-wide processes and individuals' understandings of the process of implementing RTI of Aspen Time, this research used a qualitative case study design (Creswell, 2009) and focused on important stakeholders' perspectives: the leadership team and teachers. This section briefly describes the case study approach as well as the specific data collection methods used.

\section{Qualitative Case Study}

As described in more detail in chapter three, to assess the approach to RTI designed by Aspen High School, a case study using qualitative methods was the best design. This design allowed for an exploration of the processes, procedures, and events surrounding the formation and implementation of a program, which is described as the purpose of a case study according to Creswell (2009). Qualitative methods were also useful in program evaluations and when studying new initiatives or those that had not been studied significantly in the past (Creswell, 2009). RTI is a rather new idea and has not been studied significantly at the secondary level.

\section{Research Questions}

The following question (in bold) served as the overarching focus of this study, which was guided by three sub-research questions:

\section{- How was RTI implemented at Aspen High School?}

A. To what degree was each of the four essential elements of RTI evident in weekly student support team meetings and the classroom?

- formation of intervention teams

- development of a universal screening process 
- continual monitoring of students for progress

- use of evidence-based interventions

B. When an essential element was not evident, which barrier(s) to implementation limited the presence of the element?

C. How did different stakeholders (administrators and teachers) view Aspen Time?

Each guiding research question had specific data collection methods associated with it. For the first sub-question, the researcher used document review and field notes to examine the research question about the four essential elements of RTI at Aspen. Most important, being the former chairman of the school's scheduling committee, the researcher had access to several documents including meeting minutes, timelines, and worksheets that were used to plan and implement Aspen Time. He analyzed these meeting documents to determine the absence or presence of the four essential components of RTI during Aspen Time.

In addition, following guidelines by Emerson, Fretz, and Shaw (2011), the researcher took field notes in six different classrooms during the Aspen Time intervention period and attended two student support team (SST) meetings. These notes were compared to the literature to analyze the evidence-based interventions and interactions that occurred between teachers and students and amongst members of the SST meetings. These field notes also helped to answer the first question about the degree to which the essential elements were implemented.

The second sub-question asked: if an essential element was not present, then what was the barrier to implementation that prevented it from being present? After field notes 
were taken in each Aspen Time class period, a follow up conversation was held with each teacher. During this interview, questions were asked about the evidence-based interventions teachers used with the students, processes and procedures used in Aspen Time, and possible barriers that did not allow implementation.

Following suggestions by Hatch (2002) and Krueger and Casey (2009) and using focus group protocols, a total of two focus groups were conducted to help answer the third sub-question about the perspective of Aspen Time implementation from different stakeholders. One focus group was with the Aspen leadership team (one principal and four assistant principals) and one focus group was with four members of the original scheduling committee (three teachers and one counselor).

The data from these four sources (document review, field notes, interviews, and focus groups) were triangulated and published in a final report. The basic premise of this triangulation was to evaluate Aspen Time's implementation at a high school and locate weaknesses in Aspen Time as compared to the literature. Once triangulated, themes that emerged offered both positive and negative aspects of Aspen Time. Then a list of recommendations was created and given to the school's administration for Aspen Time improvement.

\section{Assumptions and Biases}

Several assumptions of the study must be articulated and addressed. Most significant, this study was conducted in the building in which the researcher had previously served as an administrator. He led the scheduling committee that designed and proposed Aspen Time, so the researcher was invested in this process personally and 
professionally. Next are assumptions and how the researcher addressed potential biases in the study.

First, perspectives about the implementation process aimed to be reported accurately and personal biases about the program were reduced. However, this was challenging because researchers may not be aware of their own personal bias. The researcher was partial to the RTI program and in favor of Aspen Time as the appointed leader of the committee due to his background of student support and having created a bell schedule at his previous school. As a check on this potential bias, the data was triangulated throughout the data collection and analysis process. An "audit trail" was also completed and the researcher received feedback from outside readers (his dissertation committee) as he developed and implemented this study. These procedures helped the researcher to assess and address possible weaknesses in the study.

The researcher's second assumption was that his previous leadership role in the building did not influence the answers of the participants. Specifically, he expected that having developed relationships through creating Aspen Time collaboratively among many stakeholders, he would be able to collect authentic responses in his focus groups. Aspen Time was created by a group of 17 volunteer faculty members at Aspen. A collaborative process where ideas were shared and shaped over the course of 11 months ultimately led to the processes associated with Aspen Time. Even after the initial year of implementation, the committee continually met and refined the Aspen Time procedures and regularly critiqued their own process. Therefore, it was assumed that Aspen Time committee members participating in this study wanted to be honest about the 
implementation of Aspen Time because they, too, wanted to improve this academic intervention period.

In addition, the researcher assured participants that the answers to their questions in the focus group had no relationship to their evaluation at the end of the school year. The researcher was now an administrator at another building within the same school district. However, responses by Aspen staff would not be shared directly with Aspen administration. Participants did not have to answer the questions that they did not want to answer. They could drop out of the study at any time or not participate all together. The researcher allowed a dialogue between Aspen colleagues where they were able to openly share their views of Aspen Time during the focus group. The questions were designed to solicit information about the program and not to reveal information that would identify participants in the study.

Third, it was important that this system operated to its fullest potential and was designed to help all students achieve at the high school level. So, another assumption was that Aspen created a unique program that was designed and implemented to the best of the committee's ability. The researcher is a very organized person and believed that the committee created a unique program to assist academically struggling students. However, he recognized that this program had room for improvement. To ensure that the study did not focus upon positive responses from only a few individuals, this research project collected data using different methods and from multiple individuals. These methods and perspectives ensured that the researcher was not only looking to find positive results. This study was conducted to improve conditions, so areas of weakness were located and then became recommendations for improvement. 
Fourth, the researcher was upfront with participants (both administrators and faculty) about the purpose of the research, and, as discussed above, situations were created where participants felt comfortable answering questions honestly and to the best of their ability. The researcher did not want individuals to feel uncomfortable, so setting the stage for data collection was important; in each interaction, he made clear the statement of purpose. Participants were past colleagues within Aspen. An assumption was made that participants answered questions honestly and to the best of their ability because they knew the positive benefits of this study for Aspen. The facilitator also established rapport with participants in the focus group, which helped set them at ease.

\section{Definition of Key Terms}

Listed below are definitions of the key terms that are found throughout this research study.

Academic achievement. This referred to a specific student or a group of students' grades in a given course at a moment in time or at semester. An example of increasing academic achievement for a student would be for a student to increase his grade from a "B" to an "A."

Credit. A student must earn 24 credits of academic work to graduate from any public school in the state where this study was conducted. There are specific credits that a student must earn in each academic content area (Math, English, Science, Fine Arts, etc.) as written by the state's Department of Elementary and Secondary Education. One

credit was earned for one course taken in an academic school year. Thus, a student earned 0.5 credit for one semester class. An example would be if a student were to take an Algebra 1 course for one academic year and successfully completed the class with a 
grade of "D-" $(60 \%)$ or higher, the student earned one credit toward a total of 24 needed for graduation.

Response to Intervention (RTI). This term came from language in the IDEIA of 2004 where it was a program designed to "develop and implement coordinated, early intervening services" that "may use a process that determines if the child responds to scientific, research-based intervention as a part of the evaluation procedures" $(H$. Res. 1350, 2004). Effective RTI programs contained four essential elements: an intervention team, universal screening mechanism(s), continuous monitoring, and evidence-based intervention(s).

Tiered Interventions. Tiered interventions referred to a series of academic or behavior interventions that could be put in place to support students. These interventions were measured in both frequency and duration where the frequency and duration of the intervention depended on the needs of the student. The more academic support a student needed, the greater the frequency or duration of the intervention.

Student Support Team (SST) Meetings. Weekly meetings were held at Aspen between two assistant principals, cooperating counselors, one crisis counselor, the school nurse, the school resource officer and the home school communicator. Meetings reviewed the students under this assistant principal's purview and developed plans to support students academically, mentally, emotionally, behaviorally, and socially.

\section{Summary}

When a student has shown she/he has not learned the course material, action should be taken by PLCs to ensure student knowledge attainment. At the building level, schools have established system-wide approaches that support students at the first sign of 
academic failure, but too few secondary schools have implemented or studied the nationally accepted approach, RTI. Through a case study, this research provided details on how one school implemented such a program. To prepare for this study, the next chapter provides an extensive literature review of the four essential elements of RTI and the impediments to RTI implementation at the secondary level using both empirical research and current practicing leadership techniques. 


\section{Chapter II: Review of Literature}

The focus of the literature reviewed for this research was located in both empirical studies and practice journals related to RTI. The purpose of this case study was to explore the implementation of RTI in the Aspen Time program through experiences of administrators and faculty at Aspen High School to determine how it operates and delivers services to intended students. After a brief discussion of the research highlighting students' reasons for falling behind in credits toward graduation, the literature reviewed below examines the history and empirical research on RTI, including its use in secondary schools.

\section{The Importance of Addressing High School Academics Through RTI}

In 2014 a report was published by America's Promise Alliance and its Center for Promise at Tufts University that outlined some of the reasons students left high school prior to their graduation. The Center staff facilitated 30 group interviews with more than 200 participants and collected nearly 3,000 survey results from students in all 50 states to contribute to both the qualitative and quantitative data for this report. The report stated, "Approximately 1 in 7 of the interrupted-enrollment respondents reported being bored, disengaged while at school, and failing" (America's Promise Alliance, p. 29). In addition, the report cited Table 34 on p. 66 where the respondents to the research indicated the number one reason for stopping school, "I was failing too many classes." In order to alter the course of these continuing dismal results, action must be taken at the high school level to support students.

When students had low academic achievement and failed multiple classes, they did not earn the necessary credits towards graduation. Haynes (2010) contended, "the 
graduation rate for low-income students and students of color hovers around 50\%" (p. 1).

Research has shown that it was crucial to intervene because students identified as academically at risk were at great risk of dropping out entirely. For example, Suh and Suh (2007) found that students with an academic risk (low grade point average due to failing courses) increased the likelihood the student would drop out by $115.9 \%$. A system-wide approach needed to be implemented to support students at the first sign of academic failure. This support should be individualized for each student to meet his/her current needs. In fact, one of America's Promise Alliance (2014) recommendations was to "surround the highest-need young people with extra supports" (p. 39).

One popular system-wide approach, called RTI, has emphasized helping students at the first sign of academic failure. Several schools throughout the nation have created different RTI services for their unique situations (National High School Center, 2010). The phrase RTI came from language in the Individuals with Disabilities Education Improvement Act (IDEIA) of 2004 (H. Res. 1350, 2004). Local educational agencies were encouraged to design a system that identified students at the first sign of academic failure. This system implemented high yield academic interventions and evaluated to what degree these supports worked or did not work and then reassessed what occurred next. For instance, a school may offer additional academic support, so students better understand content knowledge and obtain credits toward graduation at the same rate as their peers; such an approach aimed to ensure students did not fall behind their cohort class.

This review examines literature surrounding the use of RTI, especially at the secondary level. Specifically, the sections below will examine the history of RTI, explain 
the three tiered components of a RTI system, for both academic and behavioral concerns, review the transition of RTI implementation from an elementary to a secondary model, examine the barriers to implementation at the secondary level, review current practice of RTI in the school setting, and, finally, summarize the four essential elements in a successful RTI model as defined by extant research.

\section{History of RTI}

RTI was designed per theoretical frameworks from a public health prevention model (Caplan, 1964) and a prevention science methodology. These two models/frameworks will be reviewed below. In addition, students who qualified for special services used to be identified using the discrepancy model. An adaptation of the frameworks was used to design a three-tiered system that later was incorporated into school settings (e.g., Klingman \& Ben Eli, 1981; Klingman, 1986) and used to identify students who struggled in school. Targeted interventions were put in place to support individual students as they moved through the tiers. Special education services were then considered if all other interventions were exhausted. So, this three-tiered model became more widely used in the general education setting.

\section{Health Prevention Model \& Prevention Science Framework}

The health prevention model suggested that the medical system should "assess the population's risk status as a whole and initiate widespread preventive actions to inoculate the population against a disease or condition" (Mellard et al., 2010, p. 217). The public health prevention model proposed three levels--primary, secondary, and tertiary--to determine a person's risk to society and then used this risk level to properly respond to 
the disease or condition. That is, the action or response that followed was dependent upon where the person was placed in the level system.

Prevention science also shaped the development of RTI systems in schools. Prevention science is a method used to research health and social problems in a community and avert them from occurring (i.e. substance abuse, HIV/AIDS, mental health issues, etc.). The National Research Council and the Institute of Medicine (2009) released a report that described the three levels: universal interventions, selective interventions, and indicated interventions prevention cycles. These levels parallel the public health prevention model's three levels of risk detailed above. For example, people used a prevention science model to pass laws for a minimum drinking age to prevent and reduce underage drinking whereas people using a public health prevention model designed a vaccine to stop people from obtaining a disease.

Kellam and Langevin (2003) proposed the prevention science research cycle. This framework contained six themes to understand the meaning of evidence in prevention science research and programs. The third theme that emerged was that prevention programs (like RTI) addressed different segments of a population based on the associated risk. A prevention program was directed at the population as a whole, a smaller population at greater risk required additional support, or yet an even smaller subpopulation at a higher risk required yet more support or an entirely different prevention program. More recently, Lembke et al. (2010) used prevention science as a context to study reading intervention in a RTI model.

So, using the health prevention model and prevention science method, RTI in schools has adapted the use of a three-tiered or level system. This system was used to 
classify students into three categories and then created interventions to support the unique students at each level.

\section{Discrepancy Model in Special Education}

Prior to the RTI model, students considered for special education services were identified using the IQ-achievement discrepancy model. This model served more as a "wait to fail" model versus early identification and implementing preventative intervention strategies before the problem became exacerbated. After students did not perform well, they were assessed for special services. Fletcher, Denton, and Francis (2005) argued that the discrepancy model for identification of students with learning disabilities was flawed and a new model such as response to instruction would be more accurate.

The discrepancy model continued to be used to identify students for special services until the early 2000's when a new model of identification would be suggested in public law through the implementation of IDEIA in 2004. Since IDEIA was passed in 2004, RTI was implemented as a process in elementary schools throughout the nation, to support students in the area of reading (e.g., Al Otaiba \& Fuchs, 2006; McMaster et al., 2005; Vaughn et al., 2003). In this work, when students entered elementary school they were assessed to identify their reading level. Students that needed more intense supports were given these supports in the classroom setting. If even more intense supports were needed, the students were provided this intervention in a small group setting. This structure became known as RTI where teachers monitored student progress closely and then provided more intensive instruction in the early literacy skills where needed (O’Connor, Fulmer, Harty, \& Bell, 2005). 


\section{RTI Outside of Special Education}

Due to some documented successes, as detailed in the following sections, RTI became a model used by some schools to identify special education students; this replaced the older model of IQ testing. However, movement through the tiered levels of RTI was not just to identify students needing supports through special services. Moving through the multiple levels became a common practice for a variety of other academic and behavioral areas in schools throughout the United States.

If a student needed more support for a specific task or academic objective, more support was provided (i.e. smaller group intervention, more frequent intervention, etc.). If less support was needed and the student mastered the intervention, then the student would move down the triangle to where more universal support was provided to all students (i.e. less targeted or less frequent interventions). This practice of movement up and down the triangle became a tool for identifying academic intervention for students, not just as a triangle for special education testing.

\section{The Three-Tiered Components of RTI}

As suggested by the history described above, RTI commonly uses a three-tiered approach. Klingman and Ben Eli (1981) related a two-tiered approach (primary and secondary prevention) set to a terrorist attack or a crisis that occurred in 1979. "Common programs of primary prevention are of an anticipatory nature and are carefully preplanned...” (p. 524). This statement described the primary level or tier that was planned, structured or organized, then decided what occurred next.

The secondary tier targeted issues that became more severe or had the possibility of a long-term effect. The goal was to mitigate these challenges before they became too 
compounded. Klingman (1986) recognized the lack of explanation of the tertiary level of a preventative model and presented the case for the important role of this tier. $\mathrm{He}$ advocated that individuals impacted by these strategies "will be hampered as little as possible by their present or past difficulties or by unfavorable conditions in their present environment" (p. 6). So, this third level prepared the student to re-enter the regular population by examining past conditions in a present environment. With this additional level, a more complete picture was developed of the three levels a student might be placed in to obtain additional academic supports.

These three levels were described similarly between researchers and authors in the field of education. What was different between each level was the targeted audience, the level of intervention intensity, and the objective. "As the prevention level increases, the portion of the population served is generally smaller and the intensity of the intervention is generally greater" (Mellard et al., 2010, p. 217). Tier one of the model reached about $85 \%$ of the student population and was the high quality instruction available in all classrooms in a school setting. Every student had access to this level and generally speaking the daily interventions that classroom teachers conducted, supported, and worked for about $80 \%$ of the students. Tier two impacted about $10 \%$ of the student population. When the instruction at tier one was not enough support for a student, more intensive and targeted interventions were put into place that supported the students' academic needs. Tier three provided $5 \%$ of the student population with an even more intensive and targeted intervention. Mellard, McKnight, and Jordan (2010) recommended that these supports were specialized and individualized and required progress monitoring. 
Students' movement up and down the triangle, and levels of support, were based on individual needs or when students mastered the desired outcome.

The three levels or tiers discussed above were visually represented with a triangle (see Figure 1).

\section{Application of the Three Tiers of RTI}

The three tiers of RTI can be applied to both student academics and behavior. Some school districts and states have adopted the theory of Multi-Tier System of Supports (MTSS) when examining interventions for students. Through this system, not only were academic interventions considered, but also a child's social, emotional, and discipline/well being were taken into account. States such as Kansas and Florida were early adopters of the MTSS model. These states worked with local school districts and implemented a broad range of supports and services (teacher professional development, positive behavior intervention support, and reading and math programs) to impact student learning. Below, the researcher distinguishes between the three tiers of RTI found in academics and the three tiers of RTI found in behavior.

\section{Three tiers of RTI in academics.}

Buffum et al. (2009) examined the three-tiered system as it applied to academics. As evidenced in Figure 1, when students are moved toward the top of the pyramid, the academic interventions increased in concentration and included fewer students. Tier one was the first level of response that was offered by all teachers in all classrooms. When students did not master the essential learning objectives of a course, general education teachers took action and provided academic intervention within the classroom to support students in mastering the curriculum. An example of this was when a math teacher 
worked one-on-one with a student during class time and helped her find the slope of a line.

Tier two was the second level of response, which included fewer students but more intense interventions. An example was when a teacher met with students twice a week after school in a small group for three weeks to understand how to write a paragraph using proper techniques.

Finally, tier three offered even more individualized supports and impacted fewer students than tier two. An example of a tier three academic intervention was when a teacher and student met daily after school for one hour for two weeks where the teacher re-taught a lesson on factoring to the student using a different instructional strategy.

\section{Three tiers of RTI in behavior.}

The three-tiered system was also applied to a behavior model. Horner, et al. (2009) researched the effects of school-wide positive behavior support in 30 elementary schools (K-5) in Illinois and 30 elementary schools in Hawaii. Tier one of the model was set for all students in both classrooms and non-classrooms (hallways, commons, media center, etc.). In these areas, social and behavior expectations were taught, monitored and either rewarded or consequences were given when expectations were not met. A tier one example was when a teacher set the expectation at the beginning of the year that students should be quiet and listen when the teacher gave a demonstration at the front of a science classroom. The teacher actively monitored and corrected students talking to each other during a physics demonstration on rate of change when a toy car went down different sloped ramps. 
Tier two benefited students that required "low-intensity interventions that can be administered with high efficiency" (Horner et al., 2009, p. 134). An example of a tier two intervention was when a group of students at lunch who continually left trash on their table were required for three days to help clean the commons after the lunch period ended. Since students were already in the lunch room after eating and were not required to stay after school and clean where transportation had to be arranged, etc., this was an example of a low-intensity intervention. It was assumed that custodians were also removing trash after lunch and thus this task became one of high efficiency where the custodians directed this group of students on what to do in order to help with the task.

Finally, tier three supports were very individualized interventions that were based on the results of conducting a functional behavioral assessment and involved more people (i.e. family or community) to help change the behavior. An example of a tier three intervention was a student who continued to leave class without permission. After a functional behavioral assessment was conducted, a team of people then developed a unique plan that helped the student change his/her behavior from leaving the classroom but still obtain a similar outcome of needing a break from the classroom instruction.

\section{RTI at Elementary versus Secondary Levels}

The overview of the research in chapter one demonstrated that primary schools have found some success with RTI (many studies that are based on specialized implementation), but we know less about its implementation at the high school level. In addition, there were few studies of the design and implementation of RTI at the secondary level. Furthermore, more research was needed to examine how high schools implemented RTI and the barriers that correlated with implementation. 


\section{Results of Research on RTI in Elementary Schools}

Since IDEIA of 2004 was passed, RTI has been studied in elementary schools throughout the nation. Several of these studies focused on reading intervention (Al Otaiba \& Fuchs, 2006; McMaster et al., 2005; Vaughn et al., 2003). Students either improved their reading skills or were not enrolled in remediation programs due to the early identification and interventions performed in the studies. Therefore, research suggested that the RTI systems established in these schools worked for the intended purposes.

A more current study was recently released on RTI implementation. In November 2015, the U.S. Department of Education's Institute of Education Sciences commissioned an evaluation completed by the National Center for Education Evaluation and Regional Assistance. This report evaluated RTI reading practices across 13 states comparing a reference sample of elementary schools to those in the impact sample, those schools with three or more years of RTI implementation (Balu et al., 2015, p. 1). Several results were published, but two of the most significant findings were 1) First graders receiving tier two interventions performed $11 \%$ lower on the reading assessments than the comparison students who barely missed qualifying for the tier two intervention approaches and 2) The second and third graders receiving tier two interventions experienced no significant reading benefits. The significance of these findings is that there was a smaller gain in reading scores than expected after the intervention was applied. This study was not a randomized controlled trial and based on the study's design cannot be comprehensive to all intervention areas. This report only initiated several more questions for researchers to investigate on the implementation of RTI not only at the elementary level, but what work 
had been done with RTI at the secondary level since 2004. Many questions around barriers to implementation existed when RTI implementation strategies used at the elementary level were transferred to the secondary level. These barriers made implementation of RTI at the high school level challenging.

\section{Challenges with RTI in Secondary Schools}

A small but growing number of studies at the secondary level have emphasized the structure and practices of RTI implementation in reading and math. For example, several experimental studies existed that supported the role of reading intervention at the secondary level (Vaughn, Cirino, et al., 2010; Vaughn, Denton, \& Fletcher, 2010;

Vaughn \& Fletcher, 2010; Vaughn, Wanzek, et al., 2010; Vaughn et al., 2012).

Additional studies at the secondary level have included research on curriculum-based measurements (CBM) as defined by Deno (1985). Lembke and Stecker (2007) proposed a framework for identifying students in need of math remediation at the middle school level. The authors claimed that teachers should use resources like the National Council of Teachers of Mathematics and Linking Research to Practice Initiatives to provide necessary interventions to students (Lembke \& Stecker, 2007). As will be shown in the review, few studies exist at the secondary level outside of reading and math intervention; however, there are some "how to" journals and policy "briefs," which can help educators and researchers apply general implementation measures to other academic areas.

One empirical study by Pyle and Vaughn (2012) examined reading difficulties in middle school students. A signficant conclusion of this research was "secondary students with significant reading difficulties who were not provided intervention exhibited substainal declines in their reading performance, whereas students who were provided 
reading intervention maintatined reading achievement and did not experience the same decline" (Pyle \& Vaughn, 2012, p. 281). The study also noted barriers to implementing a RTI program at the middle school level which included a smaller sample size of students, demands on the curriculum, the application of RTI (roles of staff members, schedules, graduation requirements, school culture), and a change in role of the school psychologist.

Several studies also addressed barriers to implementation at the high school level. The first study by Sansosti, Goss, and Noltemeyer (2011) reviewed four themes (systems structures, roles and attitudes, evidence-based practices, and training and professional developement needs) that special education directors noted regarding RTI use in secondary schools. This qualitative study by Sansoti et al. (2011) noted the barriers in implementing a RTI program at the secondary level: the structure of secondary schools, a lack of evidence-based practices, and a need for more professional development for teachers centered around RTI.

The roles and attitudes of individuals at the secondary level must also change in order to create and implement a RTI program. Marston, Muyskens, Lau, and Canter (2003) discussed the use of the problem-solving model to identify students for targeted intervention and ultimately a referral to special education. One main focus in this study was how students responded to the early interventions that were enacted in the classroom. The authors argued that the problem-solving model was good for both students in general education and those identified as special education. In another study, Sansoti, Noltemeyer, and Goss (2010) reviewed principals' perceptions of RTI at the secondary level. The authors contended that RTI was important in their schools, but barriers (such as those mentioned earlier) existed when implementing RTI in their schools. Finally, 
Mazzotti, Rowe, and Test (2013) provided teachers with evidence-based practices that were applicable to students with disabilities at the secondary level. The researchers reported the need to "(a) follow a research-based framework...(b) use practices with the best available research evidence to support effectiveness, and (c) use data-based decision making to guide use of evidence-based practices" (p. 1). The researchers concluded that time and research knowledge were challenges for special education teachers at the high school level. The article concluded with a list of resources that can be used when making decisions for specific students, thus eliminating the barriers of time and research knowledge.

\section{Policy Briefs and "How To" Manuals on RTI in Secondary Schools}

Although there is a lack of empirical research in school settings, several "briefs" and "how to" manuals existed at the secondary level related to RTI implementation. One brief, published by the National High School Center and funded by the U.S. Department of Education, was written by Duffy (2007) and reviewed the implementation issues associated with tiered interventions at the high school level. Duffy (2007) advocated for the following: screening and progress monitoring tools for high school level students across subject areas, high school appropriate intervention models to work across subjects, implementation issues unique to high schools including moving through the process and intervention timelines, changing roles for general and special education teachers, universal instruction across content areas, structural supports for professional collaboration, ongoing professional development, and the expansion of parent communication. This brief also included one high school example where RTI was implemented and listed resources needed to support such a RTI program. The 
signficance of this brief was that it provided a first look at a high school RTI model and the associated implementation challenges.

In addition, the National High School Center (2010) published a report that defined RTI as a "framework for promoting access to high-quality core instruction and providing increasingly intensive educational interventions in a timely manner for students who struggle in core instruction" and also reviewed the components of a RTI framework at the high school level (p. 1). The study provided a profile of eight high schools and how each one implemented the components of RTI (high quality Tier 1/core instruction, universal screening, ongoing progress monitoring, tiered interventions, and data-based decision making) in their buildings.

\section{Barriers to RTI Implementation in Secondary Schools}

There are several published "how to" manuals and "briefs" that explain the RTI implementation challenges at the secondary level. These barriers to implementation can be grouped into the following categories: scheduling/structure, curriculum issues, fidelity, and staff capacity/professional development.

\section{Barrier to Implementation - Scheduling/Structure}

The most commonly noted barrier to RTI implementation at the secondary level emphasized the challenge of scheduling additional time to implement the tiers of instruction or put another way, the structure of a given high school daily schedule. Johnson, Smith, and Harris (2009) emphasized that secondary students did not have one teacher all day long that alternated between subjects. Instead, students in high school had several teachers who were content experts and taught subjects like reading and writing through their content. Mellard (2009a) continued by stating the move from one classroom 
at the elementary level to multiple classrooms as the secondary level created "less individualized attention and instruction for each student," which created a challenge to build intervention for particular students into the class period. Intervention within a class period would be challenging due to limited time before the student was required to move to the next class on his/her schedule.

Time within the school day to provide intervention at tiers two and three was also cited in Johnson et al. (2009), Pyle and Vaughn (2012), and O'Connor and Freeman (2012). Students have state-mandated graduation requirements and need to earn a set number of credits in order to graduate. Secondary schools created time in the day or within the class period to provide additional interventions. Teachers competed for time within a school day to support students in mastering their content knowledge during an academic period. With limited time in a school day, there was a concern that a student will get further behind in credit attainment when remediation is offered for one course at the expense of another course. Other authors noted the same challenge with student schedules and the difficulty to schedule the time needed for intervention within a student's day in the school building (Mellard, 2009b; Sansosti, Goss, \& Noltemeyer, 2011). Along with a specific student's schedule possibly matching another student's schedule for the same intervention, at the high school level, there was a challenge due to the student population size where more students were in a high school setting versus an elementary setting. Since high schools typically have a larger student population, it was assumed that more students would also need a specific intervention. When more students needed the same intervention, with a limited number of staff members, and students needed a specific number of credits to graduate, it was challenging to offer a course for 
non-credit where the needed intervention competed with core content classes in a student's schedule.

\section{Barrier to Implementation - Curriculum Issues}

Another commonly noted barrier to RTI implementation at the high school level is related to curriculum and content. Pyle and Vaughn (2012) stated that the intervention at the high school level became that of content recovery where the elementary level was more aimed at early intervention. At the first sign of a student struggling in reading at the elementary level, supports were put in place that helped a student become a better reader. At the secondary level, students got behind in content attainment and knowledge acquisition where intervention were more centered on remediation, how to help a student recover the missed content knowledge.

Pyle and Vaughn (2012) also argued that the demands of the curriculum (vocabulary, writing prompts, discussion of abstract ideas) created a barrier to intervention implementation at the high school level. Sansosti et al. (2011) noted a curriculum barrier when a student had to sacrifice a content course in order to build academic intervention in a student's daily schedule. These authors also claimed secondary teachers were concerned when students did not master their specifically taught content, but were not necessarily concerned about other classes the student was also enrolled. Finally, Johnson et al. (2009) contended that teachers created classrooms of "siloed" instruction where they did not work collaboratively to share instructional strategies and best practices with other colleagues. If collaboration occurred more frequently, RTI strategies were easier to implement when teachers worked together to 
develop interventions in their classrooms and divide students based on need to provide interventions at tiers two and three.

\section{Barrier to Implementation - Fidelity}

Another barrier to the execution of a RTI program at the high school level related to fidelity of program implementation. Professional development for teachers to learn strategies and create a RTI system was important for success. Mellard (2009b) claimed there was not enough time in a teachers' day to attend the necessary professional development opportunities. When this did not occur, there were issues with teachers following the proper procedures to enact a RTI program. Mellard and Johnson (2008) dedicated chapter eight of their book to a three-dimensional model of fidelity of RTI implementation: method, frequency and support systems. They advocated that this model be used to ensure fidelity of a RTI program in a school.

Another factor similar to fidelity that shaped RTI implementation was the complicated nature of "sensemaking." When a teacher was presented information about a program, she/he made sense of the program by interpreting meaning, structure, process, and implementation (Coburn, 2005). Coburn (2005) indicated that teacher sensemaking was influenced by "working knowledge, interaction with others, workplace norms, conditions for learning, and connection to policy” (p. 478). So, based on a teacher's working knowledge of RTI, whether or not a teacher had a lot of knowledge about RTI depended on how effectively or not this teacher implemented RTI in his/her classroom. In fact, Sansosti et al. (2011) argued that site-specific implementation strategies (classrooms) connected to variations of implementation within a given building or between grade levels within the building. Spillane, Reiser, and Reimer (2002) claimed 
that a teacher's prior knowledge obstructed a policy implementation simply because he/she was not able to separate this knowledge from the intent of the new program. This also created a challenge because each teacher brought a different set of prior knowledge and interpretation with him/her and applied it to a newly designed program. For example, when ten different teachers arrived at a meeting, there would be ten different ideas presented, simply due to the prior level of experience each teacher had with the program.

\section{Barrier to Implementation - Staff Capacity/Professional Development}

One final barrier to RTI implementation at the high school level centered on staff capacity and professional development. O'Connor and Freeman (2012) considered the importance of culture and the capacity of a staff to truly believe and put in practice the idea that all students can learn and master essential targets. Their study argued that if this belief was not in place then RTI was not implemented, but that the school was just "doing RTI." Similarly, Pyle and Vaughn (2012) advocated that school culture and the idea of teachers collaboratively reviewing supports for all students' needs, as in a RTI approach, made implementation challenging at the secondary level.

In addition, O’Connor and Freeman (2012) supported more training at the collegiate level to support RTI implementation. Teacher training programs in colleges and universities needed to incorporate more RTI practices in their coursework so students entering the education field had more professional development and were more familiar with RTI components. Sansosti et al. (2011) also encouraged RTI practices be taught in colleges of education throughout the country. Then, school districts could hire candidates to go directly into their field knowing how to implement the RTI components and be 
confident and competent in their instruction. Continuing after they are hired, Johnson et al. (2009) advocated that more professional development opportunities for teachers should exist to continually support teachers in developing their skill and effectively implement the tiers in RTI.

\section{RTI in Practice}

Although there were not many studies on the implementation of RTI in secondary schools at the time of this study, practitioners have written about RTI and its implementation in their buildings. Their perspectives have been published in Principal Leadership, sponsored by the National Association of Secondary School Principals, and Educational Leadership, sponsored by ASCD (formerly the Association for Supervision and Curriculum Development). Although these are not empirical research studies, such work provides a glimpse into how schoolteachers and administrators interpret and implement RTI at the secondary level.

First, Canter, Klotz, and Cowan (2008) and Burns (2008) offered a two-part series that analyzed RTI through the lens of student services. Canter et al. (2008) provided a rationale for RTI and then continued by describing the tier system. The authors concluded by listing nine elements for an effective RTI program: administrative support, systematic data collection, staff support and training, parent support and involvement, understanding of legal requirements, realistic time line, strong teams, integration of existing scheduling, and coordination of existing intervention programs. They contended that when RTI was successfully implemented, one advantage was students attained essential course standards. Burns (2008) continued the discussion by describing the importance of RTI and stressing the components necessary to improve literacy skills: multiple modes of 
assessment, multiple ways of service delivery, and using problem solving to identify supports for students.

Second, Feuerborn, Sarin, and Tyre (2011) contended that professional development to both teachers and leaders was an important component of RTI implementation. Professional development must not only discuss what are the applicable strategies of RTI but also why these strategies were essential. Staff members must also work collaboratively in all phases of RTI planning and implementation to ensure consensus. In other words, their "sensemaking" about RTI must be continually supported.

Four authors of articles in Educational Leadership put an RTI system into practice in their buildings, each naming essential components to their school's systems. First, Greene (2010) described how to develop a RTI system where teams worked collaboratively with a problem-solving model when working with students on discipline issues. Second, Buffum et al. (2009) offered a rationale for RTI use in the education setting and suggested that schools must begin by making sure educators asked the right questions. Then, the authors described and offered examples of the three tiers in an academic setting. Third, Jackson (2010) developed an early warning system for teachers to implement in their classroom to identify students who needed extra supports and interventions in the future. Fourth, Engels (2015) claimed that decisions in a RTI model should be left to a classroom teacher team to develop interventions necessary for individual students. She supported the use of formative assessments (rather than standardized tests) to determine RTI placements and interventions.

In summary, these practice journal articles begin to demonstrate the results of RTI implementation at the secondary level. These articles emphasized the elements for 
effective RTI implementation, the need for collaboration amongst staff members, and the use of formative assessments to progress monitor. While RTI has not been fully researched in the secondary setting, these journals in practice offered a small glimpse into buildings attempting to scratch the surface of RTI implementation at this level.

\section{Summary: The Four Essential Elements of RTI}

After reading multiple journals, books, "how to manuals" and practice journals, four basic areas of RTI emerged: the use of an intervention team, universal screening of all students, continuous monitoring of student data and reaction to implemented strategies, and evidence-based interventions. These four essential elements are discussed below.

\section{Using an Intervention Team}

The first essential element in an effective RTI implementation was to have an intervention team. This team worked together to identify students classified at-risk. Then the team implemented strategies and individualized instruction for each student. Each intervention team also decided which process they followed when analyzing students and data points.

To review, this intervention team decided to operate using the standard treatment protocol or the problem-solving model. Several studies emphasized the difference between the standard treatment protocol (Fuchs et al., 2004; Vaughn et al., 2003) and

problem-solving model (Deno, 2002; Marston et al., 2003; Tilly et al., 1999) of intervention teams. The standard treatment protocol was when an "intensive fixedduration trial...is used, involving a validated standard treatment protocol" (Fuchs et al., 2004, p. 218). All students whom were tested received the same treatment. If the student 
responded positively to the treatment, she/he returned to the general education setting. However, if the response was negative then further information was needed to determine if a disability existed.

Differing from the standard treatment protocol, a problem-solving model in the referenced studies involved a process whereby an intervention team identified a student's academic challenges and then worked to provide the needed student support. Therefore, not every student received the same initial treatment as in the standard treatment protocol. "Solutions to instructional and behavioral problems are induced by evaluating students' responsiveness to a four-stage process" (Fuchs et al., 2003, p. 160). Students received different interventions based on their need for intervention. A cyclical process was designed until the ultimate treatment worked to resolve the problem.

Buffum, Mattos, and Malone (2018) outlined specific steps to take to create a RTI leadership team. These authors discussed the importance of locating a team of individuals that have positional power, expertise, credibility, and leadership ability as described in Kotter (1996). The purpose of this leadership team was "to unite and coordinate the school's collective efforts to help every student succeed and to allocate the school's resources to best achieve this goal" (Buffum, Mattos, \& Malone, 2018, p. 39). They continued and offered several tools and tips on how to build this team of individuals.

\section{Universal Screening of All Students}

Another essential element in a successfully implemented RTI program identified in this literature review was the use of a universal screening technique. The purpose of conducting a screening of all students was to identify which students achieved the 
academic outcome and which students did not. Once this was determined, then an intervention team determined next steps for individual or groups of students. The team would screen students for similar purposes as proposed by Johnson et al. (2009), to identify: 1) students at risk of dropping out, 2) students with learning needs, and 3) students at risk of not meeting performance indicators on state assessments. Once the data was collected on a specific item, related cut scores and decision rules determined next steps or interventions needed for the student.

When analyzing the universal screening data, accuracy and efficiency were used to determine interventions. Johnson et al. (2009) and Mellard and Johnson (2008) discussed this importance. The intervention team decided how to intervene with students who scored a false positive or a false negative. They also decided on the number of data points to include to ensure an accurate representation of the student in addition to the length of intervention in tier one before a student moved to a tier two intervention.

A universal screening process was also described in Buffum et al. (2018): universal screening, common assessments, and staff-recommended process. Academic intervention data included "state tests, end-of-course exams, common summative and formative assessments, diagnostic assessments, running records, and information assessment data" while behavior intervention data included "functional behavioral analyses and other behavior screening scales" (Buffum et al., 2018, p. 229). A team of individuals used all this data, and information from teachers, to properly assign students to the appropriate intervention. 


\section{Progress Monitoring of Student Data}

Once students were identified using data and placed into a tier by an intervention team, students were continually monitored to see if they were making progress. The following questions were addressed once an RTI program was implemented: How often were students monitored? Why were students monitored? For how long were students monitored? Who or what determined this schedule? In other words, progress monitoring meant tracking students to see if they responded to the intervention put in place. A common assement was typcially used as a method of measurement to determine if a particular intervention was working or not. Mellard and Johnson (2008) dedicated chapter four of their text to the "systematic, continuous" process of progress monitoring (p. 60). No matter the tier, students were monitored at each level to determine if the student was properly placed or if movement on the intervention triangle should occur.

In Buffuam et al. (2018), progress monitoring took place during both tier two and tier three instruction. Once students were identified as needing more time and support, an intervention was used to support the student. Then the team monitored if the intervention worked or not. If the intervention worked, then the team's assessment and strategy was correct. If the intervention did not work, then it meant one of two things: "the intervention was not targeted properly or that the diagnosis was correct, but they selected the wrong treatment" (Buffum et al., 2018, p. 175). Also, if placed in a tier three intervention, students were monitored for progress at this level where the team decided if the appropriate duration and intensity was applied. If a student was successful, he/she moved down to a tier two intervention and if the student did not show success, another diagnosis of the problem needed to be explored. 


\section{Using Evidence-Based Interventions}

The final essential element to a successfully implemented RTI program was the use of evidence-based interventions. Johnson et al. (2009) defined these as strategies designed to augment the instruction provided in a tier one program. These interventions were more targeted and specific to the students' need. These authors also presented several evidence-based strategies in Figure 6.1 on p. 92. These strategies were shown on a continuum and included both teacher and student mediated instructional strategies. Mazzotti et al. (2013) provided teachers with evidence-based practices that were applicable to students with disabilities at the secondary level. Resources described in the article can be located and used when making decisions for specific students. Another resource for evidence-based models was located in Mellard, Stern, and Woods (2011) where models were placed into a table format of the following authors: Batsche, Curtis, Dormán, Castillo, and Porter (2008); Fuchs and Fuchs (2005); Johnson, Mellard, Fuchs, and McKnight (2006); Vaughn (2005); Shinn (2008); Chun and Witt (2008); and Sugai and Homer (2007a). I replicated most of Table 1 (p. 5) and all of Table 2 (p. 6) in Appendix A and Appendix B, respectively, that summarized their findings.

This study will specifically review interventions in place for Algebra 1 students. Fuchs (n.d.) outlined six key principles (instructional explicitness, instructional design that eases the learning challenge, a strong conceptual basis for procedures that are taught, an emphasis on drill and practice, cumulative review as part of drill and practice, and motivators to help students regulate their attention and behavior and to work hard) to use in tier two mathematics interventions. In addition, Star et al. (2015) made three recommendations (use solved problems to engage students in analyzing algebraic 
reasoning and strategies, teach students to utilize the structure of algebraic representations, and teach students to intentionally choose from alternative algebraic strategies when solving problems) of teaching strategies on how to improve algebra knowledge in high school students. To successfully teach Algebra 1 students in a RTI system, these strategies should jointly be used.

\section{Summary}

This literature review examined the role of RTI implementation in a secondary school setting. A thorough history of RTI was explored followed by a detailed explanation of the three-tiered system. Next, the tiered system was applied to examples at the high school level. Due to limited research at the secondary level, several "how to" manuals and current practice journals were examined to review RTI implementation in high schools. Next, several barriers to RTI implementation at the high school level were explained in detail. A few empirical studies examined RTI in the secondary setting and were discussed. Finally, the four essential elements to a successful RTI program were discussed. The next chapter will outline the methods of this study that were used to evaluate the RTI implementation at Aspen. 


\section{Chapter III: Research Design and Methodology}

This chapter outlines the research design and methods associated with this study. First, the research purpose and questions are reviewed. Next, the chapter includes the following: a rationale and description of the research design, a description of the data gathering tools and procedures, participants, and data analysis details. Next the chapter covers ethical concerns with research, including the human subjects' protection and a positionality statement of the researcher. The chapter concludes with strategies to address issues of quality and a section on limitations and assumptions.

\section{Purpose of the Study}

As mentioned in chapter one, the prevention model used at Aspen is the RTI system-wide program called Aspen Time. Barriers to implementation at the high school level proved challenging. In addition, the number of students who had fallen behind in accumulated credits towards graduation continued to increase, even after implementing Aspen Time. Thus, there was a need for an evaluation of the RTI process in part to look for improvements that could be implemented. In addition, the study could add to the literature, given that there is a lack of studies on the implementation of RTI at the secondary level.

Thus, the purpose of this case study was to explore to what degree the essential elements of RTI, as defined by the literature, were implemented in the Aspen Time program developed at Aspen High School. At this stage in the research, the RTI system was defined as a system-wide intervention program that targeted and designed a specific learning environment for each student. 


\section{Research Questions}

The question in bold served as the overarching focus of this study, which was guided by three sub-questions:

\section{- How was RTI implemented at Aspen High School?}

A. To what degree was each of the four essential elements of RTI evident in weekly student support team meetings and the classroom?

- formation of intervention teams

- development of a universal screening process

- continual monitoring of students for progress

- use of evidence-based interventions

B. When an essential element was not evident, which barrier(s) to implementation limited the presence of the element?

C. How did different stakeholders (administrators and teachers) view Aspen Time?

\section{Research Design}

In order to better understand the use and implementation of RTI at the secondary level, this dissertation developed a qualitative case study at "Aspen," a high school in the mid-continental United States of America. This section explains the rationale for choosing qualitative methods, in general, and a case study approach, in particular.

\section{Qualitative Methods}

Qualitative methods were used in order to explore the process of implementing Aspen's RTI program. A qualitative approach was chosen due to the unique design of the study and employed many of the characteristics declared in Creswell (2009). With a 
qualitative study, observations of participants took place in a natural setting in the field. In addition, multiple sources of data were reviewed and themes were located, which is also characteristic of qualitative research. Other critical components to program implementation involved meaning making and the process of program development. Creswell (2009) emphasized that the entire process of qualitative research revolved around meaning and this study worked to understand participants' perspectives and opinions about the RTI process at Aspen.

Qualitative methods were also very useful for evaluations of single programs. The design of this study allowed for rich descriptions about the RTI implementation from stakeholders. Thus, qualitative data collection practices in Creswell (2009), Emerson et al. (2011), Hatch (2002), and Krueger and Casey (2009) were followed to conduct this study. All of the data collection sources used in the study (document review, field notes, interviews, and focus groups) were triangulated and results were published in a final report.

\section{Qualitative Case Study}

This project followed the design elements of a case study, as recommended by Hatch (2002). This case study took on a constructivist research paradigm. Specifically, this study constructed meaning of the voices of the participants so that readers could place themselves in participants' shoes, a case study characteristic defined by Hatch (2002). A case study allowed the researcher to identify the implementation of RTI through the examination of documents, observations, interviews, and focus groups, studying the actual events as constructed by participants. 
Hatch (2002) argued that a case study "investigates a contextualized contemporary... phenomenon within specified boundaries" (p. 30). Having only been identified as an acceptable practice in 2004, RTI was a recent experience addressed by this study. Also, case studies are very useful to use when studying something that has not been studied significantly in the past, to build theory about the event, policy, or program. The focus of the study was on one school building and the study lasted for one academic semester; these are the characteristics that set the boundaries and helped classify this as a case study.

Another reason for a case study is because the researcher regularly worked in the context of the study on a daily basis, and in fact, helped to design the original program until he left the school one year before the study took place. This allowed for a detailed description of the context and the reader can imagine himself or herself in the school building at the exact moment in time. The researcher himself is examining the RTI system at his current high school of employment and so therefore had an invested interest in the topic and something to gain from learning the findings and eventual recommendations of this case study.

\section{Research Context}

This section of the study describes the context of Character School District and Aspen High School. It also outlines the details of Aspen Time, including how students were assigned to attend their intervention locations at the time of this study.

\section{The Context of Character School District}

Character School District is located in a mid sized city in the Midwest. Census Bureau statistics on the surrounding county provided the following resident population 
characteristics for 2014 (numbers are rounded to preserve anonymity): $80 \%$ White, 10\% Black, $5 \%$ Asian, $4 \%$ Hispanic or Latino, $3 \%$ two or more races, and less than $1 \%$ American Indian and Pacific Islander; 50\% female; 90\% high school graduate or higher, and 55\% bachelor's degree or higher. Although the majority of residents sent their children to the public school district, the area also had several private schools offering classes for students in grades K-12. There were also a number of post-secondary options in the area. At Character School District, 0.6\% more students dropped out in 2017, in comparison to the state (State Department of Elementary and Secondary Education, 2018). Character has shown a steady drop out increase in the last few years, and the drop out rate has been higher than the state average the past three years. In 2017, 132 students dropped out of high school in Character, which are too many students who ended their education early.

\section{Aspen High School}

Character was the largest school district in the county with a student population of approximately 18,000 in 2016. Aspen was a new building in the district that opened to students in August 2013. Demographics of the students in this building mirrored the current student population for the school district. In January of 2018 the following were student demographics at Aspen: approximately 1,400 total students, 53\% male, 47\% female; 55\% White, 30\% Black, 7\% Hispanic, $8 \%$ multiple ethnicities; $54 \%$ students on free or reduced price lunch; 46\% students on paid lunch; 4\% English as a Second Language students; $81 \%$ Non-504 or IEP students, $5 \%$ students on a 504 plan, 14\% students with an IEP; $64 \%$ of students in the super subgroup (any student classified Black, Hispanic, English as a Second Language, having an individualized education plan 
or on free or reduced price lunch). The percent of students at or above $90 \%$ attendance rate for the 2017-2018 academic school year was 70\%.

Based on grades from May of 2012, 250 students out of approximately 1,300 failed at least one or more classes at Aspen. There were 140 students at Aspen who were behind in credits towards graduation. Black students composed $30 \%$ of the population at Aspen, but they composed $63 \%$ of the total number of discipline incidents. In addition, $4 \%$ of the student population generated $40 \%$ of the total number of discipline incidents at Aspen. The leadership team that helped open Aspen knew that from the research and having worked with similar student demographics prior to opening Aspen (at other feeder schools to Aspen or the other high school which students were transferred from after Aspen opened), students at Aspen would need additional interventions to assist them academically. So, the scheduling committee began constructing a bell schedule that built in a daily period for academic intervention. This period became known as Aspen Time.

\section{Aspen Time}

Aspen Time was a 30-minute period that occurred every day and was designed by a group of 17 volunteer faculty members who met one year prior to the new school opening. This group established the intervention criteria for students during Aspen Time. Students earning a grade of "C-" or higher in all their courses were on "privilege" and essentially had this period as free time. These students traveled to the commons for social time, media center for quiet individual or group work, or to the auxiliary gymnasium to play basketball. However, students who had at least one grade of " $\mathrm{D}+$ " or lower were "directed" to go to a specific location; they worked with their teacher who taught the course in which the student earned the low grade. 
To determine who attended the intervention of Aspen Time for extra support, the school followed a specific protocol. Every other Thursday at 9:00 AM CST, a series of reports were generated in the student information system, in order to collate the data for the next two-week period. There were several tedious steps (Appendix C) that occurred in this process, which generated the reports necessary to assign students to either a directed or privileged area.

First, individual student academic data was downloaded from the student information system software and put into a Microsoft Excel document. This finalized document was emailed to the guidance counselors at Aspen. If these reports suggested that students needed support in more than one course, counselors prioritized the courses that students would attend during Aspen Time based on the following criteria: (1) the course with the highest academic grade, (2) the course where students had a strong relationship with the teacher, and (3) the course where the student would likely experience the most success with the Aspen Time intervention (based upon knowledge of the student and the above characteristics).

The Aspen Time coordinator (one assistant principal at Aspen) then reviewed the recommendations and balanced the classes so no more than 20 students were assigned to each teacher for intervention. This data was imported into Microsoft Access where reports were generated to give to both teachers and students. Three reports resulted: (1) a master sheet of where students were assigned for each course during Aspen Time; (2) a report for each teacher that listed the students coming to them during Aspen Time on any given intervention day; and (3) a report for each student, stating where he/she was assigned to attend to obtain his/her intervention. Finalized assignments were distributed 
to all teachers every Friday (following the Thursday in which the reports were ran) for them to prepare for the students' attendance the following Wednesday.

\section{Data Gathering Tools and Procedures}

Each of the sub-research questions had specific data collection methods associated with it. Table 2 shows the data collection methods and how these are associated with each research question.

Table II

Data Collection Methods Associated with Research Questions

\begin{tabular}{|c|c|c|}
\hline Research Question & How Data Collected & When Data Collected \\
\hline \multirow{4}{*}{$\begin{array}{l}\text { To what degree was each } \\
\text { element evident? }\end{array}$} & $\begin{array}{l}\text { Document review/personal } \\
\text { knowledge, field notes }\end{array}$ & Winter 2018 \\
\hline & & Classroom visits on \\
\hline & $\begin{array}{l}\text { Observation analysis-field } \\
\text { notes in classrooms \& } \\
\text { student support meetings }\end{array}$ & $\begin{array}{l}\text { February } 27,28, \text { March } 1, \\
6,8, \text { and } 12 . \\
\text { Attended two student } \\
\text { support meetings on May } 3 \\
\text { and } 9 .\end{array}$ \\
\hline & Focus groups & $\begin{array}{l}\text { One with the leadership } \\
\text { team on May } 30 \text { and one } \\
\text { with the scheduling } \\
\text { committee on June } 27\end{array}$ \\
\hline \multirow{5}{*}{$\begin{array}{l}\text { What limited the presence } \\
\text { of the element? }\end{array}$} & Document review & Winter 2018 \\
\hline & & Classroom visits on \\
\hline & Observation analysis, field & $\begin{array}{l}\text { February } 27,28, \text { March } 1, \\
6,8, \text { and } 12 .\end{array}$ \\
\hline & $\begin{array}{l}\text { notes in classrooms \& } \\
\text { student support meetings }\end{array}$ & $\begin{array}{l}\text { Attended two student } \\
\text { support meetings on May } 3 \\
\text { and } 9 .\end{array}$ \\
\hline & Focus groups & $\begin{array}{l}\text { One with the leadership } \\
\text { team on May } 30 \text { and one } \\
\text { with the scheduling } \\
\text { committee on June } 27\end{array}$ \\
\hline $\begin{array}{l}\text { How was Aspen Time } \\
\text { implemented from various } \\
\text { perspectives? }\end{array}$ & Focus groups & $\begin{array}{l}\text { One with the leadership } \\
\text { team on May } 30 \text { and one } \\
\text { with the scheduling } \\
\text { committee on June } 27\end{array}$ \\
\hline
\end{tabular}


The first sub-question related to what degree RTI was implemented in a new high school, and the researcher used document review, personal knowledge, field notes, and focus groups to answer this question. Being a former administrator at this high school and chairman of the school's scheduling committee, the researcher had personal knowledge about how the process was constructed. Also, the researcher had access to several documents including 12 agendas and minutes of the scheduling committee, timelines, and worksheets that were used to plan and implement Aspen Time. The researcher analyzed these documents and took field notes (in six Algebra 1 classrooms on February 27, 28, March 1, 6, 8, 12 during Aspen Time and attended two student support team meetings on May 3 and 9) and held two focus groups on May 30 and June 27 to determine the absence or presence of the four essential components of RTI during Aspen Time.

The researcher conducted observations and took field notes in six different classrooms (February 27, 28, March 1, 6, 8, 12) to analyze the interventions being used between Algebra I teachers and students. The same teacher was observed 2/27-3/1 and then another teacher was observed 3/6-3/12. After each set of three observations was conducted, an annotated memo was written. Algebra I classes were chosen because this content had the most F grades than any other content area PLC at Aspen High School. Students at the end of this course were required to take a state mandated test in which the results were reported on the school's report card for the state department of education. In addition, three math credits are required for graduation, of which Algebra I must be passed before the other two courses can be taken. These dates were chosen to allow for several cycles of Aspen Time to pass in the new academic semester. These field notes 
were collected in accordance with Emerson et al. (2011) and recorded whether/how the RTI process was followed (a detailed observation tool was used - found in Appendix D).

The researcher also attended two SST meetings held on May 3 and May 9 where student placement and appropriate supports were decided for individual students (a detailed observation tool was used - found in Appendix E). There were four assistant principals at Aspen. Two assistant principals worked together to form two teams where each team held a weekly SST meeting. The researcher attended both team meetings and thus viewed two different perspectives and interpretations of how a student support team was conducted. The researcher took numerous field notes during these meetings to provide documentation as to the types of interventions provided to students. The researcher used these tools in addition to focus groups (described below) to answer the first and second sub-questions.

The second sub-question reviewed that if the essential element was not present, then what was the barrier to implementation that prevented it from being present. After field notes were taken in each Aspen Time class period, a follow up conversation was held with each teacher. During this interview (questions located in Appendix D), questions were asked about the evidenced based interventions he/she used with the students, processes and procedures used in Aspen Time, and possible barriers that did not allow implementation. Through these interviews, the field notes mentioned above, and the focus groups below, the second question was able to be answered.

In addition to document review, field notes, and interviews, the researcher conducted two focus groups to answer the third sub-question on how Aspen Time was implemented. Each group followed a protocol, lasted approximately 60 minutes, and was 
recorded and transcribed for reporting accuracy. A focus group was chosen because this allowed one participant to answer the question posed by the focus group leader and then other participants added additional information to clarify points or contradict or confirm information of others. This was a way to gather information with the input of several individuals. The researcher conducted the focus groups since he was previously employed in this building, which allowed for quick rapport with participants having previously known him. The researcher established rapport with the participants first by asking a general question introducing himself or herself and then continued with questions based on the focus group's role of individuals within the RTI model. For instance, the questions asked of the scheduling committee (Appendix F) were different than the questions asked of the leadership team (Appendix G) as their roles during Aspen Time differed. Teachers were questioned on evidence-based interventions used during Aspen Time where the leadership team's questions were on the formation and implementation of SSTs and the process of monitoring students. When preparing for these focus groups, the researcher used Krueger and Casey (2009) and the processes described therein.

The questioning strategies for the focus groups were developed to model the questioning route outlined on page 41 of Krueger and Casey (2009). The researcher "tested" focus group questions on a counselor at another school, who was a student in the researcher's academic coursework. The researcher wanted to see if this individual gave answers to the questions or if the questions needed to be modified for clarity or easier understanding. Since the researcher had two focus groups to analyze, it was good to 
write annotated memos between the focus groups. The researcher used the knowledge gained in the focus groups to compare and analyze against the research questions.

\section{Participants and Sampling Procedures}

The sampling of participants in this study was purposeful. Individuals with knowledge related to the second and third research questions were chosen based on their involvement with the scheduling committee and members of the leadership team. Students and parents were considered as participants in this study, but ultimately not included. Limitations of the study will discuss this decision more in depth.

Following guidelines by Emerson et al. (2011), I took field notes in six different classrooms. These notes were compared to the literature to analyze the evidence-based interventions and interactions that occurred between teachers and students. In addition, I used the questioning route articulated by Krueger and Casey (2009) and wrote the interview questions asked of Algebra 1 teachers. These field notes and interviews helped me answer the first and second questions about the degree to which the essential elements were implemented and the barriers that prevented some of the elements from being implemented if absent.

I conducted two focus groups: one with the Aspen leadership team (one principal and four assistant principals) and one focus group with members of the scheduling committee (three teachers and one counselor). The leadership team focus group was held May 30 at 10:15 AM in the main office conference room at Aspen. The principal, through email with the researcher, set up the focus group meeting time with her administrators. A composition of those individuals is in Table 3 below. Since one assistant principal had accepted a new position outside the district, this individual was 
already at this new site and not present for the focus group. The newly hired administrator had not begun his official duties until July 1 and thus was also not present for the focus group. The scheduling committee focus group was held on June 27 at 4:15 PM in the main office conference room at Aspen. The composition of those individuals is in Table 4 below. Ten of the former members of this team were invited to attend the focus group. Two other members of this team were administrators and previously interviewed and the other five individuals of the original committee had moved either to another building in the district or to another school district. Thus these five individuals were not invited to attend the focus group.

Table III

Characteristics of Members of the Leadership Team Focus Group

\begin{tabular}{|c|c|c|c|c|}
\hline $\begin{array}{c}\text { Pseudonym } \\
\text { Name }\end{array}$ & Degrees & $\begin{array}{c}\text { Years in } \\
\text { Education }\end{array}$ & $\begin{array}{c}\text { Years in } \\
\text { CSD }\end{array}$ & Current Position \\
\hline Ms. Principal P & $\begin{array}{l}\text { - } \text { Bachelors in Math } \\
\text { Education } \\
\text { - Master's and } \\
\text { Specialist in } \\
\text { Secondary } \\
\text { Administration } \\
\text { - } \mathrm{PhD} \text { in Ed. Admin. }\end{array}$ & 29 & 28 & Principal \\
\hline $\begin{array}{l}\text { Mr. Assistant } \\
\text { Principal L }\end{array}$ & $\begin{array}{l}\text { - Bachelors in } \\
\text { Chemistry } \\
\text { - Master's in } \\
\text { Biochemistry } \\
\text { - Master's in } \\
\text { Science Ed. } \\
\text { - Master's in Ed. } \\
\text { Admin. }\end{array}$ & 18 & 1 & Assistant Principal \\
\hline $\begin{array}{l}\text { Mr. Assistant } \\
\text { Principal T }\end{array}$ & $\begin{array}{l}\text { - Bachelors in } \\
\text { Business } \\
\text { - Master's in School } \\
\text { Admin. } \\
\text { - Specialist in } \\
\text { School Admin. }\end{array}$ & 8 & 8 & $\begin{array}{l}\text { Assistant Principal } \\
\text { for Athletics \& } \\
\text { Activities }\end{array}$ \\
\hline
\end{tabular}




\begin{tabular}{|c|c|c|c|c|}
\hline $\begin{array}{l}\text { Mr. Assistant } \\
\text { Principal J }\end{array}$ & $\begin{array}{l}\text { - Bachelors in } \\
\text { Education } \\
\text { - Master's in } \\
\text { Admin. } \\
\text { - Specialist in } \\
\text { Admin. }\end{array}$ & 19 & 18 & Assistant Principal \\
\hline $\begin{array}{l}\text { Ms. Assistant } \\
\text { Principal M }\end{array}$ & $\begin{array}{ll}\text { - } & \text { Bachelors in } \\
\text { Secondary Ed. } \\
\text { - } & \text { Master's in Ed. } \\
\text { - } & \text { Master's in Curr \& } \\
\text { Instruction } \\
\text { - } & \text { Master's in } \\
& \text { Admin. } \\
\text { - Specialist in Ed. } \\
\text { Leadership }\end{array}$ & 17 & 16 & Assistant Principal \\
\hline
\end{tabular}

Table IV

Characteristics of Members of the Scheduling Committee/Teacher Focus Group

\begin{tabular}{|c|c|c|c|c|}
\hline $\begin{array}{l}\text { Pseudonym } \\
\text { Name }\end{array}$ & Degrees & $\begin{array}{c}\text { Years in } \\
\text { Education }\end{array}$ & $\begin{array}{l}\text { Years in } \\
\text { CSD }\end{array}$ & Current Position \\
\hline $\begin{array}{l}\text { Ms. Counselor } \\
\text { S }\end{array}$ & $\begin{array}{ll}- & \text { Bachelors in } \\
\text { Journalism } \\
\text { - } \\
\text { Master's in Ed. } \\
\text { Counseling }\end{array}$ & 24 & 24 & Counselor \\
\hline Ms. Teacher Ad & $\begin{array}{l}\text { Bachelors in Elem. } \\
\text { \& Middle School } \\
\text { Ed. } \\
\text { - Master's in Ed. } \\
\text { Counseling }\end{array}$ & 26 & 26 & $\begin{array}{l}\text { Social Studies } \\
\text { Teacher }\end{array}$ \\
\hline Ms. Teacher Ag & $\begin{array}{l}\text { - } \text { Bachelors in } \\
\text { Spanish Ed } \\
\text { - Master's in } \\
\text { Teaching a Second } \\
\text { Lang. }\end{array}$ & 17 & 10 & AVID Teacher \\
\hline Mr. Teacher R & $\begin{array}{l}\text { - Bachelors in Music } \\
\text { Ed } \\
\text { - Master's in Special } \\
\text { Ed. }\end{array}$ & 16 & 11 & $\begin{array}{l}\text { Special Education } \\
\text { Teacher }\end{array}$ \\
\hline
\end{tabular}




\section{Human Subjects Protection}

My study involved human subjects at Aspen so the necessary approval was garnered from the Institutional Review Board (IRB) and the cooperating Character School District. This process ensured individuals were protected and not harmed while participating in the study. Since only adults participated in the study, the IRB process was not as lengthy had it involved minors. I ensured the adults were protected in my research and also that my research was ethical.

I had each participant sign an informed consent letter (Appendix H). The letter included items that described me as a researcher, the purpose of my research, time requirements of the participants, what happened to the data once it was collected and a statement that participants could discontinue at any time. I also included that participants were not identified in the final report and that my data was kept confidential where others did not have access.

I also included a conflict of interest clause in the informed consent letter. I made it clear that participant responses were not included nor reflected in their year-end evaluations. This was important to clarify so I ensured participants felt comfortable answering the questions. The benefit to them was that the study improved Aspen Time. Once I had the full IRB approval, I conducted my study and thus began collecting data.

\section{Data Analysis Procedures}

While collecting data and during the triangulation stages, I used a constructivist approach to identify themes that surfaced in the answers to focus group questions around the four essential RTI elements. I used the format in Appendix I to analyze my data from multiple sources. When or if one of the essential elements was not present in the table for 
Appendix I (all of the boxes in that given column were blank), I moved to and inserted information in Appendix J. This table asked what kind of barrier(s) to implementation led to the absence of the element. I analyzed the focus group transcripts to scrutinize the data and found key words or phrases that supported answers to my research questions. If a phrase was used more than three times in the responses, I considered that an overall idea that needed to be addressed in the findings. The field notes provided detailed descriptions and were where I obtained quotes to support the themes. The process of data analysis and interpretation described in Creswell (2009) was followed.

I used the data analysis steps in qualitative research and triangulation strategies as my guide when I analyzed the data as described in Creswell (2009). My process was ongoing as I continually looked for patterns and coded with each focus group conducted. Since this was a case study in practice at Aspen, I provided a "detailed description of the setting or individuals, followed by analysis of the data for themes or issues" (Creswell, 2009, p. 184).

I used the open coding method while triangulating the data for each sub-research question. For the first question about the four essential elements, I reviewed the documents and field notes. Each time I saw one of the elements present, I used the following guide to label the passage using colored highlighters: formation of teams (yellow highlighter), universal screening (green highlighter), continuous monitoring (blue highlighter), and evidenced based interventions (pink highlighter).

For sub question number two on barriers to implementation, I again used a similar coding procedure above and analyzed the field notes taken during the classroom and student support meeting visits and interviews: scheduling/structure (yellow highlighter), 
curriculum issues (green highlighter), fidelity (blue highlighter), staff capacity/professional development (pink highlighter). Appendix J documented the barriers to implementation associated with each element. Appendix K was a master coding sheet where I coded information specifically related to the barriers to RTI implementation at the secondary level. I developed a master coding sheet that I continually consulted to ensure accurate labeling.

For the final sub question related to various perspectives, I located four major themes evident in each of the focus group transcripts and coded them using a similar structure as listed above: logistics behind Aspen Time was time consuming (yellow highlighter), supervision of students was time-consuming (green highlighter), SST meetings can be more effective (blue highlighter), and the universal screening tool was flawed (pink highlighter).

\section{Strategies to Address Issues of Quality}

There are several techniques I considered to ensure the quality of data I collected through the appropriate data analysis stages. After reviewing the ethical practices in Hatch (2002), I was cognizant of having teachers participate in my study. After I clarified the purpose of the study and benefits it provided to our school, teachers and the leadership team did not feel coerced to participate in the study as stated in Hatch (2002).

One limitation to the study was that it was conducted over the course of one academic semester. More thorough results and analysis would have been garnered if this study were to take place over a full year or a multi-year study. Due to time constraints and an anticipated completion date, this study was limited to one academic semester. The dates for the field notes were chosen in late February and early March to allow for some 
assignments and scores to be present for student grades, but there was enough academic data present to track students not attaining necessary skills and potential credit in a given class.

I also considered several ethical concerns presented in Creswell (2009). I read through my field note transcripts at the end of each day to ensure no mistakes were made in transcription and added my interpretations. I submitted my focus group transcripts to www.rev.com for dictation. Once I received the final transcripts, I listened twice more to the recordings to ensure accuracy of statements made. I also developed a coding system and maintained its consistency in reporting throughout the focus groups by continually checking my master-coding sheet.

In addition, the researcher ensured participants that the answers to their questions in the focus group had no relationship to their evaluation at the end of the school year. Participants did not have to answer the questions that they did not want to answer. They could drop out of the study at any time or not participate all together. The focus group facilitator allowed a dialogue between Aspen colleagues where they were able to openly share their views of Aspen Time. The questions were designed to solicit information about the program and not to reveal information that would identify them in the study.

Creswell (2009) also addressed several validity strategies. The strategies of triangulation and using rich, thick descriptions were addressed above in this study. In addition, I did not need to member check to be sure what participants said was accurate as I reviewed the focus group recordings when necessary. Creswell (2009) also addressed bias on the part of the researcher. My biases are listed below and in the following 
anticipated study assumptions section of this chapter. I also had two external auditors (a colleague and my advisor) read my study from an outside perspective.

First, the author aimed to make sure that perspectives about the implementation process were reported accurately and that his personal biases about the program were reduced. However, this is challenging because researchers may not know when they are being biased. The researcher is partial to the RTI program and in favor of Aspen Time since he was the appointed leader of the scheduling committee prior to moving to a different school. This was due to his background of student support and having created a bell schedule at his previous school. As a check on this potential bias, the data was triangulated throughout the data collection and analysis process. An "audit trail" was also completed and the researcher received feedback from outside readers (his dissertation committee) as he developed and implemented this study. These procedures helped the researcher to assess and address possible weaknesses in the study.

Second, it was important that this system operated to its fullest potential and was designed to help all students achieve at the high school level. So, another assumption was that Aspen created a unique program that was designed and implemented to the best of the committee's ability. The researcher is a very organized person and believed that the committee created a unique program to assist academically struggling students. However, he recognized that this program had room for improvement. To ensure that the study did not focus upon positive responses from only a few individuals, this research project collected data using different methods and from multiple individuals. These methods and perspectives helped ensure that the researcher was not only looking to find 
positive results. This study was conducted to improve conditions, so areas of weakness were located and then became recommendations for improvement.

\section{Anticipated Study Assumptions}

Several assumptions existed on my behalf as the researcher. The researcher's first assumption was that his previous leadership role in the building did not influence the answers of the participants. The researcher worked on this issue through the development of relationships. Specifically, he expected that having developed relationships through creating Aspen Time collaboratively among many stakeholders, he would be able to collect authentic responses in his focus groups. Aspen Time was created by a group of 17 volunteer faculty members at Aspen. A collaborative process where ideas were shared and shaped over the course of 11 months ultimately led to the processes associated with Aspen Time. Even after the initial year of implementation, the committee continually met and refined the Aspen Time procedures, and regularly critiqued their own process. Therefore, it was assumed that Aspen Time committee members participating in this study wanted to be honest about the implementation of Aspen Time because they, too, wanted to improve this academic intervention period.

Second, the researcher was upfront with participants (both administrators and teachers) about the purpose of the research, and, as discussed above, situations were created where participants felt comfortable answering questions honestly and to the best

of their ability. The researcher did not want individuals to feel uncomfortable, so setting the stage for data collection was important; in each interaction, he made clear the statement of purpose. Participants were past colleagues within Aspen. An assumption was made that participants answered questions honestly and to the best of their ability 
because they knew the positive benefits of this study for Aspen. The facilitator also established rapport with participants in the focus group, which helped set them at ease.

\section{Summary}

This chapter outlined the research design and methodology. A qualitative case study was used to study this particular issue of RTI at Aspen High School. The research questions were outlined along with a detailed account of the participants used in the study. Data gathering tools and procedures were described in detail along with a note about protection of those subjects used in the study. Data analysis procedures were discussed and strategies to address issues of quality were analyzed. A final note on anticipated assumptions was also included. 


\section{Chapter IV: Overview of Findings}

This chapter outlines the findings of the research study of Aspen Time, specifically in the Algebra 1 classrooms. As a reminder there was one overall research question and three sub questions in the design of the study.

\section{- How was RTI implemented at Aspen High School?}

A. To what degree was each of the four essential elements of RTI evident in weekly student support team meetings and the classroom?

- formation of intervention teams

- development of a universal screening process

- continual monitoring of students for progress

- use of evidence-based interventions

B. When an essential element was not evident, which barrier(s) to implementation limited the presence of the element?

C. How did different stakeholders (administrators and teachers) view Aspen Time?

Each section of this chapter directly correlates with each of the sub-research questions.

First, I discuss the presence or absence of the four essential elements of RTI through an analysis of document review, classroom field observations, SST meeting observations, and focus groups. Findings demonstrate that intervention teams are in place, there is a universal screening process, students are monitored for progress, and there are evidencebased interventions being used. However, the recommendations below compare Aspen Time to the cited literature and offer areas for improvement. These recommendations come from an analysis of the barriers to Aspen Time implementation, including 
scheduling/structure, curriculum issues, fidelity, and staff capacity/professional development. The chapter concludes with a review of stakeholder views of Aspen Time through individual teacher interviews and focus group meetings with both a teacher and leadership group of individuals.

\section{Presence or Absence of Four Essential Elements of RTI}

The four essential elements of RTI as defined in the literature review are: formation of intervention teams, the development of a universal screening process, continual monitoring of students for progress, and the use of evidence-based interventions. To better understand if there was a presence or absence of these four essential elements at Aspen High School, observations were completed, document review was done, interviews were conducted, and two focus groups hosted. A summary of the presence or absence of each of the four elements is detailed below. There was a presence of each of the elements at Aspen High School but only a slight presence of teams, a universal screener, and continued monitoring of students. There was a strong presence of evidence-based interventions witnessed in this study.

Based upon the methodologies used in this study, along with personal knowledge, it was challenging to identify a clear definition of the three tiers of interventions at Aspen High School related to Algebra 1. Tier one was the interventions that a teacher used and implemented inside the classroom setting. Tier two appeared to be the interventions used during the daily Aspen Time period followed by tier three when students were pulled from the advisory classroom to complete additional work with a tutor in the math lab. There was no clear line of these tiers on any written document, and the lines between a tier two and tier three intervention were not clear - where one tier ended and one tier 
began. This tier three as I have defined was only being used with Algebra 1 students at Aspen High School, but not in any other mathematics or other content course.

\section{Lack of Thoughtful Intervention Teams Meeting to Discuss Academic Progress}

Intervention teams worked together to identify students classified at-risk. This team of individuals inside the school implemented strategies and individualized instruction for each student. The team operated using either a standard treatment protocol or problem-solving model. The team of individuals at Aspen High School who decided on appropriate interventions for students was present at the time of the study, but it was not clear on their intended outcomes related to Aspen Time. The Aspen Time coordinator oversaw the implementation of the daily Aspen Time model, but there were also Student Support Teams (SSTs) that worked to support student needs inside the building. It became clear that the teams did not focus on Aspen Time intervention placement; instead this was left solely to the coordinator who assigned students to an intervention based upon a course academic grade.

Document review demonstrated there was a group of individuals that initially designed and implemented Aspen Time. This group of individuals was composed of the principal, two assistant principals, one counselor, and 13 teachers (Committee Meeting Minutes, October 12, 2012) was known as the Scheduling Committee. This committee allowed volunteers to attend nine planning meetings (10/12/12, 11/1/12, 11/15/12, $12 / 13 / 12,1 / 24 / 13,3 / 21 / 13,4 / 18 / 13,5 / 9 / 13,9 / 6 / 13)$ prior to the first Aspen Time implementation on $9 / 26 / 13$. Access was also provided to the minutes of additional committee meetings held on $11 / 13 / 13,12 / 5 / 13,7 / 11 / 14$, and $7 / 18 / 14$, which was after the first Aspen Time implementation. These later meetings were held to refine the Aspen 
Time process and procedures. While the committee met to set up the process and implementation of Aspen Time, this group of volunteers did not meet every other week, when each Aspen Time report was conducted, to assign students to an intervention based on academic ability. The primary responsibility of running the every other week Aspen Time report was assigned to only one person, an Aspen assistant principal, the Aspen Time Coordinator (Aspen Time Handbook, 2018, p. 5).

From September 2013 through May 2014, Aspen Time was officially conducted every two weeks. The coordinator ran a report, then sent the student names to the two other assistant principals, who would priority rank which course the student would attend first, second, third, etc. This report was emailed to counselors for review but generally they rubber-stamped the rankings (knowledge of these procedures and changes are based upon prior experience as the Aspen Coordinator at this school). The report would then return to the coordinator to complete the cycle. From September 2014 through December 2014, the process changed and after the coordinator ran the Aspen Time report, it was emailed to building level counselors who priority ranked which course the student would attend first, second, third, etc. The counselors then emailed the report to their assigned assistant principal in the building for review. The assistant principals rubber-stamped this priority ranking and then returned the list of names to the coordinator to complete the report. The building assistant principals felt it was not necessary for them to see these rankings, so from January 2015 through May 2017 the process was changed again. The list of student names went directly from the coordinator, to the counselor, and then back to the coordinator. 
After the coordinator left Aspen High School in July 2017, a new assistant principal was placed in charge of Aspen Time in August 2017. From September 2017 through the current day, the coordinator not only ran the initial report but also completed the student rankings, a change from the last process (personal communication with current Aspen Time Coordinator). So, the coordinator runs the Aspen Time report from beginning to end and no other assistant principals or counselors are involved in the process. Therefore, there is no team approach to assigning students to particular courses for interventions related to Aspen Time.

While only one person currently runs the assignment process for Aspen Time, since September 2013 a group of individuals has met weekly to discuss students in regards to holistic academics, emotional supports, behavior interventions, and family needs. The four assistant principals that worked directly with families and students took on a portion of the alphabet and one assistant principal oversaw all students classified as special education. The assistant principals were assigned to two SSTs. Each SST met weekly to discuss student needs. Inside this meeting were any of the following individuals: school counselors that worked with this group of students, the school outreach counselor, school nurse, school resource officer, home school communicator, school social worker, and/or the special education department chair. One observation was conducted in each of these SST meetings on May 3, 2018 and May 9, 2018.

The SST meeting held on May 3, 2018, began at 7:45 AM in the main office conference room at Aspen High School. Present were two assistant principals, two school counselors, one home school communicator, and the school social worker. As the team talked about specific students, it appeared they already added student names to a list of 
students to discuss prior to this meeting (Field Notes, May 3, 2018). The researcher did not have access to the list of students. The first student the team discussed had several truancies to school. They assigned that student to academic lab (an in-school suspension support for special education students) for the remainder of the year (13 days of school remaining) to get all work caught up and finals completed.

The team then switched to another list of students. It appeared to be a list of seniors that were possibly not graduating due to low grades in their current courses. The first student was not attending, was considered his own guardian, and no one knew how to contact him (no working phone number). The team did not know where he was living and had a possible concern of drug use. Their decision was to enroll him in classes for summer school, should he not attend the remainder of this year, and complete the courses needed for graduation.

The next student discussed only needed to take a post-test on his online course and finish his physical education class with a passing grade. These were the only two items he needed to graduate. He had been hanging around in the building and the team decided someone needed to address him and this situation. One of the assistant principals was given the duty of speaking with him.

The third student the team discussed was a male that already had committed a large discipline infraction and instead of suspending him from school at the time of the incident, the suspension was removed from the end of the school year. So, his last day of school was earlier than the other students' last day of school. Due to the infraction, the team decided that some mental health services could be offered to the family on behalf of 
the student. One of the administrators asked the school social worker to contact the student's grandmother, the guardian, to offer some services to support the student.

This meeting continued for several more minutes as several other students were discussed. This team made recommendations on calling the hotline for educational neglect on a student, offering services for a therapist, contacting other adults in the building for more information about particular students, contacting other school personnel in the district for more information about particular students, reaching out to the school resource officer and also reaching out to the school district central office for supports and suggestions with some students.

In summary, during this May 3 meeting, no academic interventions related to Aspen Time were discussed. There were lots of interventions and recommendations made regarding academic progress in general, social and emotional supports, and plans put in place for students to finish out the school year. However, this team of individuals was not deciding or discussing the every other week Aspen Time academic interventions for students.

The other SST meeting was similar to the previous meeting discussed but with different adults in the building representing different students. This SST meeting was held on May 9, 2018, and began at 9:15 AM in one of the assistant principal's offices at Aspen High School. Present was one assistant principal and one school counselor (Field Notes, May 9, 2018). The first student the team discussed needed four classes during her senior year. The team wanted the student to attend summer school and complete some of her needed credits to graduate but they had tried unsuccessfully to reach her. The assistant principal reached out to the student through Facebook and text and asked her to 
respond to her counselor's email. The family was homeless and probably Wi-Fi was an issue to responding to the email.

The second student discussed was a current senior and the team needed to design a plan for him to graduate in the next few days. His teachers reported to the team that he would not pass all of his classes although he is working diligently to complete work. The assistant principal agreed to meet with him to talk about not graduating and then also call his mother in Atlanta, Georgia, to report the news so she did not purchase a plane ticket to fly in for graduation.

The next four students that were discussed were all in similar situations where graduation was either in the future or not based on the last few weeks of that semester. The team was not as concerned about these students as the ones above but agreed to maintain contact with each student and family in the next few weeks.

Similar to the other observed meeting, this meeting continued for several more minutes as several other students were discussed. This team made recommendations on contacting parents, supporting the school resource officer with an intelligence report, contacting an outside counseling therapy agency for students, contacting a student to attend the alternative school, and supporting a student in obtaining an IEP. However, during this May 9 meeting, no academic interventions related to Aspen Time were discussed. In fact, Assistant Principal J stated during a focus group that SST meetings are “more about behaviors. A lot of times it coincides with academics, but there isn't a direct link with Aspen Time unless that's specifically brought up, but it rarely is, so that may be something that we need look into, because we usually don't discuss Aspen Time during those meetings" (Administrative Focus Group, May 30, 2018). There were lots of 
interventions and recommendations made regarding academics in general, social and emotional supports, and plans put in place for students to finish out the school year. However, this team of individuals did not decide the every other week academic interventions for students during Aspen Time.

In addition, another principal during the focus group related a similar position of the SST meetings. Assistant Principal M stated,

Typically during those meetings, we discuss students who we have serious behavioral and/or academic concerns. So really specifically, as it ties in to Aspen Time, if a student is regularly having more classes Ds or Fs than they do passing grades, then those students would generally fall into our students of academic concern. So we discuss those concerns with guidance counselors, outreach counselors, at times the SRO when appropriate, homeschool communicator, and determine what's the best next step of intervention that we need to support those students (Administrative Focus Group, May 30, 2018).

This quote further distinguished that SST meetings discussed student behaviors and significant academic deficits or issues at hand. These meetings did not discuss the placement of students during the Aspen Time intervention period.

The SST operated using the problem-solving model. Not every student that was discussed received the same treatment or recommendation on how to support that student, i.e. the standard treatment protocol. Each student was discussed separately and a unique action plan was developed. Examples of action plans were to call the parent, recommend an outside therapist or program, check in with the student, assign the student to in school suspension for the remainder of the semester to focus on work, etc. In these cases a 
problem was proposed with each student and then a solution was developed. Some students may have received a similar solution or action plan but no two plans were identical.

This study reviewed those interventions specifically associated with Algebra 1 students and faculty. There was no specific intervention team that met and discussed Algebra 1 students. This might have been done between the two faculty members that taught Algebra 1 but was not witnessed in this study.

In answer to the first research question, to what degree was each of the four essential elements of RTI (formation of intervention teams) evident in weekly SST meetings and the classroom, yes, there were intervention teams put into place at Aspen High School. But, the real question became were these the "right" intervention teams as described in the literature review and as put into practice? The answer to this question became no, as further evidenced in the following sections.

\section{Lack of Purposeful Universal Screening Process \& Tool}

Universal screening processes are designed to determine which students needed to be placed in an academic remediation intervention and at what level. The teams screen students for purposes as proposed by Johnson et al. (2009), to identify: 1) students at risk of dropping out, 2) students with learning needs, and 3) students at risk of not meeting performance indicators on state assessments. Ideally, once data is collected on a specific item, related cut scores and decision rules determine next steps or interventions needed for the student. There was a universal screener (a course academic grade) and process used at Aspen High School to assign students to an academic intervention, at the time of this study (Committee Meeting Minutes, May 9, 2013). 
One document reviewed to determine the kind of process employed was the list of steps created to run Aspen Time (Appendix C). This process entailed several tedious steps that eventually led to a report with grades of each course for each student at Aspen High School. However, when the report was generated, only grades of F, D-, D, and D+ were transferred to a Microsoft Excel sheet. These grades were then ranked and put onto an individual sheet that was given to each student that indicated the grade, name of course, teacher name, and room number of that teacher. This was the screening process for students: running a report and assigning students to an intervention with the teacher to which the student had a D or F grade in the course.

In addition, each year the Aspen Time Coordinator assembled a document titled Aspen Time Handbook. This document, also reviewed, discussed why the time period was held, how students were assigned or unassigned during this period, interventions that might exist, and general guidelines about Aspen Time. The handbook contained the following rule for Aspen Time, "Any student with a class score of a $69.44 \%$ or lower is directed (mandatory) to go to a specifically assigned area with the instructor of the course to which the student has this grade" (Aspen Time Handbook, 2018, p. 4). So again, in another document, the universal screening process was shown that students were assigned to a specific intervention based upon the grade in the course at that given moment in time.

Through both the teacher focus group and the Algebra 1 teacher interviews, the process outlined above is how it was implemented at Aspen High School. Teacher Ag in the teacher focus group stated the following: 
Grades are pulled from our [learning management system] and students with Ds and Fs are sorted into 'priorities.' There is a pretty lengthy process behind the scenes that needs to occur in order to pull the grades - including teachers having updated and accurate grades - but once they are pulled, students are assigned to teachers based on the interventions they need in classes. There is a process of sorting students into those 'priorities' so that one teacher does not end up with large numbers of students while another has very few. The administrator pulling the grades tries to distribute/assign students in a way that does not overload one teacher, but also allows students the opportunity to be successful (Teacher Ag, Scheduling Committee Focus Group, June 27, 2018).

This teacher understood the exact process documented above in the documents. In order for this to work well, teachers had to have their grades updated and an accurate reflection of where the student stands academically in his/her course. A report was generated based on D and F grades that students have in particular courses. Classes that students were to attend were prioritized, and the Aspen time coordinator balanced courses so no teacher was initially assigned too many students.

There was general understanding of this process among teachers at Aspen. For example, one of the Algebra I teachers was asked in an interview, "Can you tell me what you understand about Aspen Time and the screening process of students?" and the teacher responded, "Student grades are pulled and students with grades below a 69.5 are assigned to that teacher. Students are provided a prioritized order if they have more than one grade in the D or F range" (Teacher B, Interview, February 27, 2018). This Algebra 1 teacher understood the process as documented in that students were placed in an 
intervention with their teacher in which they had a grade of D or F. Both the focus group and teacher interview examples exemplified that what was documented and written down was what was implemented. It appeared that teachers at Aspen understood the grade report to be the universal screening process used to assign students to an academic intervention during Aspen Time.

Therefore, the universal screening tool in place at Aspen High School was a report that generated a list of student grades and students were assigned to an intervention based on the grade the student received for that course. This tool was the screener and was seen and discussed throughout the study. Principal P indicated that this universal screening tool is "one of the tough parts of Aspen Time, because when you pull, the progress monitoring is about a grade. There are lots of reasons why a student has a D or an F. So being able to target an intervention is really difficult for our teachers based upon that" (Administrative Focus Group, May 30, 2018). There was no team of individuals witnessed in this study who were determining interventions for students based on the criteria outlined by Johnson et al. (2009). A student who earned a grade of D or F in a particular course only seemed to raise more questions to be asked: Why was the student earning this grade? Did s/he miss a major summative assessment? Was the student not completing homework? Was the student absent for an extended period of time? Did the student not have the will or the skill (or both) to perform in the course?

While the screening tool did not indicate which interventions could be helpful, individual teachers knew their students and made informed choices about what they needed during Aspen Time. As noted in a summary memo written after field observations on 2/27, 2/28 and 3/1, "It appeared he [Algebra 1 teacher, Teacher B] knew exactly what 
each student needed upon entering his classroom (quiz, test, extra practice, complete homework, etc.). There was an individualized plan for each student in the classroom." Since the students were assigned to their Algebra 1 teacher for intervention, the individual teacher appeared to be alone in making decisions on what the student needed to improve his/her grade.

Assistant Principal T indicated that the building and district were shifting focus to a standards-referenced grading system and once this occurred a more targeted intervention could be provided to students when he said, "I think it's basically what Principal $\mathrm{P}$ was talking about earlier, is that as we move towards a more standards-based grading system, then we can do a better job of identifying where kids are academically" (Administrative Focus Group, May 30, 2018).

In conclusion, and to further answer the first research question, to what degree was each of the four essential elements of RTI (development of a universal screening process) evident in weekly SST meetings and the classroom, yes there was a universal screening process in place at Aspen High School. But, the real question became was this the "right" universal screening tool as described in the literature review and as put into practice? The answer to this question became no. Considering the first two essential elements together, it became clear that there were not weekly team meetings nor the use of a universal screening tool to determine the best intervention for each student.

\footnotetext{
Absence of Progress Monitoring Tool for Students Outside of Algebra 1 Classroom

In an ideal RTI system, after students are identified using data from a universal screener and placed into a tier by an intervention team, students should be continually monitored to see if they are making progress. The following questions should be
} 
addressed once an RTI program is implemented: How often are students monitored? Why are students monitored? For how long are students monitored? Who or what determines this schedule? In other words, progress monitoring meant tracking students to see if they responded to the intervention put in place. Mellard and Johnson (2008) dedicated chapter four of their textbook to the "systematic, continuous" process of progress monitoring (p. 60). Students at Aspen High School were monitored at each tier to determine if the student was properly placed or if movement on the intervention triangle needed to occur.

There are several different levels that data was monitored throughout Aspen Time. This process was discussed in two of the founding documents when the committee began looking at a RTI model at Aspen. This committee composed of 17 faculty members held a meeting on March 21, 2013. Committee members were split into three groups, and each group read a different article and answered the following questions: "Describe the progress monitoring system established in the article. What are current, effective progress monitoring systems you have seen in Character School District? What is the progress monitoring system we will put in place during Aspen Time? What does intervention look like? What are the logistics behind intervention? What could enrichment look like during this time?" (Committee Meeting Minutes, March 21, 2013). When the committee reviewed these articles and questions, they were designing the overall progress monitoring system at Aspen. This was the building level and tracking system that monitored all students at the system level, not the classroom level. Students were assigned to intervention based on their overall grade in a class.

Another example of progress monitoring located in the document review was found in the first Aspen Time Handbook. This handbook was created for all stakeholders 
to better understand Aspen Time. This handbook listed information for students, faculty members, and parents. It was published on the school website for anyone to access. Two sentences contained in this document reviewed the progress-monitoring tool, "Teachers will monitor student progress in class, especially mastery of course essential learning outcomes (ELO). Every two weeks, the intervention time will reset and the intervention team and the assistant principal in charge of Aspen Time will determine those students who are student directed" (Aspen Time Handbook, 2013, p. 5). The first line in this quote discussed the classroom level and how teacher's tracked students based on mastery of course ELO's. The handbook did not indicate how the teacher would do this, but I assumed there was a common assessment or body of evidence used to judge where a student was academically in relation to each course ELO. The intervention team (system level) assigned students based on their course grade that was a representation of student knowledge attainment compared to course ELOs. This was witnessed in the administrative focus group as Assistant Principal T said, "it's systematic in that it's each individual student's progress in each of their classes is monitored on a bi-weekly basis to determine performance in those classes" (Administrative Focus Group, May 30, 2018).

The classroom level of progress monitoring was also brought out in teacher interviews. Teachers were asked, "Are the decisions about whether or not a student is responding to interventions based on progress monitoring data? Describe the process used for monitoring student progress.” Teacher B responded, In my class, yes. With few exceptions, improving a student's grade requires reassessment of some kind. Classes with a higher percentage of the grade determined by homework or classwork will not require the same. Because all of 
the incentives and disincentives are grade based, students are focused on improving their grade beyond a 69.5 (Teacher B, Interview, February 27, 2018). In this example, the teacher required the student to re-assess in order to improve his/her grade, which was ultimately the way to get out of that teacher's course during Aspen Time, improve his/her grade above a $69.5 \%$. This process was witnessed through several classroom observations where some students practiced problems on their desk using a dry erase marker and others seemed to be completing a packet of problems. Students in these scenarios were improving their skills to better prepare for the assessment. As witnessed during a classroom observation on February 27, once a student was ready to take the assessment then the teacher and student arranged for that to occur during the appropriate time. In the February 28 classroom observation, a student finished the assessment and the teacher signed off on the student's paper and told her she was on "privilege." She had increased her grade above $69.5 \%$ and the teacher indicated with his signature and she was released from his classroom because she had successfully completed her intervention for that Aspen Time cycle.

Another progress monitoring tool outside of the system or classroom level was also present during the study. After the classroom observation on March 8, the researcher held an informational conversation with the teacher. These are the notes recorded after that conversation:

She says math lab was put into place this year and believes this has cut down on the number of students in her Aspen Time sections. Has noticed the decrease even from beginning of first semester to now. Lab is offered every period. If student needs extra support or to make up test, etc. she sends this information to the 
teacher when the student has an off period (advisory, study hall, etc.). More direct instruction in lab than just students stopping in for help but it's targeted help (Teacher C, Interview, March 8, 2018).

The researcher noted that freshmen students used math lab as another support or intervention in addition to Aspen Time. As noted, this support was targeted, and a math teacher pulled one of the Algebra 1 students out of freshman advisory and provided targeted intervention to the student based on the teacher recommendation. Principal $\mathrm{P}$ added the following in the administrative focus group, "Those math lab teachers would take that information and intervention and pull those kids out of Algebra or out of advisory and reteach them and reassess them, so that they could then meet the standard, so to speak" (Administrative Focus Group, May 30, 2018). So this intervention became another tier or level of intervention for math students. There were no other content area labs that were discussed by any of the individuals during the study. So, this was a unique intervention to the math department.

Meanwhile, the SST meetings appeared to be focused on progress monitoring of students on emotional, social, and behavioral levels. Very little academic progress monitoring took place during team meetings, and, if so, there was a focus on students classified as seniors and putting interventions in place to get them enough credits to graduate. After each student support meeting, notes were recorded on interventions put in place. These included the following: how to get outside agencies involved to support families, individual counseling for students, mental health services, and general practices from the school (emailing teachers, contacting parents, meetings with families and their school supports). Based upon on these interventions there was no progress-monitoring 
tool consistent with each student as each student provided a unique experience and personal situation. The faculty did not have a specific outline of practices or steps to assess the student and monitor his/her progress that was witnessed during these SST meetings. In general, there was a significant amount of monitoring emotional, social, and behavioral needs and how to intervene and support these students, but little was mentioned about academic progress monitoring during these SST meetings.

In conclusion, yes there was a process in place to monitor students for progress at Aspen High School. But, the real question became were the "right" items being monitored as described in the literature review and as put into practice? The answer to this question became no and will be further discussed in chapter five.

\section{Strong Presence of Evidence-Based Interventions Inside the Algebra 1 Aspen Time Intervention}

The final essential element to a successfully implemented RTI program is the use of evidence-based interventions. Since this study focused on Algebra I specific interventions during Aspen Time, the broader category of secondary mathematics curriculum was located in Fuchs (n.d.) and Star et al. (2015). These nine interventions were noted on the data collection tool that was used during classroom field observations, see Appendix D. Several of these evidence-based interventions were present at Aspen High School and this essential element was the strongest essential element present during Aspen Time.

Potential interventions during Aspen Time were listed in some of the founding documents. One document I reviewed was a description of Aspen Time that was developed for distribution in a parent newsletter for the school. The document stated, 
"Here are just some of the interventions that have taken place so far in our building during AT: one-on-one tutoring, make-up assignments, quizzes, and tests, basic math skill practice, writing skills, homework help, Advanced Placement support and test preparation as well as interactions through clubs and extracurricular activities." In regards to the mathematics classroom, there occurred one-on-one tutoring and basic math skill practice summarized in this newsletter but also correlated to those evidence-based interventions of "instructional explicitness" (Fuchs, n.d., p.1) and "teach students to utilize the structure of algebraic representations" (Star et al., 2015, p. 16).

In addition, another document reviewed was the first Aspen Time Handbook. Under the title of student assistance it was stated, "Teachers are to work closely with students in their class who are showing a need for additional assistance and intervention. Teachers will carefully monitor individual student progress/mastery of essential learning outcomes (ELO) and provide focused support (as appropriate) during Aspen Time” (Aspen Time Handbook, 2013, p. 7). This document also mentioned the procedure that teachers would identify areas that students have gaps in their learning and then provide an evidence-based or focused intervention of support to each student. Both of these documents speak to the generally system-wide interventions put in place to support students.

As witnessed during classroom observations and documented using field notes, many evidence-based interventions took place to support Algebra 1 students. After the February 27 observation, I noted that students were specifically taught to utilize the structure of algebraic representations when they used the equation $y=m x+b$. At one point in the observation, there is a conversation between the instructor and one student: 
Teacher looks at the student's paper.

Teacher: I like this. Is this 2 over 4 ?

Student: Yes.

Teacher: Excellent you're doing a great job.

The student asks a question about the $\mathrm{Y}$ going with the $\mathrm{X}$.

The teacher responds, what do you think? The student response is inaudible.

Teacher: That's what we've been doing on the other ones so it makes sense to keep doing that....Keep on keeping on then. Get $\mathrm{Y}$ by itself, then you know what to do to graph it (Field Notes, February 27, 2018).

In this exchange the teacher is walking the student through the slope equation above. When the teacher said two over four he noticed this was the slope or " $m$ " in the equation. After the student posed a question to the teacher, the teacher responded with a question to the student and then left the conversation with one piece of advice: get the $\mathrm{Y}$ by itself and then the equation was in a format in which the student can graph. Here, the teacher utilized the structure of an algebraic equation to intervene and taught the student a gap in his/her learning, the process of isolating the $\mathrm{Y}$ to ensure proper format before graphing.

In another example, the March 12 observation, Teacher $\mathrm{C}$ used instructional design that eased the learning challenge to teach a student about the slope-intercept form:

Teacher: If we start at the beginning we need to get it into slope-intercept form. How do we get the Y by itself? Talk me through it.

Student: Ummm.

Teacher: What is the first thing you do?

The student responds something about $2 \mathrm{X}$. 
Teacher: Okay, how did you do that?

The student says something about subtracting it.

Teacher: Okay if you subtract it here then you have to do the same thing here. The teacher points to the paper on the desk in front of the student. Teacher, what's left on this side?

Student: $5 \mathrm{Y}$ is equal to this...

Teacher: Which you re-wrote here so you need to write that down. Now what's our goal?

The student answer is inaudible.

Teacher: So how do we make that happen? (Field Notes, March 12, 2018).

In this example of instructional design that eased the learning challenge, the teacher retaught the process of getting a formula into $\mathrm{y}=\mathrm{mx}+\mathrm{b}$ form. The student required a stepby-step re-teaching as the teacher asked the student what occurred first, how did we make something happen, what is on the left side of the equation based upon the change you made, etc. This student required the teacher to tutor him/her one on one as mentioned in the newsletter to parents above. The student had a gap in his/her learning about how to get a formula into the correct form before proceeding to graph the equation.

After each field observation, the researcher asked the teacher what interventions s/he used with students during that given Aspen Time period. A total of five responses were submitted and are contained in Table 5 below. One of the evidence-based interventions mentioned in the literature was to teach students to utilize the structure of algebraic representations. Teacher $\mathrm{C}$ responded after the March 6 observation, 
I question the same way, always, because it is consistent for the students and they know my expectation is that they come to a conclusion on their own. I do not verify for them. With retaking tests, it is important for me to model the thinking students should have. That way while they take the test or work problems in the future, they have those problem solving skills and feel more comfortable.

This evidence-based intervention wanted students to question why they did what they did. In this specific case the teacher modeled this questioning strategy out loud in anticipation that the student would use the same strategy when s/he needs to solve the problem alone. This questioning helped students think through the process of which strategy could be used to solve the problem.

Table V

Teacher Interview Responses to Instructional Strategies Used During Aspen Time

\begin{tabular}{|c|c|}
\hline Date & Response \\
\hline $1-12-18$ & Individual practice \\
\hline $2-27-18$ & Differentiated instruction, structures questioning \\
\hline $2-28-18$ & Differentiated instruction, structures questioning \\
\hline $3-6-18$ & $\begin{array}{l}\text { Scaffolding material, questioning techniques that require } \\
\text { student thinking, having students identify errors and explain } \\
\text { why that was an error. }\end{array}$ \\
\hline $3-8-18$ & $\begin{array}{l}\text { Questioning techniques that require student thinking instead } \\
\text { of me leading them to the answer. I also ask my scaffolding } \\
\text { questions multiple ways until I find something that clicks } \\
\text { with the student. }\end{array}$ \\
\hline
\end{tabular}

In conclusion, yes there were evidence-based mathematical interventions being implemented inside Algebra 1 classrooms at Aspen High School. This essential element was the strongest and most notably present during Aspen Time. However, recommendations for enhancements related to these interventions are noted in future chapters, which should allow students to acquire a higher yield of results. 


\section{Summary of Four Essential Elements}

To answer the first subquestion of the study, I discussed the presence or absence of the four essential elements of RTI (formation of intervention teams, development of a universal screening process, continual monitoring of students for progress, and use of evidence-based interventions) through an analysis of document review, classroom field observations, SST meeting observations and focus groups. Findings demonstrated that intervention teams were in place but could be enhanced to also target academics; there was a universal screening process but it could be altered to screen and evaluate students at a deeper level; students were monitored for progress but examples of other tools to use could also be incorporated; and there was a strong presence of evidence-based interventions being used. These four elements in relation to the literature and recommendations of enhancements to the elements will be discussed further in chapter five.

\section{Barrier(s) to Implementation}

The four essential elements of RTI as defined in the literature review are: formation of intervention teams, the development of a universal screening process, continual monitoring of students for progress, and the use of evidence-based interventions. A summary of the presence or absence of each of the four elements was detailed above. There was a presence of each of the elements at Aspen High School but only a slight presence of teams, a universal screener, and continued monitoring of students. There was a strong presence of evidence-based interventions witnessed in this study. The barriers that limited the presence of each of these elements can be summarized into the four broad categories of scheduling/structure, curriculum issues, fidelity and staff 
capacity. In addition, one new barrier to implementation will be discussed that was not located in the literature. This barrier of outside influences caused students to miss school, which hindered their participation in the RTI system. Each of these barriers will be discussed below and how these hindered the implementation of Aspen Time.

\section{Barrier to Implementation - Scheduling/Structure}

The first barrier to implementation of Aspen Time was scheduling/structure. As noted in the literature review above, these barriers related to the structure of a secondary school day, how time was used within that day and the placement of students within their daily schedules. This barrier was noted in the early committee meeting minutes, interviews with staff after classroom observations, and in the scheduling committee focus group.

The original scheduling committee of Aspen Time struggled with scheduling the intervention period during the school day and the types of interventions that would take place during that period. After reviewing the documents, there were nine versions of the daily bell schedule as the team worked to locate the best placement of this 30-minute period during the school day. It was over the course of several meetings that eventually the committee decided to place the intervention period in the morning between first and second periods. But, the short length of time was further witnessed in the teacher focus group as Teacher Ag stated, "It is really difficult to get a lot of rich re-teaching and intervention in such a short amount of time (30 mins.)" and Teacher Ad also indicated “it’s a fairly short amount of time” (Scheduling Committee Focus Group, June 27, 2018). Thus, the short length of Aspen Time was not only discussed in the beginning of the early planning stages but also continues to be a point of discussion more recently. 
During the September 13, 2013, scheduling committee meeting, it was noted in the minutes that a discussion was held around the "can but won't kids," the possible need for an "Aspen Time detention room" and another discussion that centered around the question "How do kids know their objectives?" These were all conversations where the committee debated what the intervention or schedule looked like. Several intervention types were built into this period and the committee had to think about those students who cannot do the work in the intervention period. Where would they be assigned and to whom? They also debated if there would be a detention room where students who continually skipped or were truant from their assigned Aspen Time class would be sent to sit and complete work. Their assignments would be sent to one location rather than the student rotating between the rooms. And they also discussed how students would be assigned if it were based on a grade or if it were particular objectives. Would students know their weaknesses and be able to identify these and connect this to the reason why they were in the intervention assignment?

In another scheduling committee meeting on December 5, 2013, the committee brainstormed what to do with students "who are in Aspen Time but not doing the work and are being disruptive." Just as above, the committee continued to discuss the schedule and how to work with different groups of students during the intervention period. During this meeting the committee reflected on students who were behavior problems and discussed why students were behavior disruptions (the student did not know the material, the student refused to work but did know the material, some other ulterior motive affecting the student that day, etc.) and how each disruption required a different intervention for the student. No resolution was reached in the committee meeting and 
students to this day are still all placed in an intervention based on a grade, not taking into account any other information (low reading level, refusal to work, can but will not do the work, etc.).

There were two Algebra 1 teachers that were observed during Aspen Time, a 30minute daily intervention period that occurred from approximately 10:30 - 11:00 AM. Each teacher was sent a link to complete a Google Form that asked several questions about each of the four essential elements of an RTI system. One teachers' response indicated several scheduling barriers to implementation. Teacher B stated, Aspen Time is the following:

...Potpourri of failed objectives. Because of this, students require different attention that means either a) we plan an intervention that doesn't apply to all or most students in Aspen Time or b) we have to plan and run multiple interventions simultaneously. This means that in most cases, we rely on missing work as the intervention without further specificity. Teachers with multiple preps have these problems to an even greater extent. The assignment system sometimes requires that I have more than 30 students in my room. No real intervention is possible (Teacher B, Interview, February 27, 2018).

This quote indicated that it was challenging to have any intervention in a 30-minute period; that no effective intervention took place in this short time period, especially when a larger number of students were assigned to one teacher. This quote also speaks to a teacher with multiple courses that $\mathrm{s} / \mathrm{he}$ teaches at the secondary level. If a teacher taught more than one preparation, this teacher also has the possibility that students of different subjects, needing different interventions would all be present at the same time during this 
intervention period. Thus, the time limit became a barrier to successful intervention implementation.

\section{Barrier to Implementation - Curriculum Issues}

The second barrier to an effective RTI implementation related to curriculum issues. At the secondary level, curricular issues stemmed around content recovery, demands placed in the different curricular content areas, and how siloed teachers' intervention looks different. These barriers were evidenced in a review of the original committee meeting minutes and also in the teacher focus group.

The major barrier that the initial Aspen Time scheduling committee discussed and that the current administration continues to discuss related directly to content recovery. It was noted in the September 13, 2013, July 11, 2014, and July 18, 2014, committee meetings that there was a need to develop a procedure for what to do with students who have multiple F letter grades. While a process was developed for a student who has two low grades within the same grading period and him or her being able to raise one grade and then travel to the next teacher. These conversations stemmed around the many students who have multiple F grades consistently during the entire semester, for example,

a student who is failing Math, Language Arts, Social Studies, and Science classes every grading period all semester long. In fact, this barrier continued to be of concern as Principal P related during the administrative focus group when she said,

One of the things that we talked about that we're gonna address with a group of teacher leaders is we've found that it works great for a group of kids who might have one or two classes to go to, but when you have kids who are failing three or more classes, we're really talking about what different interventions those kids 
might need, and how to systematically respond to those kids (Administrative Focus Group, May 30, 2018).

So, there was and still remains a need for further examination of what supports needed to be put in place to support students failing multiple classes.

An additional curriculum barrier to Aspen Time intervention related to elective or siloed teachers. During the scheduling committee focus group, Counselor S stated, Elective teachers say because they are lower priority, in terms of getting to see kids sometimes, they feel, number one they don't feel that their class is as valued as they believe it should be. And also, kids that really do need to come in to work with them, never get assigned to their classroom (Scheduling Committee Focus Group, June 27, 2018).

This quote reiterated another flaw in the system related to priority ranking and students with multiple low grades. During the process of assigning students to teachers, a priority was made for core classes over elective courses. So if a student was failing Algebra 1 and Sewing 1, the student was assigned to attend the Algebra 1 teachers' course until the grade increased. Elective teachers were many times siloed teachers and only taught one or two unique courses that no other teacher in the school taught. This created a curriculum issue when teachers were planning interventions by themselves instead of a group of teachers that might all teach the same subject, like Algebra 1. The other issue presented above simply is how or when does a student who is failing an elective course receive intervention when a core class is prioritized over the elective course. This scenario continued to be a barrier to effective RTI implementation. 


\section{Barrier to Implementation - Fidelity}

The third barrier to a successful RTI implementation at Aspen High School related to fidelity of implementation amongst all teachers at the school and how each of them made sense of the RTI system and thus implemented it in their classrooms. The barrier of fidelity amongst staff members was witnessed in both the scheduling committee and administrative focus groups in addition to the interview with one of the Algebra 1 teachers.

The first issue of fidelity relied on both personal knowledge and an interview. The researcher used to be in charge of Aspen Time at Aspen High School. Contained in the original document review were the handouts presented at the building level introduction to new staff members that occurred a few days before the start of a new school year. This proved that a 30-minute session or training was provided each year to new teachers during their staff development days. However, I did not find any evidence of ongoing professional development that occurred throughout the school year that related to Aspen Time intervention or successful RTI implementation or teacher training for curriculum used during Aspen Time. In fact, Teacher B stated, "None of which I am aware" when asked if there was ongoing professional development available to staff to provide tier two interventions (Interview, February 27, 2018). So, professional development directed towards teachers throughout the year had not occurred which was needed for successful RTI implementation. Additionally, a 30-minute session at the beginning of the school year was not enough time either. If professional development were offered, there would be more of an opportunity to be consistent throughout the year and throughout practices carried out by several different individuals. 
In addition to a lack of ongoing professional development, since Aspen Time was based solely on a student's academic grade, there was a lack of consistency amongst teachers, because what one teacher counted as points for a grade could differ from another teacher teaching the exact same subject and grade level. It was also difficult for teachers to keep up with their grade books, which was necessary for the system to work. Teacher Ad spoke to the challenge of grading during the focus group, "That's one thing that is a challenge for me, I need to make sure that I got everything graded. I have everything recorded. I can give them a very accurate view of what is going on with their grade so they know what to do. Sometimes that's a little bit of a challenge to keep that up" (Scheduling Committee Focus Group, June 27, 2018). This quotation provided evidence that teachers needed to maintain consistency and required them to update grades every two weeks in their grade books so accurate priorities were made in the newest Aspen Time cycle. How a teacher interpreted the grade, what goes into that grade, and differences that existed from teacher to teacher within the same building highlighted the idea of sensemaking and teachers interpreting what's in a grade differently. To expand on this point, Principal P stated, "Indicators are their grades, so it's not based upon, at this point, any test or anything like that, but based upon their academic grades in a class. So it can vary from teacher to teacher because of that" (Administrative Focus Group, May 30, 2018). This inconsistency from teacher to teacher provided a barrier to implementation related to teacher fidelity.

\section{Barrier to Implementation - Staff Capacity}

The final barrier to implementation was building staff capacity through collaboration, changing their mindset, and providing appropriate professional 
development for teachers. This barrier was evidenced in the Aspen Time committee meeting minutes and in the administrative focus group.

Increasing staff capacity included teachers working together to plan and support students. After the beginning of the first year that Aspen High School was opened, the Aspen Time scheduling committee began thinking about putting this concept into practice during their intervention period. It was stated in the September 13, 2013, committee meeting minutes, "encourage intervention collaboration amongst PLTs [professional learning teams] to focus each teacher's time and energy; Combine efforts in PLC [professional learning community]" (Committee Meeting Minutes, September 13, 2013). PLTs at Aspen were teachers who taught the same course and had a common planning time during the school day. It was written in the committee minutes that they discussed how these teams of teachers could work together in a team. Teachers were to divide students needing intervention amongst themselves rather than one teacher attempting to intervene with his/her students all needing something different at the same time. While this was the goal in 2013, during the administrative focus group, Assistant Principal $\mathrm{T}$ reiterated this was still a barrier to implementation,

In a perfect, ideal world, and what we're working towards, is the PLT process probably being the biggest part of that. I don't think we're there yet, but in an ideal world, what we've talked about and what we're trying to implement in some specific PLTs, and those are ones that we're using right now that have high-stakes testing, mostly EOC testing, then we've been in those PLTs specifically to talk about the data process. And so what we'd like to see happening is that, within a content-specific PLT, they would be having discussions about specific students 
and where they're lacking in a specific skill, so that then the intervention can be targeted by teachers by skill (Administrative Focus Group, May 30, 2018).

Assistant Principal T discussed how he worked with teams of teachers to identify skill deficits of students and then worked with these teams and created interventions to support students. Then the teams of teachers implemented these interventions with their students. Building staff capacity was important and necessary when creating a successful RTI system but was a barrier to implementation.

\section{Barrier to Implementation - Others Noted}

In addition to the barriers to implementation as noted in the literature, another major barrier to implementation surfaced in the SST meeting observations and associated field notes. In both the May 3, 2018, and May 5, 2018, SST meetings, different students were discussed. The purpose of these meetings, from my perspective, was to provide supports for students related to non-academic issues. In both meetings it was discussed that many of the barriers that students faced related to issues going on outside of the school setting (Field Notes, May 3, 2018 and May 5, 2018). For example, one participant in one of the SST meetings related the following story, "I've got two seniors who are not graduating. Student A - not attending, own guardian, not sure where living (homeless), issues with drug use and concerned but I don't know how to find him." (Field Notes, May 3,2018 ). This student had issues outside of school that were barriers to a successful implementation of any RTI system because he was not attending school. This student was of age to be considered his own guardian and thus was not living with guardians or parents to care for him. Based on the conversation, the team members were concerned about this student's drug use, of which they could not control but wanted to provide 
assistance if they could locate him. This student was homeless and probably sleeping in different places, thus the team members were unable to locate him to encourage him to attend school and provide an academic intervention for him during Aspen Time.

In another SST meeting, one student discussed was homeless and had a drug problem too. The student was staying with his sister but the team member noted, "Dad is homeless, was sleeping under an over pass. Dad knows she [sister] is drug addict so not good place for son. Dad is working extra to get an apartment. Flips it [weed] to make money for his addiction" (Field Notes, May 5, 2018). This quote stated that the family was homeless and the student was living with a drug-addicted sister. While dad was working to save money, the student was also making money by selling marijuana. Fortunately, the team continued to talk about how this all came out in the last meeting and dad and the team worked with an outside agency to provide needed supports to the student. However, these outside the building circumstances had a direct impact on the student's low academic grades inside the educational setting. These two stories served as evidence that there were extreme barriers to a successfully implemented RTI program that existed outside the school and were beyond the staff control. But, this staff and team dedicated their meetings to tackling these issues rather than the academic needs of the student, as they saw these barriers more limiting than simple academic interventions the students might need.

\section{Summary of Barriers to Implementation}

To have a successful RTI program, the four essential elements of formation of intervention teams, the development of a universal screening process, continual monitoring of students for progress, and the use of evidence-based interventions are 
needed. However, these elements may not be implemented due to barriers that prevent their existence. There were four barriers outlined above: scheduling/structure, curriculum issues, fidelity, and staff capacity. The length of the intervention period and the idea of what to do with students who will not do the work or disruptive students were discussed within the barrier of scheduling. Curriculum issues that presented themselves as barriers to implementation included students with multiple academic F grades and how to support students failing a teacher's course who is considered an elective or siloed teacher. Ongoing professional development through the school year and teachers differing in how they make sense of their professional development were barriers related to fidelity. The barrier of staff capacity was teachers collaborating together and the need for more professional development throughout the school year. And finally, the barrier of outside school influences prevented successful RTI impementation inside the building. These were the barriers that existed during Aspen Time, an example of a secondary building that implemented a RTI program at Aspen High School.

\section{Stakeholders' View of Aspen Time}

The third and final research question analyzed in this study was: How did different stakeholders (administrators and teachers) view Aspen Time? This question was answered after conducting two focus groups. One focus group was held on May 30, 2018, where the following individuals participated: Principal P, Assistant Principal L, Assistant Principal T, Assistant Principal J, and Assistant Principal M. A second focus group was held on June 27, 2018, where the following individuals participated: Counselor S, Teacher Ad, Teacher Ag, and Teacher R. Throughout the two focus groups there were many successes evident as a result of Aspen Time implementation. However, there are 
also many challenges that were presented. This section contains a discussion about the four main findings of the focus groups: (1) logistics behind Aspen Time is timeconsuming, (2) supervision of students is time-consuming, (3) SSTs can be more effective, and (4) the universal screening tool is flawed.

During the May 30, 2018, administrative focus group, one of the administrators at Aspen summarized the challenges faced in their building related to RTI when she said, "The more diverse your population, the more difficult it becomes. So the more learning disabilities kids have, the more poverty that they experience, the more trauma that they have in their lives, the more difficult it is to intervene. It's so complex. It's a wicked problem" (Principal P, Administrative Focus Group, May 30, 2018). This quote introduced the myriad of challenges that the teachers and administrators confronted each day at Aspen High School. This viewpoint emphasized the important work that took place each day and provided the appropriate supports that helped students be successful.

\section{Stakeholders' View I - Logistics Behind Aspen Time}

The first finding that developed out of the focus groups was that the logistical pieces and instruments behind the scenes that correlated with Aspen Time running smoothly was too time consuming for one individual but led to the realization that more time was needed within the intervention period. Too much effort was being put into the development and assignment of students to their interventions, and not enough time was being spent on the actual intervention period each given day.

After both the teacher and administrative focus groups, it was clear that all parties had a basic knowledge of how the screening tool of student academic grades was then put into a series of reports and at the end of the process students were assigned to specific 
classrooms and teachers during Aspen Time. After a document review, the researcher located Appendix C: Steps to Run Reports for Aspen Time Intervention. This listed the steps necessary to generate the reports and assignment of students. However, these steps took several hours to put together the final product. Principal P stated, "I was gonna say the amount of time, logistically, that it takes to identify who those kids are and create a plan for them on where they go, I think is a huge obstacle" (Administrative Focus Group, May 30, 2018). Assistant Principal M continued this sentiment when she stated, "I think the turnaround time, as well, sometimes is a barrier to how efficient we can reach these kids that need intervention" (Administrative Focus Group, May 30, 2018).

These quotes in addition to the steps needed to run Aspen Time, related the extensive length of time needed to generate the appropriate documents that assigned students to the intervention period. In addition, Assistant Principal J stated, "If the system was easier to spit that information out or put that information together, I don't know if we would have so much controversy or conversations about Aspen Time. I think as an admin that poses such a barrier to the quality or the benefit of Aspen Time" (Administrative Focus Group, May 30,2018). This comment accentuated the logistical pieces of Aspen Time. If a quicker system were designed to assign students to their intervention, then the benefit of Aspen Time would greater outweigh the challenges associated with RTI at Aspen High School.

If a quicker system were in place, then having a longer period of time within the intervention period would also be advantageous. Many individuals in the focus groups echoed this sentiment of adding time to the already 30 minute intervention period. Assistant Principal J commented that the amount of work that goes into student 
intervention assignments shows a need that the length of time students are in those assignments should be greater than the allotted period.

I think it's tough for me to think about what Assistant Principal M or you had to do to do Aspen Time, and we only have 25 minutes or whatever time it is. I'd feel more comfortable knowing the work that Assistant Principal M did with Aspen Time and knowing that we gave the kids 40 to 45 minutes, let's say. That would just seem more worthwhile” (Administrative Focus Group, May 30, 2018).

The scheduling committee focus group held similar viewpoints except from the angle of the support taking place in the classroom setting. Teacher Ag stated, "It is really difficult to get a lot of rich re-teaching and intervention in such a short amount of time (30 mins.)" (Scheduling Committee Focus Group, June 27, 2018). In addition, Counselor S affirmed, "It's a fairly short amount of time by the time the kids get in there and dig out whatever it is they're looking for. Then it's time to go. Sometimes I think it feels like perhaps it's too short a time” (Scheduling Committee Focus Group, June 27, 2018). So not only was there an argument in both focus groups for a shorter turn around time to generate the Aspen Time report and produce individual student assignments, but there was also an agreement that adding more minutes to the 30 minute Aspen Time intervention period made sense as well.

\section{Stakeholders' View II - Supervision of Students}

The first finding that developed out of the data from both the administrative and scheduling committee focus groups related to the time consuming act of supervising students during the 30 minute Aspen Time period at Aspen High School. With approximately 1,500 students at this comprehensive high school, it became difficult to 
manage where all students were going and what they were doing during this time period. This active supervision of students required all administrators, counselors, and a few staff members to observe and supervise students who were not working with teachers in their classrooms for needed academic interventions. Teacher Ad addressed this specific issue when she stated, "I would say managing almost 1500 kids is, that's a huge challenge" (Scheduling Committee Focus Group, June 27, 2018) and also reiterated by Assistant Principal $\mathrm{T}$ when he stated, "I think that our specific role ... a lot of it is logistical and supervision; so making sure that students are getting to the proper locations and that those locations are safe and secure" (Administrative Focus Group, May 30, 2018). So active supervision of students was of concern for this building. However, Assistant Principal T stated that since the team knew Aspen Time was good for students, then they would do whatever it took to make the intervention period successful. He stated, "We've still adopted a model, even though it's very cumbersome and it's very challenging and it's very intensive on a supervision standpoint from us, it's still beneficial for kids, and so we continue to fight through some of those barriers" (Administrative Focus Group, May 30, 2018). So, despite the time consuming supervision of students, the administrative team was willing to put in the time and active skills of management to benefit students. As the Administrative Focus Group discussed supervision of students, there became some clear possibilities of how to restructure student time within the intervention period to benefit even more students. Principal P stated,

You very rarely see a kid who is able to get through more than two or three [courses to which a student has an F grade] in any given two weeks when they're behind in multiple classes. So how do we need to respond differently for those, 
what I would call "the chronic?" For the kid who has multiple struggling grades. Is there a better intervention for them? (Administrative Focus Group, May 30, 2018).

In fact, one assistant principal proposed in the focus group that maybe these students with multiple low grades, rather than go teacher to teacher to increase his/her grades, maybe the student goes to one location and the work comes to him/her. Assistant Principal J stated,

I think one thing I began noticing is ... I think we have to examine what are we gonna do about students who have just an overwhelming amount of work to do? Is Aspen Time the most optimal way of getting them back on track, or is there a different strategy we need to impose with them, versus having them run around to all these teachers? (Administrative Focus Group, May 20, 2018).

One assistant principal even brainstormed the need for an attendance intervention, prior to the academic intervention. If the student was not attending school, then it was challenging for student academics to increase. Assistant Principal M stated, "Talking about attendance, there's a pretty significant correlation between kids that our not meeting our attendance goal and kids who are undirected. There almost needs to be an intervention on the attendance piece prior" (Administrative Focus Group, May 30, 2018). So, the focus group explored how to manage and supervise students that were assigned to specific teachers but were not successful under the current model.

Principal P shared one effective strategy that was implemented during the 20172018 school year with the Algebra 1 cohort of students. Math lab was located in one room in the building and staffed each period by one of the teachers in the math 
department. Any student could choose to attend math lab in any given period of the school day. So, during math lab the Algebra 1 teachers were required to communicate with the tutors in Math Lab what intervention the student needed based on an assessment. Principal P continued,

Those math lab teachers would take that information and intervention and pull those kids out of Algebra or out of advisory and reteach them and reassess them, so that they could then meet the standard, so to speak. We found that, for a lot of the kids, it was beneficial. For a group of kids, they still needed more intervention. So we created tier three for them, and we pulled them out of their Algebra 1 class and put them in a special Algebra 1 class that was smaller and went through the concepts longer, so those kids are gonna be in summer school to finish Algebra 1 because they didn't get through the curriculum (Administrative Focus Group, May 30, 2018).

So, in addition to Aspen Time, the students who received this intervention saw increases in their STAR math scores (a district standardized assessment). This example reiterated the need for additional supports for students in Algebra 1 and what was designed to enhance the RTI model at Aspen High School. These groups of students with different supports also required teams of staff members working together to assign students to these specific interventions. The need for more effective design of teams is discussed in the next section.

\section{Stakeholders' View III - Teams Could be More Effective}

Another finding that became apparent from the focus group data was that the student support teams, which Aspen operated, were successful in discussing students and 
developing possible plans for each student. These teams operated to the best of their knowledge but could be enhanced based on the responses to the focus group questions.

One of the glaring findings came from the scheduling committee focus group. When the researcher asked, "How are students assigned to Aspen Time?" none of the teachers in the focus group mentioned the role of the SST in deciding which intervention a student was assigned to attend. Teacher Ad stated, "Directed, is really from a grade pull. I know it's a tedious process, but students are pulled according to their grade in class" (Scheduling Committee Focus Group, June 27, 2018). This teacher knew that grades were pulled for her grade book to make decisions on student placement. She continued on by stating that a process was then followed and student assignments were made based on their grade in that specific class. Counselor S also contended, "Counselors used to have a role in that ranking process, this year we didn't do that in the interest of time and it's a quick turn around on the process. I think anything that was slowing the process down, we've eliminated" (Scheduling Committee Focus Group, June 27, 2018). This quote reflected that counselors, or at least other individuals, had been involved in past years regarding student placement in their interventions. However, this teacher noted that steps were eliminated to offer efficiency to the system.

In addition, this same question was asked in the administrative focus group. Similarly, SST meetings seemed to not play a role in deciding student interventions for Aspen Time, however, the administrative team began exploring some possibilities for these teams. Assistant Principal M stated,

Typically during those meetings, we discuss students who we have serious behavioral and/or academic concerns. So really specifically, as it ties in to Aspen 
Time, if a student is regularly having more classes Ds or Fs than they do passing grades, then those students would generally fall into our students of academic concern. So we discuss those concerns with guidance counselors, outreach counselors, at times the SRO [school resource officer] when appropriate, homeschool communicator, and determine what's the best next step of intervention that we need to support those students (Administrative Focus Group, May 30, 2018).

This definition of the SST discussed Aspen Time and a scenario when a student was at a high academic risk. But it appeared these teams are not used regularly to discuss student placements within the Aspen Time intervention period. This viewpoint was reiterated when Assistant Principal J continued,

It's more about behaviors. A lot of times it coincides with academics, but there isn't a direct link with Aspen Time unless that's specifically brought up, but it rarely is so that may be something that we need look into, because we usually don't discuss Aspen Time during those meetings (Administrative Focus Group, May 20, 2018).

As this question was explored in the focus group, the administrative team further defined the role of the SSTs and realized they could play a more active role with assignments, as stated in Assistant Principal J's comment above, and then shifted to discuss other intervention options. Principal P stated,

One of the things that we talked about that we're gonna address with a group of teacher leaders is we've found that it works great for a group of kids who might have one or two classes to go to, but when you have kids who are failing three or 
more classes, we're really talking about what different interventions those kids might need, and how to systematically respond to those kids (Administrative Focus Group, May 20, 2018).

These interventions began a conversation on the ineffectiveness of the universal screening tool, which will be discussed in the next section.

\section{Stakeholders' View IV - Ineffective Screening Tool}

The fourth and final finding of the study was that the universal screening tool that was used to base interventions was flawed. It was flawed because it did not provide enough information to make accurate student intervention assignments. The universal screening tool was a student grade in a specific course. If the student received a grade of $\mathrm{D}$ or $\mathrm{F}$ for that given course, the student was then assigned to that teacher during the Aspen Time intervention period. During the scheduling committee focus group, Teacher Ag related the difficulty of these assignments,

If you teach more than one level, it can be difficult to manage the variety of levels the students are at in their learning. If you are in a 'core' area, the amount of students who are coming to you can also be difficult to juggle. Many teachers spend a lot of time with kids just completing homework and making up assignments to get their points, rather than true re-teaching and intervention time. Students become more focused on the grade than meeting the objectives or learning the material (Scheduling Committee Group, June 27, 2018).

Since the universal screener was based on a student's grade that became the target of the intervention: how can a student quickly raise his/her grade to exit the intervention. And 
the goal of the intervention should be on the student skill level and how to improve that skill for that content area. Assistant Principal T emphasized this goal when he stated, In an ideal world, what we've talked about and what we're trying to implement in some specific PLTs, and those are ones that we're using right now that have highstakes testing, mostly EOC [end of course] testing, then we've been in those PLTs specifically to talk about the data process. And so what we'd like to see happening is that, within a content-specific PLT, they would be having discussions about specific students and where they're lacking in a specific skill, so that then the intervention can be targeted by teachers, by skill. This group of students that we've identified from our courses just need to make up a test, so during Aspen Time they can go to this one classroom and do that (Administrative Focus Group, June 27, 2018).

The administrative team noticed that Aspen Time was not working as effectively as it should and brainstormed ways to further divide students, based on skill level of the targets needed to successfully pass the state issued end of course exam. So the leadership team of this building was early in the planning stages of developing a new or additional universal screening tool that began to identify student skill gaps at a more detailed level, rather than just the grade for a course.

In addition, and later in the administrative focus group, two members mentioned another universal screening tool being developed to further identify gaps in student learning. Assistant Principal T stated,

As we move towards a more standards-based grading system, then we can do a better job of identifying where kids are academically... What I'm getting at is that, 
with standards referenced grading, it would allow more targeted intervention, and it would be a more true, accurate reflection of how we need to support our kids then (Administrative Focus Group, June 27, 2018).

Since the researcher was a member of Character School District, he knew that the district was shifting from a traditional grading system to a standards-referenced grading system. By moving to a system that tracks student progress at the individual target or objective level, more informed decisions can be made about students placed in a RTI intervention system. Assistant Principal L highlighted this level of specificity at the teacher level, "Once we adopt these standards-referenced grading, they can really even focus more on a specific standard that they're working with this student on" (Administrative Focus Group, June 27, 2018). Another universal screening tool that provided data not only at the skill level of the end of course exam but at the target tied to district curriculum in a standardsreferenced grading system would only enhance the unique interventions that could take place in a successful RTI model.

\section{Summary of Stakeholders' View}

Out of the scheduling committee and administrative focus groups came four major findings explored in this chapter. Finding one, the logistics behind Aspen Time were very time-consuming for one individual, but led the school to realize more time is needed within the intervention period. Finding two, the administrative supervision of students was very time-consuming, but led the school to know which kids needed "something else" perhaps. Finding three, SSTs operated with effectiveness, but had the potential to become more effective after certain practices were established. Finding four, the universal screening tool was flawed, but led the school to realize the importance of a 
move to standards-referenced grading and enhancement of professional learning teams. These findings would connect to the actual recommendations proposed to Aspen Time in chapter five.

\section{Summary}

This chapter sought to outline the findings of the research study. First, the presence or absence of the four essential elements (formation of intervention teams, development of a universal screening process, continual monitoring of students for progress, and use of evidence-based interventions) of RTI was discussed where a strong presence was linked to evidence-based interventions and only slight presences were located in the other three elements. Next, barriers to Aspen Time implementation were analyzed which included scheduling/structure, curriculum issues, fidelity and staff capacity. The chapter concluded with a review of stakeholder views of Aspen Time through two focus groups and where the following themes emerged: time-consuming logistics, time-consuming supervision, ineffectiveness of teams, and a flawed universal screening tool. The next chapter will make recommendations that will closer align Aspen Time with cited literature and thus the study's implications beyond Aspen High School. 


\section{Chapter V: Discussion, Implications, and Conclusions}

This chapter discusses the relationship of the findings to the research, the theoretical implications, future research opportunities, limitations of the study, and implications and recommendations. This chapter will begin with a discussion of each of the findings in relation to the four essential elements of RTI outlined in the research questions. Each element will be discussed in relation to the literature review. Then, theoretical implementations will be considered followed by implications for future research and limitations of the study. After exploring Aspen Time, future research includes content areas besides students in Algebra 1, other math courses or courses in different content areas too: English/Language Arts, Social Studies, and Science. Future research also involves a quantitative study that compares student grades between two different high schools in the district, one that includes intervention built into the school day and one that does not. Finally, there will be three recommendations explored that include a change to the universal screening tool and empowerment of teams, changing the logistics behind Aspen Time, and moving from a grade to a proficiency scale. The chapter concludes with a summary of the study of Aspen Time.

\section{Discussion of Findings}

Each of the sections below will mirror the four essential elements of RTI (intervention teams, universal screening process, monitoring of students for progress, and using evidence-based interventions) as outlined in the research questions. First, a discussion on the composition of intervention teams at Aspen High School and how these teams compared to the literature will be reviewed. Next, the universal screening tool and process used at Aspen High School will be discussed as compared to literature. Then the 
process of monitoring students for progress at the classroom and building level will be examined in comparison to the above literature review. Finally, the evidence-based interventions in the Algebra 1 classroom at Aspen High School will be reviewed in comparison to literature.

\section{Intervention Teams}

Teams of individuals got together weekly at Aspen High School to discuss students; however, their discussions centered more around behavior plans and mental health needs of these students rather than academics. Intervention teams implement strategies and individualized instruction for each student. As described in the literature review, these teams would use either the standard treatment protocol or the problemsolving model. Several studies emphasized the difference between the standard treatment protocol (Fuchs et al., 2004; Vaughn et al., 2003) and problem-solving model (Deno, 2002; Marston et al., 2003; Tilly et al., 1999) of intervention teams. Teams at Aspen High School used the problem-solving model when deciding appropriate interventions for students.

As each student was uniquely discussed, a plan was designed for each student to help him/her be successful. From the May 3, 2018, SST meeting, a student was discussed who had several truancies to school. Since it was close to the end of the semester, the team's plan for this student was to assign him to academic lab (an in school suspension support for special education students) for the remainder of the year to get all of his work caught up and finals taken. This plan was uniquely designed for this student, and no other student during this meeting was given this same plan. This was an example of a problemsolving model where the team located the problem of truancy, devised a plan unique to 
this student, and planned to implement the plan of keeping the student in one room the entire day, thus preventing him the ability to leave class or campus.

The two SSTs operated using the problem-solving model. The team of individuals around the table developed an exclusive plan for each student, which attempted to overcome the students' challenges. However, what was discovered through these field observations was that these meetings rarely discussed student academics and student placement during Aspen Time. In fact, from what I can recall, there was no mention of Aspen Time during these SST meetings.

Buffum, Mattos, and Malone (2018) outlined specific steps to create a RTI leadership team. They advocated that members of the team must exert these types of power: positional power, expertise, credibility, and leadership ability. The SSTs in place at Aspen appeared to contain these power types. While it was not directly reviewed in this study, the members of the team appeared to contain all the qualities necessary as set forth in Buffum, Mattos, and Malone (2018). The purpose of this leadership team was "to unite and coordinate the school's collective efforts to help every student succeed and to allocate the school's resources to best achieve this goal" (Buffum, Mattos, \& Malone, 2018, p. 39). So, based on this study, the overall purpose of the SST appeared to be creating individualized plans for students, which matched the purpose of the leadership team defined in the literature.

The idea of teaming at the secondary level seems more foreign, where at the elementary level a teaming approach seems to be more prevalent. Barriers to implementation, as mentioned above, were also present at Aspen High School, which prevented the empirical research model from being implemented. The barrier of 
scheduling when and where will these teams meet seemed impossible unless done before or after school. Teachers were not present in these SST meetings. While one SST meeting was before school and one was during the school day, it would be rare that all teachers of each student discussed could all be present at the same time of the school day. Secondary schools also have more students than elementary schools, which would require teams to meet for longer periods of time just to discuss all students on their caseload. These barriers prevented appropriate intervention teams from forming at the secondary level, where these meetings would be easier to implement in the elementary setting.

However, a recommendation below will be to revise these teams to discuss student academics and empower them to design specific interventions for each student based on their individual academic weaknesses. In addition, Character School District supports a formal process titled a Problem Solving Team and this will also be recommended to tighten and formalize the process of the current SSTs at Aspen High School.

\section{Universal Screening Process}

The universal screening process at Aspen High School, a course academic grade, was used to assign students to an academic intervention during Aspen Time. However, this screener became difficult to assign students to a particular intervention because each student inside the assigned classroom needed something different. There were many different reasons why a student's academic grade was low (would not complete the work, missed one assignment, missed an exam, did not have the skills to complete the work, etc.). 
As described in the literature review, intervention teams analyzed data over the summer and assigned students to appropriate interventions at the beginning of the school year. Data includes "state tests, end-of-course exams, common summative and formative assessments, diagnostic assessments, running records, and information assessment data" for academics and "functional behavioral analyses and other behavior screening scales" for essential and academic behavior skills (Buffum et al., 2018, p. 229). Also, these authors advocated teachers recommending students to the intervention team. In addition to an academic grade, "it is important that teachers provide more than a letter grade for each at-risk student, but also use targeted comment codes as to why the student is struggling” (Buffum et al., 2018, p. 202). Aspen High School used a course academic grade to determine intervention placement of students during Aspen Time, which was only one piece to the data considerations for appropriate intervention placement.

From this study, evidence supported a course grade was used as the universal screening tool for Aspen Time intervention placement. Both the Aspen Time Handbook and the Steps to Run Spartan Time (Appendix $C$ ) documents provided written confirmation about the course grade requirement. The 2018 edition of the Aspen Time Handbook stated, “Any student with a class score of a $69.44 \%$ or lower is directed (mandatory) to go to a specifically assigned area with the instructor of the course to which the student has this grade" (p. 4). Thus, in the document delivered to teachers, the emphasis was on student assignments during Aspen Time, based upon a student's course grade. In addition, from step one of Appendix C, "Remind teachers to update grades by the deadline," this document supported the notion that the Aspen Time Coordinator reminded teachers to update grades in their grade book by the deadline established. 
Johnson et al. (2009) indicated that teams screened student data to identify: 1) students at risk of dropping out, 2) students with learning needs, and 3) students at risk of not meeting performance indicators on state assessments. When the SSTs at Aspen High School discussed individual students and their plans, they analyzed the anecdotal evidence of reasons why students may be at risk of dropping out (outside school influences, mental health concerns, truancies, little work completion in a course). I rarely heard, if ever, discussion around student learning needs. In fact, I do not recall any conversations regarding students and their performance on state assessments. To better enhance their progress monitoring tool, Aspen needed to incorporate these data points.

Johnson et al. (2009) and Mellard and Johnson (2008) discussed the importance of using accuracy and efficiency when determining interventions. They also decided on the number of data points to include to ensure an accurate representation of the student in addition to the length of intervention in tier one before a student moved to a tier two intervention. Through this study, not in SSTs, field observations, or within interviews was much discussion held on the movement of students between tiers. Data was also not analyzed (to my knowledge) to determine placement in tiers or levels. Students at Aspen were either in an intervention based on an academic course grade or were not in an intervention due to a high academic course grade. There was little, if any, discussion on student supports at a tier three level, or a level of academic intervention beyond Aspen Time. What occurred with students who still did not obtain the necessary knowledge attainment of curricular items after an intervention was applied daily during Aspen Time? This question was never answered in this study or was present during field observations, interviews, or focus groups. 
Curricular barriers were more present in a high school setting than that of an elementary school. Pyle and Vaughn (2012) stated that the intervention at the high school level became that of content recovery where the elementary level was more aimed at early intervention. At the first sign of a student struggling in reading at the elementary level, supports were put in place that helped a student become a better reader. At Aspen, students got behind in content attainment and knowledge acquisition because the universal screener took place after a student earned a poor grade. Intervention at Aspen was more centered on remediation, how to help a student recover the missed content knowledge.

Thus, the literature review suggested taking into account several pieces of data to determine student placement in an intervention system and this was not currently being done at Aspen High School. So, a recommendation below will be to change the universal screening tool to multiple data points that intervention teams consider in their weekly meetings. In addition, Character School District partners with a local university to screen students three times a year for mental health and internal and external behavior skills. These scores should be considered for proper intervention placement too.

\section{Progress Monitoring}

Students were monitored for progress at Aspen High School, not by a team of individuals, but by one person, the Aspen Time coordinator. And progress was determined based on the students' course grade, not necessarily by whether the intervention was successful or not. As described in the literature, "the best way to brainstorm and identify potential solutions is through a team approach" composed of experts in "reading, writing, number sense, native language, and social and academic 
behaviors" (Buffum et al., 2018, p. 261). This intervention team reviewed student progress after an intervention was employed. A common assessment was typically used as a method of measurement to determine if a particular intervention was working or not. Aspen High carried out many aspects of monitoring students for progress as was mentioned in the literature.

Progress monitoring existed at different levels within Aspen High School. The original committee to design Aspen Time reviewed different journal articles and determined that a course grade would be evaluated every two weeks to not only determine placement of a student in the intervention system but to also monitor students for progress to determine if a different intervention was needed for a given student for the next two week period (Committee Meeting Minutes, May 9, 2013). The 2018 Aspen Time Handbook outlined that teachers monitored students on course essential learning outcomes to determine progress and intervention that individual teacher provided to the student over the next two-week period. And at the classroom level, one of the Algebra 1 teachers explained that students were monitored for progress by the score a student received after a reassessment of a particular objective, “improving a student's grade requires reassessment of some kind" (Teacher B, Interview, February 27, 2018). If the student performed better on the reassessment, this positively impacted the student's grade, which also impacted the student's intervention assignment at the next Aspen Time cycle.

In addition, during SST meetings, students were monitored and discussed for progress. As mentioned above, during these meetings, interventions were put in place and then monitored from week to week. After each SST meeting, notes were recorded on 
interventions put in place. These included, how to get outside school agencies involved to support families, individual counseling for students, mental health services, and general practices from the school (emailing teachers, contacting parents, meetings with families and their school supports). The SST did not have a specific outline of practices or steps to assess the student and monitor his/her progress that was witnessed during SST meetings. So, while there was monitoring on emotional, social, and behavioral needs and how to intervene and support these students, little was mentioned about Aspen Time academic progress monitoring during these SST meetings.

Mellard and Johnson (2008) dedicated chapter four of their text to the "systematic, continuous" process of progress monitoring (p. 60). No matter the tier, students were monitored at each level to determine if the student was properly placed or if movement on the intervention triangle should occur. Similar to establishing a universal screening process above, once students were placed in a tier, monitoring the student at Aspen was not followed as indicated in the literature. Aspen intervention was based on whether the course grade was increased. As discussed above, not in SSTs, field observations, or within interviews was discussion held on the movement of students between tiers. Data was also not analyzed (to my knowledge) to determine if a change in tier or level placement should occur. There was also little, if any, discussion on student supports at a tier three level, or a level of academic intervention beyond Aspen Time.

Through these examples, Aspen High School did monitor students for academic progress inside the classroom, but not at the system level. So, a recommendation below will be to revise the SSTs currently in place at Aspen High to empower them to monitor student progress based upon student performance on common formative assessments. 


\section{Evidence-Based Interventions}

The final essential element to a successfully implemented RTI program was the use of evidence-based interventions. Johnson et al. (2009) defined these as strategies designed to augment the instruction provided in a tier one program. These interventions were more targeted and specific to the students' needs. This study analyzed the use of evidence-based interventions in Algebra 1. Fuchs (n.d.) outlined six key principles (instructional explicitness, instructional design that eases the learning challenge, a strong conceptual basis for procedures that are taught, an emphasis on drill and practice, cumulative review as part of drill and practice, and motivators to help students regulate their attention and behavior and to work hard) used in tier two mathematics interventions. Also referenced in this study was the work of Star et al. (2015) whom made three recommendations (use solved problems to engage students in analyzing algebraic reasoning and strategies, teach students to utilize the structure of algebraic representations, and teach students to intentionally choose from alternative algebraic strategies when solving problems) of teaching strategies that improved algebra knowledge in high school students. Both teachers observed during Aspen Time implemented several of these strategies successfully.

Of the nine intervention strategies mentioned above, some of them were witnessed during document review and through field visits to the classroom. One document I reviewed was a description of Aspen Time that was developed for distribution in a parent newsletter for the school. The document stated, "Here are just some of the interventions that have taken place so far in our building during AT: one-onone tutoring, make-up assignments, quizzes, and tests, basic math skill practice, writing 
skills, homework help, Advanced Placement support and test preparation as well as interactions through clubs and extracurricular activities." In regards to the mathematics classroom, there occurred one-on-one tutoring and basic math skill practice summarized in this newsletter but also correlated to those evidence-based interventions of "instructional explicitness" (Fuchs, n.d., p.1) and "teach students to utilize the structure of algebraic representations" (Star et al., 2015, p. 16).

Evidence-based interventions are specific to the multiple curricular areas and grade levels of either the elementary or secondary setting. Those evidence-based interventions in a secondary math classroom are very different than those interventions in an elementary math classroom. The interventions also differ between different content areas such as social studies and mathematics. No matter if the setting is elementary or secondary, if the evidence-based interventions are appropriate to that level, then the higher the chance of a student completing that tier of intervention.

In conclusion, there were evidence-based mathematical interventions being implemented inside Algebra 1 classrooms at Aspen High School as outlined in the literature. This essential element was the strongest and most notably present during Aspen Time. The recommendation offered here is to continue these evidence-based interventions in Algebra 1 and expand to ensure evidence-based interventions are being implemented in each content area according to the literature.

\section{Implementation and Future Research}

Aspen Time discussed the role of a RTI system at the secondary level. A model of public health prevention framework was applied, overlaid with the prevention science research cycle. New circumstances surfaced in this study that requested a change be 
considered to this framework to incorporate mental health concerns. Next, future research opportunities are explored in addition to limitations of this program review.

\section{Theoretical Implementation}

This study reviewed the application of the public health prevention model and prevention science method in the educational setting. Using this model and method, RTI in schools adapted the use of a three-tiered or level system. Interventions were used to support students based on their performance in the academic setting. Furthermore, the four essential elements of RTI (intervention teams, universal screening, progress monitoring, and evidence-based interventions) were explored. A RTI system contains more than just the conceptual framework of a three-tiered system. This study contributed to theory by showing how these four essential elements were incorporated into a tiered system.

In both SST meetings that were observed, the focus was placed less on academic needs and more on behavioral and mental health concerns. Both the health prevention model and prevention science model take a preventative role and attempt to prevent something from occurring before it actually happens. While there may be ways to address mental health concerns and prevent them from becoming too large of an issue, there is little that can be done to prevent a mental health issue from surfacing. More so, a mental health issue must become apparent before treatment can occur. Thus, a new area of research presents itself: how a reactionary mental health issue can be applied to a model of prevention. 


\section{Future Research Opportunities}

The focus of this Aspen Time study centered on the Algebra 1 classroom due to the significant number of low academic grades for this specific course. Future research should review not only other mathematics courses, but also courses in other departmental areas. Some of the results of this study may be able to be generalized to other areas of the building at the system level. However, different evidence-based interventions would need to be considered for each content area. The scope of this study was limited to just Algebra 1 to provide a more thorough investigation into the depth of this content area rather than a surface level review into multiple academic areas. When other content areas are studied, the researcher should consider taking a content expert (i.e. Character School District Science Department Coordinator) into each classroom field visit to ensure fidelity of implementation of the evidence-based interventions.

In addition, another consideration for future research would be to conduct a quantitative study that compares students from one high school in the district with those in another school. Each of the high schools in Character School District has a different RTI system-wide program. Future research would be to analyze these three and identify the successful aspects of each program. Possible recommendations would include how to enhance the RTI programs at all buildings based on successes identified amongst the three different systems.

Future research might also include a student and/or parent focus group. The decision to leave them out of this study was purposeful. However, future studies should consider their viewpoints and compare these statements with those of the adults in the 
building. Are there similarities and differences? How can the high school capitalize and use these comments to enhance their RTI system?

\section{Limitations of the Study}

The first limitation of this study was related to the setting. This study was only reflective of what RTI looked like in one school building. Had this study examined multiple secondary buildings in multiple school districts, an easier generalizability could have been assumed as a result of the study. However, with the limitation of one building, it was hard to generalize this study to other buildings throughout the nation.

Another limitation of the study was the qualitative design. This design allowed for a comparison of Aspen Time to the four essential elements of a RTI system and a brief analysis of statistics to assess program effectiveness. If the study were a quantitative study, more attention would have been focused on the raw data and numbers with a greater emphasis on the overall effectiveness of Aspen Time. I would have conducted more statistical tests as written in Field (2009) to analyze the data from different perspectives than in this study. A quantitative design would have uncovered different results than those offered through a qualitative study.

One limitation was the number of stakeholders I was able to interview and that attended my focus groups. Since there were only two Algebra 1 teachers in the study, there were only two perspectives contained in the teacher interviews and observations were only of these two individuals. Had there been more staff members, there might have been additional unique observations that could have provided more evidence of the four essential elements of a RTI system. When the initial invites were sent to the scheduling committee members to set up the focus group, only four of the 17 teachers responded. If 
more teachers would have been present at the focus group meeting, there is a possibility that a richer dialogue would have been present with more evidence to answer the three questions of this study.

An additional limitation was that student and parent focus groups were not conducted. Since the researcher was no longer a faculty member at Aspen High School, scheduling student focus groups would prove challenging. I did not want to pull students out of their content classes or out of their intervention period to interview them for this study. Student focus groups would have required parental informed consents and would have lengthened the International Review Board process for acceptance. The committee also believed at the time of the study's proposal that student focus groups were not necessary for this particular study of RTI fidelity of implementation. Had there been a student and parent focus group, comparisons could have been made between their statements and those of the faculty members to add to the rich data in this study.

The last limitation to the study relates to me personally. I was an administrator at Aspen High School and served as the Aspen Time Coordinator. Then I transitioned to another building in Character district during the writing of the study. The transition occurred before the data collection phase. To account for my bias in the findings, I triangulated the data during the analysis phase to ensure each finding was supported by the data and not my own interpretation. However, because of my positive relationships with past colleagues, the data collected during the interviews and both the teacher and leadership focus groups produced authentic responses. I was able to ask challenging questions that arose from the literature review in order to collect honest, not always positive feedback that in turn supported the recommendations. Since the transition to a 
different building, I continued to review Aspen's RTI intervention from the lens of how I could also improve our RTI system in my new high school setting. My new location was in the initial stages of overhauling their intervention period so my knowledge from Aspen and this study were useful in providing information during this revitalization of RTI.

\section{Implications and Recommendations}

This section will review the recommendations that were developed out of this qualitative case study of reviewing Aspen Time at Aspen High School. Two recommendations will be made for all high schools in general and three recommendations will be made for Aspen High School specifically.

\section{General Recommendations for High Schools}

If other secondary buildings take on designing and implementing a RTI system in their school setting, there are two recommendations from this study and implications for practice they should consider. The first recommendation is to use the work of Johnson et al. (2009) and Buffum et al. (2018) to design a system-wide RTI intervention at the secondary level. These two texts, along with others contained in the literature review, will support creation of the initial stages of RTI implementation in another building. Per the literature review, an effort should be made to implement intervention teams that make decisions on student intervention placement, use a universal tool to assign students to similarly grouped interventions, continually progress monitor students to consider movement between tiers, and use evidence-based interventions when working with students. If these four elements are implemented with fidelity, proper RTI implementation and student academic success will ensue. 
In addition, schools should become aware of the challenges and barriers to implementation of a RTI system at the secondary level and work to overcome and plan around these barriers. See Appendix $K$ for a compilation of these characteristics. The four barriers to implementation discussed in this study were scheduling/structure, curriculum issues, fidelity, and staff capacity/professional development. Each secondary building should analyze how to overcome these barriers while designing an RTI system unique to their setting.

\section{Specific Recommendations for High Schools}

The below highlights three recommendations that high schools should consider moving forward in their quest to continually refine their RTI system. These recommendations come after having become an expert on this topic and comparing Aspen Time, the current RTI system, with that of the literature. More effort needs to focus and ensure a research-based application is also made to Aspen Time.

\section{Recommendation one - change universal screening tool \& empower teams.}

Aspen High School should change its universal screening tool and empower its teams to become more encompassing of both academic and behavior interventions. The current universal screening tool, as mentioned above, is a student's grade in an academic course. This should be changed to include more data points and a move should occur to student knowledge attainment of objectives in each of those academic courses. At the secondary level in Character School District, the following scores should be used to understand a student's snapshot of his/her learning at that given moment in time: STAR Reading, STAR Math, Aspire subject areas, ACT subject areas, End of Course test score in Algebra 1, Biology, English II, and Government, State Assessment Program (SAP) 
Communication Arts, SAP Science and SAP Mathematics for incoming $8^{\text {th }}$ grade students. Other data points to consider include students' academic grades from previous coursework, attendance percentage, number of behavior incidents, z scores from the local mental health coalition and teacher qualitative comments.

Teacher comments and intervention recommendations were deliberated in the March 21, 2013, committee meeting when it was stated the committee, "Looked at pros and cons of using grades during Aspen Time v. teachers requesting students during Aspen Time" (Committee Meeting Minutes, March 21, 2013). This additional qualitative data point would honor this committee consideration that was previously discussed. Buffum et al. (2018) helped meet this consideration when they stressed the importance that "teachers provide more than a letter grade for each at-risk student, but also use targeted comment codes as to why the student is struggling" (p. 202). When a teacher provides more information, specific areas of concern or interventions can be addressed that either relate to student academics or behaviors.

In addition, instead of just a current course academic grade, a student's knowledge attainment should be reported at the individual course standard or target level (further discussed in the third recommendation below). All of these points should be analyzed every two weeks and appropriate, unique interventions should be designed and administered to groups of students based on student need. In return, this same universal screening tool also becomes the progress-monitoring tool for each intervention as well. These items are all monitored to determine student growth or regress in each area and then interventions are adjusted accordingly. 
Character School District has begun implementation of Problem Solving Teams at the elementary school level. Aspen High School should consider implementation of these at the secondary level and define their specific purpose of determining tier two and or tier three interventions. Teams could be divided based upon the current administrative model - alphabetically by assistant principal. Each assistant principal could host a Problem Solving Team meeting each week, dividing the student population based on the students that report to that assistant principal. Student data could be analyzed, student interventions assigned, and individually assigned staff members could monitor students weekly. A distinction should be made between students that need supports for specific content "skills" and those that need supports for the "will" to complete the work. Another group of students may be those that just need to complete an exam or quiz or assessment in order to determine proficiency of a standard. These three groups of students should be teased out from the larger group and be provided specific interventions for their needs.

Many at Aspen High School consider Aspen Time a tier two intervention. There should be a clear diagram or pictorial representation of the multiple intervention supports provided to students at Aspen. Many supports, programs, and interventions are present at Aspen High School but I was not able to point to one document that explained, labeled, or described these different interventions and how they fit into the broader picture of RTI. In addition, both academic and behavior interventions should be considered, either on the same document or two separate documents. These items should be clearly labeled Tier 1, Tier 2, and Tier 3 so progression on the triangle can be described, intensified, or decreased as needed by the Problem Solving Team. 


\section{Recommendation two - logistics behind Aspen Time.}

There are several logistics that occurred not only every other week when the Aspen Time report was ran, but also within the daily intervention time that needed to be re-worked. This will provide for a quicker turn around and a more efficient and effective system.

The Aspen Time Coordinator spends considerable time on the logistical pieces of enacting the Aspen Time process every two weeks. The steps behind running the Aspen Time report (Appendix C) are very labor intensive and require considerable time copying and assembling the documents distributed every two weeks. Buffum et al. (2018) suggested, "As the leadership designs an identification process for its school, it is critical that the process is not too laborious" (p. 202). In order to proceed forward, a meeting between the Technology Services department of Character School District and the Aspen Time Coordinator should be held. The purpose of this meeting would be to discuss how to reduce the time consumed in producing individual students sheets every other week. Every student and adult in the district has a laptop and how might these be used with the many technological advances since Aspen High School opened in 2013. Another consideration to incorporate is how are the Problem Solving Team recommendations put into action and how might these teams distribute the work load, minimize the work of the Aspen Time Coordinator, and make the process of intervention assignment much more efficient. If a solution cannot be proposed for quicker turn around, Aspen should consider making the length of each cycle longer. The school should consider a three or four week cycle instead of changing student assignments every two weeks. 
The logistics and supervision required of the administrative team during the daily intervention period is very time-consuming. Administrative staff reports that they chase students around during this 30-minute period every day. This has led the staff to know which kids might need "something else." These students are typically those that are truant from Aspen Time and attempt to evade the intervention in itself. These same students "forget" where they are assigned, do not report to their initial assignment, are tardy to intervention, and have multiple courses listed on their intervention sheet. These students need something different and may not need to be placed with their individual course teacher. One option to consider is one room for these students to report. The work is brought to them versus them going out to the teacher to locate the work. Another option to consider is to individualize the intervention for these students. For example, once a Problem Solving Team reviews the data, there may be a small group of these students that are not on level for reading. A possibility would be to consider how to incorporate reading intervention during this time period to support students.

Another change to the logistics would be to consider lengthening the amount of minutes in Aspen Time, the 30-minute daily intervention. As much time and work is put into the program and providing appropriate interventions, it seems the period could be lengthened by 10 minutes that would improve the amount of time a student spends demonstrating the knowledge necessary to show mastery of a proficiency scale. This change appeared to be echoed by both teachers and administrators in the focus groups.

As emphasized in the literature review above, teachers are going to make sense of the RTI system based upon prior knowledge and their learning they can attach to this new method. The more professional development Aspen High School can provide to their 
staff on the RTI process, rules during the intervention, clarity of misconceptions and new learning, the more the program will be implemented with fidelity.

\section{Recommendation three - transition from grade to proficiency scale.}

The third recommendation is to move away from using a course grade to separate and then intervene with students to a more detailed student analysis and division of students based on specific skills or targets the student is failing to comprehend.

Character School District is moving from a traditional grading system to a Standards Referenced Grading (SRG) system. Aspen High School has begun conversations in their building about SRG but once fully implemented the proficiency scales that are developed correlate nicely with dividing students based on who has scored below a three on each proficiency scale. This allows for targeted intervention with each student based on an individual course learning target rather than completing sheets to earn more points and increase an academic course grade.

In addition, grades should represent student learning or mastery of content based upon a proficiency scale. Buffum et al. (2018) advocate "the leadership team should build shared knowledge on grading practices that promote and support a student's opportunity to learn from his or her mistakes, try again, and ultimately demonstrate what he or she has learned" (p. 157). If student learning was reported based on a score that was related to a proficiency scale, interventions could be more tailored to a specific student or group of students. The RTI team that appoints students to particular interventions could assemble all students with similar skill or content deficits together. The current model divides all students with a D or F grade and assigns them to the same classroom during Aspen Time. Each student needed something different in that classroom. However, if all students 
earning a score of one or two on a four-point scale based on a proficiency scale for the learning target 1.2 in an Algebra classroom were identified, it would be easy to determine what interventions this student or group of students might need. Teachers in each content area could each take a group of students to intervene with and know exactly what the reteaching needs to be for that specific group of students.

At the end of the administrative focus group, Principal P discussed an additional model put in place this year with the Algebra 1 cohort of students. Prior to this year math teachers operated a math lab that was available to students every period. Students could walk in any period and get support on their math assignments or review for an upcoming exam. This year, students in Algebra 1 were mandated to attend math lab during their freshman advisory course. The Algebra 1 teachers communicated to the math lab teacher what each individual student needed based on the score a student received on an assessment. Principal P stated, "Those math lab teachers would take that information and intervention and pull those kids out of Algebra or out of advisory and reteach them and reassess them, so that they could then meet the standard" (Administrative Focus Group, May 30, 2019). This model could be replicated through multiple mathematics courses across the building since the lab model is already created for this content area. However, this new emphasis would be on mandatory attendance for students not meeting the course standard. This model parallels the other parts of this recommendation related to SRG.

\section{Summary}

This chapter began with a discussion of each of the findings in relation to the four essential elements of RTI as outlined in the research questions. Each element was discussed in relation to the literature review. Then, theoretical implementations were 
considered. Next, implications for future research and limitations of the study were presented. After exploring Aspen Time, future research includes content areas besides Algebra 1 and involves a quantitative study that compares student academics between three different high schools in the district. Also, student and parent focus groups should be considered. Finally, three specific recommendations were presented to implement and enhance Aspen Time (change in the universal screening tool and empower teams, change the logistics behind Aspen Time, and move from a grade to a proficiency scale). 


\section{References}

Al Otaiba, S. \& Fuchs, D. (2006). Who are the young children for whom best practices in reading are ineffective?: An experimental and longitudinal study. Journal of Learning Disabilities, 39(5), 414-431. doi: 10.1177/002221940603900504

America's Promise Alliance and its Center for Promise at Tufts University (2014). Don't call them dropouts: Understanding the experiences of young people who leave high school before graduation. Washington, DC: America's Promise Alliance. Retrieved from America's Promise Alliance website: https://www.americaspromise.org/sites/default/files/d8/201610/DCTD\%20Final\%20Full_0.pdf

Balu, R., Zhu, P., Doolittle, F., Schiller, E., Jenkins, J., Gersten, R. (2015). Evaluation of response to intervention practices for elementary school reading. Washington, DC: National Center for Education Evaluation and Regional Assistance, Institute of Education Sciences, U.S. Department of Education. Retrieved from https://ies.ed.gov/ncee/pubs/20164000/

Buffum, A., Mattos, M., \& Malone, J. (2018). Taking Action: A handbook for RTI at Work. Bloomington, IN: Solution Tree.

Buffum, A., Mattos, M., \& Weber, C. (2009). Pyramid response to intervention. Bloomington, IN: Solution Tree.

Burns, M. K. (2008). Response to intervention at the secondary level. Principal Leadership, 8(7), 12-15.

Caplan, G. (1964). Principles of preventive psychiatry. New York, NY: Basic Books. 
Canter, A., Klotz, M. B., \& Cowan, K. (2008). Response to intervention, the future for secondary schools. Principal Leadership, 8(6), 12-15.

Coburn, C. (2005). Shaping teacher sensemaking: school leaders and the enactment of reading policy. Educational Policy, 19(3), 476-509.

Creswell, J.W. (2009). Research design: Quantitative, qualitative, and mixed methods approaches (3rd ed.). Thousand Oaks, CA: Sage.

Deno, S. L. (1985). Curriculum-based measurement: The emerging alternative. Exceptional Children, 52(3), 219-232.

Deno, S. L. (2002). Problem solving as “best practice.” In A. Thomas \& J. Grimes (Eds.), Best practices in school psychology IV (Vol. 1, pp. 37-56). Washington, DC: National Association of School Psychologists.

Duffy, H. (2007). Meeting the needs of significantly struggling learners in high school: A look at approaches to tiered intervention. National High School Center. Retrieved from Center on Response to Intervention at American Institutes for Research website: http://www.rti4success.org/resource/meeting-needs-significantlystruggling-learners-high-school-look-approaches-tiered

DuFour, R., \& Eaker, R. (1998). Professional Learning Communities at Work: Best practices for enhancing student achievement. Bloomington, IN: Solution Tree.

Eaker, R., DuFour, R., \& DuFour, R. (2002). Getting Started: Reculturing schools to become professional learning communities. Bloomington, IN: Solution Tree.

Emerson, R., Fretz, R., \& Shaw, L. (2011). Writing ethnographic fieldnotes (2nd ed.). Chicago: University of Chicago Press. 
Engels, K. (2015). RTI: What teachers know that computers don't. Educational Leadership, 73(3), 72-76.

Feuerborn, L. L., Sarin, K., \& Tyre, A. D. (2011). Response to intervention in secondary schools. Principal Leadership, 11(8), 50-54.

Fletcher, J. M., Denton, C., Francis, D., J. (2005). Validity of alternative approaches for the identification of learning disabilities: Operationalizing unexpected underachievement. Journal of Learning Disabilities, 38(6), 545-552.

Field, A. (2009). Discovering statisticecs using SPSS (3rd ed.). Thousand Oaks, CA: Sage.

Fuchs, D., Fuchs, L. S., \& Compton, D. L. (2004). Identifying reading disabilities by responsiveness-to-instruction: Specifying measures and criteria. Learning Disability Quarterly, 27(4), 216-227. doi: 10.2307/1593674

Fuchs, D., Mock, D., Morgan, P. L., \& Young, C. L. (2003). Responsiveness-tointervention: Definitions, evidence, and implications for the learning disabilities construct. Learning Disabilities Research \& Practice, 18(3), 157-171. doi:

$10.1111 / 1540-5826.00072$

Fuchs, L. S. (n.d.). Mathematics intervention at the secondary prevention level of multitier prevention system: Six key principles [Website]. Retrieved from http://www.rtinetwork.org/essential/tieredinstruction/tier2/mathintervention.

Greene, R. W. (2010). Calling all frequent flyers. Educational Leadership, 68(2), 28-34.

H. Res. 1350, 108th Cong., 118 Cong. Rec. 2647 (2004) (enacted).

Hatch, J. A. (2002). Doing qualitative research in educational settings. Albany: State University of New York. 
Haynes, M. (2010). Meeting the challenge: The role of school leaders in turning around the lowest-performing high schools. Washington, DC: Alliance for Excellent Education. Retrieved from Alliance for Excellent Education website: https://all4ed.org/reports-factsheets/meeting-the-challenge-the-role-of-schoolleaders-in-turning-around-the-lowest-performing-high-schools/

Horner, R. H., Sugai, G., Smoklowski, K., Eber, L., Nakasato, J., Todd, A. W., \& Esperanza, J. (2009). A randomized, wait-list, controlled effectiveness trial assessing school-wide positive behavior support in elementary schools. Journal of Positive Behavior Interventions, 11(3), 133-144. doi:10.1177/1098300709332067

Jackson, R. R. (2010). Flagged for Success. Educational Leadership, 68(2), 18-21.

Johnson, E. S., Smith, L., \& Harris, M. L., (2009). How RTI works in secondary schools. Thousand Oaks, CA: Corwin A SAGE Company.

Kellam, S., \& Langevin, D. (2003). A framework for understanding “evidence” in prevention research and programs. Prevention Science, 4(3), 137-153.

Klingman, A. (1986). Tertiary prevention: Conceptual framework for school counselor education and practice. International Journal for the Advancement of Counseling, 9(1), 5-10. doi: 10.1007/BF00116430

Klingman, A., \& Ben Eli, A. (1981). A school community in disaster: Primary and secondary prevention in situational crisis. Professional Psychology, 12(4), 523532.

Kotter, J. P. (1996). Leading change. Boston: Harvard Business School Press.

Krueger, R. A., \& Casey, M. A. (2009). Focus groups: A practical guide for applied research. (4th ed.) Thousand Oaks, CA: SAGE Publications, Inc. 
Lembke, E. S., McMaster, K. L., \& Stecker, P. M. (2010). The prevention science of reading research within a response-to-intervention model. Psychology in the Schools, 47(1), 22-35. doi: 10.1002/pits.20449

Lembke, E. S., \& Stecker, P. M. (2007). Curriculum-based measurement in mathematics: An evidence-based formative assessment procedure. Portsmouth, NH: RMC Research Corporation Center on Instruction. Retrieved from Center on Instruction website: http://www.centeroninstruction.org/curriculum-based-measurement-inmathematics-an-evidence-based-formative-assessment-procedure

Marston, D., Muyskens, P., Lau, M., \& Canter, A. (2003). Problem-solving model for decision making with high-incidence disabilities: The Minneapolis experience. Learning Disabilities Research \& Practice, 18(3), 187-200. doi:10.1111/15405826.00074

Mazzotti, V. L., Rowe, D. R., \& Test, D. W. (2013). Navigating the evidence-based practice maze: Resources for teachers of secondary students with disabilities. Intervention in School and Clinic, 48(3), 159-166. doi:

$10.1177 / 1053451212454004$

McMaster, K. L., Fuchs, D., Fuchs, L. S., \& Compton, D. L. (2005). Responding to nonresponders: An experimental field trial of identification and intervention methods. Exceptional Children, 71(4), 445-463.

Mellard, D., McKnight, M., Jordan, J. (2010). RTI tier structures and instructional intensity. Learning Disabilities Research \& Practice, 25(4), 217-225. doi:10.1111/j.1540-5826.2010.00319.x 
Mellard, D., Stern, A., Woods, K. (2011). RTI school-based practices and evidence-based models. Focus on Exceptional Children, 43(6), 1-15.

Mellard, D. F. (2009a). RTI in secondary schools - a review of the literature [Web log post]. Retrieved from http://cecblog.typepad.com/rti/2009/01/rti-in-secondaryschools-a-review-of-the-literature.html

Mellard, D. F. (2009b). Best guesses and remaining challenges [Web log post]. Retrieved from http://cecblog.typepad.com/rti/2009/01/best-guesses-and-remainingchallenges.html

Mellard, D. F., Johnson, E. (2008). RTI: A practitioner's guide to implementing response to intervention. Thousand Oaks, CA: Corwin Press

National High School Center, National Center on Response to Intervention, and Center of Instruction (2010). Tiered interventions in high schools: Using preliminary "lessons learned” to guide ongoing discussion. Washington, DC: American Institutes for Research. Retrieved from Center on Response to Intervention at American Institutes for Research website:

http://www.rti4success.org/resource/tiered-interventions-high-schools-usingpreliminary-lessons-learned-guide-ongoing

National Research Council and the Instutite of Medicine (2009). Preventing mental, emotional, and behavioral disorders among young people: Progress and possibilities. Washington, DC: National Academies Press.

O’Connor, E. P., \& Freeman, E. W. (2012). District-level considerations in supporting and sustaining RTI implementation. Psychology in the Schools, 49(3), 297-310. doi: $10.1002 /$ pits. 21598 
O’Connor, R. E., Fulmer, D., Harty, K., \& Bell, K. (2005). Layers of reading intervention in kindergarten through third grade: Changes in teaching and child outcomes. Journal of Learning Disabilities, 38(5), 21-48.

Pyle, N., \& Vaughn, S. (2012). Remediating reading difficulties in a response to intervention model with secondary students. Psychology in the Schools, 49(3), 273-284. doi: 10.1002/pits.21593

Sansosti, F. J., Goss, S., \& Noltemeyer, A. (2011). Perspectives of special education directors on response to intervention in secondary schools. Contemporary School Psychology, 15, 9-20.

Sansosti, F. J., Noltemeyer, A., \& Goss, S. (2010). Principal's perceptions of the importance and availability of response to intervention practices within high school settings. School Psychology Review, 39(2), 286-295.

Spillane, J. P., Reiser, B. J., \& Reimer, T. (2002). Policy implementation and cognition: Reframing and refocusing implementation research. Review of Educational Research, 72(3), 387-431.

Star, J. R., Foegen, A., Larson, M. R., McCallum, W. G., Porath, J., Zbiek, R. M. (2015). Teaching strategies for improving algebra knowledge in middle and high school students. Washington, DC: National Center for Education Evaluation and Regional Assistance, Institute of Education Sciences, U.S. Department of Education. Retrieved from https://ies.ed.gov/ncee/wwc/Docs/PracticeGuide/wwc_algebra_040715.pdf

Suh, S., \& Suh, J. (2007). Risk factors and levels of risk for high school dropouts. Professional School Counseling, 10(3), 297-306. 
Tilly, W. D., Reschly, D. J., \& Grimes, J. (1999). Disability determination in problemsolving systems. Conceptual foundations and critical components. In D. Reschly, W. D. Tilly, \& J. Grimes (Eds.), Special education in transition: Functional assessment and noncategorical programming (pp. 285-321). Longmont, CO: Sopris West.

Vaughn, S., \& Fletcher, J. M. (2010). Thoughts on rethinking response to intervention with secondary students. School Psychology Review, 39(2), 296-299.

Vaughn, S., Cirino, P., Wanzek, J., Wexler, J., Fletcher, J., Denton, C., \& Francis, D. (2010). Response to intervention for middle school students with reading difficulties: Effects of a primary and secondary intervention. School Psychology Review, 39(1), 3-21.

Vaughn, S., Denton, C. A., \& Fletcher, J. M. (2010). Why intensive interventions are necessary for students with severe reading difficulties. Psychology in the Schools, 47(5), 432-444. doi: 10.1002/pits.20481

Vaughn, S., Linan-Thompson, S., \& Hickman, P. (2003). Response to intervention as a means of identifying students with reading/learning disabilities. Exceptional Children, 69(4), 391-409.

Vaughn, S., Wanzek, J., Wexler, J., Barth, A., Cirino, P. T., Romain, M., et al. (2010). The relative effects of group size on reading progress of older students with reading difficulties. Reading and Writing: An Interdisciplinary Journal, 23(8), 931-956. doi: 10.1007/s11145-009-9183-9

Vaughn, S., Wexler, J., Leroux, A. J., Roberts, G., Denton, C. A., Barth, A. E., et al. (2012). Effects of intensive reading intervention for eighth-grade students with 
persistently inadequate response to intervention. Journal of Learning Disabilities, 45(6), 515-525. doi: 10.1177/0022219411402692 


\section{Appendix A}

Table 1. Model Overviews

\begin{tabular}{|l|l|l|l|l|}
\hline $\begin{array}{l}\text { Principle } \\
\text { Author }\end{array}$ & \multicolumn{1}{|c|}{ Model Name } & \multicolumn{1}{|c|}{ Type } & \multicolumn{1}{c|}{$\begin{array}{c}\text { Content } \\
\text { Area(s) }\end{array}$} & \multicolumn{1}{|c|}{$\begin{array}{l}\text { Targeted } \\
\text { Grades }\end{array}$} \\
\hline $\begin{array}{l}\text { Batsche } \\
\text { et al. }\end{array}$ & $\begin{array}{l}\text { Problem Solving/RTI } \\
\text { (PSM/RTI) }\end{array}$ & $\begin{array}{l}\text { Problem } \\
\text { solving } \\
\text { Fuchs } \&\end{array}$ & $\begin{array}{l}\text { Behavior } \\
\text { Academics }\end{array}$ & Elementary \\
\hline $\begin{array}{l}\text { Ruchs } \\
\text { et al. }\end{array}$ & $\begin{array}{l}\text { Standard } \\
\text { treatment } \\
\text { protocol }\end{array}$ & $\begin{array}{l}\text { Reading } \\
\text { Math }\end{array}$ & Elementary \\
\hline Vaughn & RTI & $\begin{array}{l}\text { Standard } \\
\text { treatment } \\
\text { protocol }\end{array}$ & Reading & Elementary \\
\hline Shinn & RTI & $\begin{array}{l}\text { Standard } \\
\text { treatment } \\
\text { protocol }\end{array}$ & Reading & K-8 \\
\hline $\begin{array}{l}\text { Chun \& } \\
\text { Witt }\end{array}$ & $\begin{array}{l}\text { System to Enhance } \\
\text { Educational } \\
\text { Performance } \\
\text { (STEEP) }\end{array}$ & Combined & Academics & Secondary \\
\hline $\begin{array}{l}\text { Sugai \& } \\
\text { Horner }\end{array}$ & $\begin{array}{l}\text { Positive Behavior } \\
\text { Intervention \& } \\
\text { Support (PBIS) }\end{array}$ & Academics & All Levels \\
\hline
\end{tabular}




\section{Appendix B}

Table 2. Intervention Features by Tier

\begin{tabular}{|c|c|c|c|}
\hline $\begin{array}{l}\text { Principle } \\
\text { Author }\end{array}$ & $\begin{array}{c}\text { Tier } 1 \\
\text { Primary Prevention }\end{array}$ & $\begin{array}{c}\text { Tier } 2 \\
\text { Secondary Prevention }\end{array}$ & $\begin{array}{c}\text { Tier } 3 \\
\text { Tertiary Prevention }\end{array}$ \\
\hline $\begin{array}{l}\text { Batsche et } \\
\text { al. }\end{array}$ & $\begin{array}{l}\text { Core instruction for all } \\
\text { students; school may } \\
\text { make modifications to } \\
\text { general instruction to } \\
\text { increase effectiveness } \\
\text { and/or to reduce } \\
\text { disproportionality }\end{array}$ & $\begin{array}{l}\text { Supplemental instruction, } \\
\text { in additon to core, for } \\
\text { small-group instruction at } \\
\text { intensity and frequency } \\
\text { necessary to ensure } \\
\text { improvement }\end{array}$ & $\begin{array}{l}\text { Intensive instruction, in } \\
\text { addition to core, for a } \\
\text { very small group or } \\
\text { individuals with narrow } \\
\text { focus on defined skills } \\
\text { instruction }\end{array}$ \\
\hline $\begin{array}{l}\text { Fuchs \& } \\
\text { Fuchs }\end{array}$ & $\begin{array}{l}\text { Classroom instruction } \\
\text { that provides at-risk } \\
\text { student evidenced-based } \\
\text { curriculum with a sound } \\
\text { instructional design }\end{array}$ & $\begin{array}{l}\text { Supplementary, } \\
\text { diagnostic instructional } \\
\text { trials for non-responders, } \\
\text { provided in small groups } \\
\text { of students with similar } \\
\text { abilities for } 30 \text { minutes } \\
\text { three times per week with } \\
\text { a qualified teacher or aid; } \\
\text { includes frequent } \\
\text { progress monitoring }\end{array}$ & $\begin{array}{l}\text { Interventions that are } \\
\text { generally systematic and } \\
\text { explicit, with increased } \\
\text { frequency and duration in } \\
\text { homogenous group or } 1: 1 \\
\text { by highest expertise } \\
\text { teacher with students } \\
\text { eligible for special } \\
\text { education }\end{array}$ \\
\hline $\begin{array}{l}\text { Johnson et } \\
\text { al. }\end{array}$ & $\begin{array}{l}\text { Effective, scientifically- } \\
\text { based instruction in } \\
\text { general education }\end{array}$ & $\begin{array}{l}\text { Specialized group } \\
\text { instruction that } \\
\text { supplements general } \\
\text { education for at-risk } \\
\text { students to remediate } \\
\text { deficits; provided in } \\
\text { small groups, } 3 \text { or } 4 \text { times } \\
\text { per week, in } 30 \text { to } 60 \\
\text { minute sessions for } 9 \text { to } \\
12 \text { weeks }\end{array}$ & $\begin{array}{l}\text { Special education or } \\
\text { highly individualized } \\
\text { instruction }\end{array}$ \\
\hline Vaughn & $\begin{array}{l}\text { Classroom instruction or } \\
\text { core reading program for } \\
\text { all students }\end{array}$ & $\begin{array}{l}\text { Suplemental instruction, } \\
\text { in addition to core } \\
\text { instruction, for identified } \\
\text { students; e.g., K-3 small } \\
\text { group, } 20-30 \text { minutes } \\
\text { daily, } 10-20 \text { weeks; } \\
\text { middle school } 50 \text { minutes } \\
\text { daily, } 12 \text { weeks }\end{array}$ & $\begin{array}{l}\text { Intensive instruction for } \\
\text { struggling students based } \\
\text { on needs, not necessarily } \\
\text { special education but } \\
\text { typically provided by a } \\
\text { reading teacher special } \\
\text { educator, or trained } \\
\text { interventionist }\end{array}$ \\
\hline Shinn & $\begin{array}{l}\text { High quality, research- } \\
\text { based instruction in } \\
\text { content knowledge with } \\
\text { behavior interventions } \\
\text { and supports, school- } \\
\text { wide pedagogy with } \\
\text { teaching routines and } \\
\text { strategies, effective } \\
\text { classroom management, } \\
\text { study and organizational } \\
\text { skills, curriculum } \\
\text { modification, and an } \\
\text { objective, open grading } \\
\text { system }\end{array}$ & $\begin{array}{l}\text { Remedial programs to } \\
\text { help generalize learning } \\
\text { to core curriculum } \\
\text { targeted towards basic } \\
\text { skills and content } \\
\text { knowledge, such as } \\
\text { remedial reading } \\
\text { programs }\end{array}$ & $\begin{array}{l}\text { Intensive or special } \\
\text { education matched to } \\
\text { student needs and/or } \\
\text { mainstream consultation } \\
\text { and coaching to support } \\
\text { students }\end{array}$ \\
\hline
\end{tabular}




\begin{tabular}{|l|l|l|l|}
\hline $\begin{array}{l}\text { Chun \& } \\
\text { Witt }\end{array}$ & $\begin{array}{l}\text { Core curriculum with } \\
\text { problem solving for } \\
\text { individual student } \\
\text { modifications }\end{array}$ & $\begin{array}{l}\text { Class-wide peer tutoring } \\
\text { and peer-assisted learning } \\
\text { strategies for whole class, } \\
\text { if needed, and standard } \\
\text { protocol interventions } \\
\text { selected from pool of } \\
\text { interventions based on } \\
\text { student needs }\end{array}$ & $\begin{array}{l}\text { Increased frequency and } \\
\text { duration or change of } \\
\text { intervention based on } \\
\text { problem-solving methods }\end{array}$ \\
\hline $\begin{array}{l}\text { Sugai \& } \\
\text { Horner }\end{array}$ & $\begin{array}{l}\text { Stated behavioral } \\
\text { expectations, teaching } \\
\text { expectations and } \\
\text { strengthening expected } \\
\text { behaviors, and } \\
\text { consequnces for } \\
\text { behaviors for all students } \\
\text { and staff in every settings } \\
\text { and with a data collection } \\
\text { system }\end{array}$ & $\begin{array}{l}\text { Specialized interventions } \\
\text { for unresponsive } \\
\text { students, including } \\
\text { structure and } \\
\text { predictability, positive } \\
\text { reinforcements, and good } \\
\text { home-school } \\
\text { communication }\end{array}$ & $\begin{array}{l}\text { Function-based, person- } \\
\text { centered, and intensive } \\
\text { interventions for } \\
\text { secondarily unresponsive } \\
\text { students provided with } \\
\text { consideration to school, } \\
\text { family, community, and } \\
\text { mental health context }\end{array}$ \\
\hline
\end{tabular}




\section{Appendix $C$}

Steps to Run Reports for Aspen Time Intervention

1. Remind teachers to update grades by the deadline.

2. Run the "Unload Posted Averages" report in eSchool which forces grades from the published classwork into a fake IPR run. The assistant principal extracted student grades from the teacher's grade books into a generated report. This data was extracted from eSchoolPLUS and another software program called Cognos generated a report in a csv (comma separated values) file. The purpose of moving the data into a csv file was that so the data now could be filtered, manipulated and arranged into columns that would then correlate with the data needed for the final three products.

3. Run the "Print IPRs" report. This report will prepare the data for Cognos.

4. Run the "Primary Homerooms by Period" report. This will clear primary homerooms and then you will want to add them back in by "Assign Primary Homerooms" report.

5. Run an advanced search report in eschool, mine is titled "ST PRIVILEGE-ALL STUDENTS." This will give you a list of all the students at BHS that are currently active.

6. Click on the "All AHS Students" table in the "AHSSpartanTime" database in Access. Highlight the entire table, right click, click on "Delete Record." This will clear the table. Close the tab. Then click on the tab "External Data" in the Access Program and import the excel document from step five which will populate your table. You will locate the table using the "Browse..." button. Then choose the "Append a copy of the records to the table" and choose from the drop down "All AHS Students" then click ok, then click next, then click finish, then click close.

7. Run the report in excel in Cognos $>$ Public Folders $>$ Mark Reporting $>$ MR-IPR $>$ "IPR Analysis with Drop Dates." Choose current building name, the IPR Date is "date entered," the Include Students who have a Drop Date after: "enter the current date you are running the report," and check the boxes for the letter grades of D,D+,D-,F and click Finish at the bottom. Save this report. This file is opened in Microsoft Excel that contains one row for each course grade that contains a grade of "D+" or below.

8. Delete the columns titled: Building-IPR, Yr-IPR, IPR Date, Course, Sec. Retitle the columns in the excel document using the below table:

\begin{tabular}{|l|l|l|l|}
\hline \multicolumn{1}{|c|}{ Old Name } & \multicolumn{1}{c|}{ New Name } & \multicolumn{1}{c|}{ Old Name } & \multicolumn{1}{c|}{ New Name } \\
\hline Student Id & Student Id & Curr Grade & Grade Level \\
\hline Student Name & Student Name & $\begin{array}{l}\text { Course Description- } \\
\text { IPR }\end{array}$ & Course \\
\hline HR Teacher & ST Teacher & Teacher-Course & Teacher \\
\hline HR Rm & ST Room & Rood Id-IPR & Room \\
\hline Counselor Name & Counselor & Marke Value & Grade \\
\hline Admin/Disciplinarian & Administrator & Date Dropped-IPR & Priority \\
\hline
\end{tabular}

Organize the list by course teacher. Delete the rows for the following teachers who are absent from AHS during ST: teacher A, teacher B, etc.. Organize the list by ST teacher and locate the ones that are blank. Check the "ST HOMEROOM TEACHER ASSIGNMENTS" excel document and insert the name of the ST teacher for those 
students that have ST on B days only. All students will go to teacher A in room A109 who have a $\mathrm{CC}$ class at AHS they have a D/F in, but the teacher is absent during ST.

9. Reorder the columns to this order from left to right: Counselor, Student Name, Priority, Grade, Course, Teacher, Student Id, ST Teacher, ST Room, Administrator, Grade Level, Room. Sort the excel document using a custom sort: Counselor-A to Z, Student Name-A to Z, Grade-A to Z. Email this report to counselors. Counselors will rank the priority of which courses the students will attend in which order. They will email the ST coordinator back who will put it into one large document.

10. Click on the "D F List" table in Access. Highlight the entire table, right click, click on "Delete Record." This will clear the table. Then click on the tab "External Data" in the Access Program and import the completed excel document from step eight.

Locate your document using the "Browse..." button. Choose the line titled "Append a copy of the records to the table" and choose "D F List" from the drop down menu. Click "Ok" then click "Yes" then click "Next" then "Next" then "Finish" then click "Close."

11. The three reports in Access will automatically populate after the above data has been entered. One report is a single sheet of paper designated for each student that has the prioritized courses in rank order with number one on top. Another report is a sheet of paper designated for each teacher in the building that will host a student during the Aspen Time period. It gives a rank order of all students assigned to the teacher and when they will be assigned to obtain help from that teacher. The last report is a sheet of paper designated for each Aspen Time homeroom teacher. This report contains all the students assigned to this teacher's roster and gives a detailed account of the locations each student has been assigned for the next two-week period. I only print "BY ST TEACHER" and "BY COURSE TEACHER (ALL)" on white paper and collate them by teacher. If you click on the actual report, you can then mouse over and right click on the tab of the report and click "Print Preview" to see what they will actually print looking like. You can tab through the pages to check for a quick accuracy or you can on the top choose "PDF or XPS" which will convert your report into a pdf file. I print the "BY STUDENT (ALL)" report on the colored paper. This report is the student assignments for ST. BOTH SIDES OF PAPER

12. Click on the Query titled "ST PRIVILEGE." This is pulling all of the kids from the All AHS Student list who are not on the DF List (the ones you uploaded in steps 6 \& 9). These students are those on privilege and have all grades at a " $\mathrm{C}$-“" or higher. Click on the tab in the Access Program titled "External Data." Then choose the export icon for excel. Locate on your computer where you want the excel file saved and then click both of the first two boxes under "Specify export options." This list contains the student name, student ID, and Aspen Time homeroom teacher.

13. Arrange the excel document by "Primary Homeroom" and then "Student Name." Open my excel sheet titled "ST HOMEROOM TEACHER ASSIGNMENTS." On the right side of this sheet, delete the students from the privilege list who are not in our building during ST. List the primary homeroom teacher for those students that appear on your list but don't have a primary homeroom teacher b/c they have CC one day and ST at AHS the other day. Then check the list of names who don't have primary homeroom teachers. Delete those that are not needed on the list, but use the Students 
at CC during ST list on the excel document to narrow the list down. Delete those students who are assigned to room D216 \& D217.

14. On the excel document from step 11, you will need to replace each Primary Homeroom with the actual teacher, using the excel document from step 12. It's not necessary to have the counselors on this list. Make sure and arrange the document by primary homeroom teacher then student last name one more time to catch any that are out of order.

15. Open the document titled "STUDENT ST ASSIGNMENT FORM-PRIVILEGE." Change the dates for the privilege period on the actual document then click save. A mail merge is then created into a Microsoft Word document that is one single sheet of paper for each student on privilege. This way, every student on every other Monday is given a sheet of paper that either indicates they are on privilege for the next two weeks or assigned to one or more classes and thus directed to a specific location for the next two-week period. Click on the "Mailings" tab and click on "Start Mail Merge" then "Step by Step Mail Merge Wizard." Check Letters, then click Next. Check use the current document, then click Next. Check use an existing list, then click on the browse icon and choose the list from step 13. Click OK three times, then click Next. Highlight the name Smith, Johnny on the actual Word document and click the "More items..." icon on the right side of the screen. Select student name, click insert then close. Place your cursor after the words Student ID on the actual Word document and click the "More items..." icon on the right side of the screen. Select Student ID, click insert then close. Place your cursor after the words ST Teacher on the actual Word document and click the "More items..." icon on the right side of the screen. Select Primary Homeroom, click insert then close. Click Next. Click Next. Then choose the "Print..." icon on the right side of the screen and print these all on colored paper. 


\section{Appendix D}

Tool Used to Take Field Notes in Classroom Setting

Date of Observation: Time: Classroom \#:

Content of Class: \# of Students:

Composition: Male: Female:

AMIN:

AS:

BL:

HSP:

MULTI:

WH:

PI:

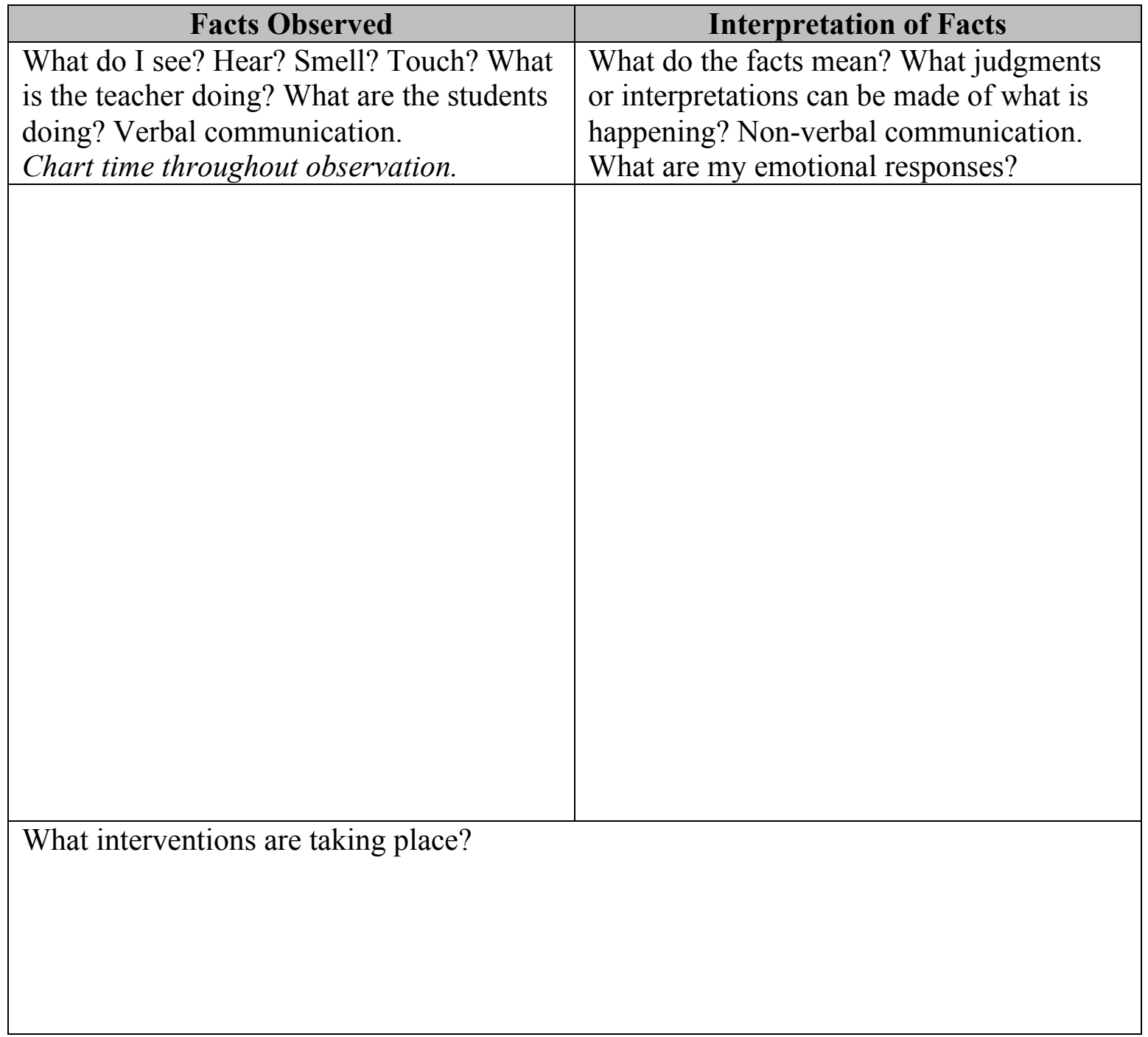

*Go back each night and completely fill in this document and add more detail as necessary. 
Notes to Complete After Observation

\begin{tabular}{|l|l|}
\hline \multicolumn{1}{|c|}{$\begin{array}{c}\text { Evidence-Based Intervention Strategies } \\
\text { Related to Mathematics }\end{array}$} & Notes \\
\hline $\begin{array}{l}\text { Using solved problems to engage students } \\
\text { in analyzing algebraic reasoning and } \\
\text { strategies }\end{array}$ & \\
\hline $\begin{array}{l}\text { Teach students to utilize the structure of } \\
\text { algebraic representations }\end{array}$ & \\
\hline $\begin{array}{l}\text { Teach student to intentionally choose from } \\
\text { alternatively algebraic strategies when } \\
\text { solving problems }\end{array}$ & \\
\hline Instructional explicitness & \\
\hline $\begin{array}{l}\text { Instructional design that eases the learning } \\
\text { challenge }\end{array}$ & \\
\hline $\begin{array}{l}\text { Strong conceptual basis for procedures that } \\
\text { are taught }\end{array}$ & \\
\hline Emphasis on drill and practice & \\
\hline $\begin{array}{l}\text { Cumulative review as part of drill and } \\
\text { practice }\end{array}$ & \\
\hline $\begin{array}{l}\text { Motivators to help students regulate their } \\
\text { attention and behavior and to work hard }\end{array}$ & \\
\hline Other & \\
\hline
\end{tabular}

*Adapted from:

Fuchs, L. S. (n.d.). Mathematics intervention at the secondary prevention level of multi-tier prevention system: Six key principles [Website]. Retrieved from http://www.rtinetwork.org/essential/tieredinstruction/tier2/mathintervention.

Star, J. R., Foegen, A., Larson, M. R., McCallum, W. G., Porath, J., Zbiek, R. M. (2015). Teaching strategies for improving algebra knowledge in middle and high school students. Washington, DC: National Center for Education Evaluation and Regional Assistance, Institute of Education Sciences, U.S. Department of Education. Retrieved from https://ies.ed.gov/ncee/wwc/Docs/PracticeGuide/wwc_algebra_040715.pdf

Follow Up Questions for Instructor

Instructions: All nine questions will be asked during the first meeting with a given instructor. Should that instructor's classroom be observed again, only question one will be asked after the second visit and any subsequent visits to the classroom.

1. What instructional strategies did you use during Aspen Time today when working with students?

a. Describe how these strategies are or are not different than what you use during the regular class period?

b. Please tell me your reasons for using the same or different strategies than those used during the regular period.

2. UNIVERSAL SCREENING - Can you tell me what you understand about Aspen Time and the screening process of students? 
3. FORMATION OF TEAMS - Describe how decisions are made to move students between levels (in and out of Aspen Time). Who is involved in decision-making? What data are used to inform those decisions, and how are they used?

4. PROGRESS MONITORING - Are the decisions about whether or not a student is responding to secondary level interventions based on progress monitoring data? Describe the process used for monitoring progress.

5. EVIDENCE-BASED INTERVENTIONS - What program(s) does the math department use for secondary intervention? Are procedures in place to monitor the fidelity of implementation of the secondary level interventions? If so, please describe.

6. PROFESSIONAL DEVELOPMENT - What ongoing professional development is available to staff who provide secondary interventions?

7. What do you think are the drawbacks or challenges of Aspen Time?

8. What do you think are the benefits of Aspen Time?

9. Do you have any additional thoughts on Aspen Time or is there anything that I have not asked that you feel is important for me to know? 


\section{Appendix E}

Tool Used to Take Field Notes in SST Meeting

Date of Observation: Time:

Room:

Participants:

\begin{tabular}{|l|l|}
\hline \multicolumn{1}{|c|}{ Facts Observed } & \multicolumn{1}{|c|}{ Interpretation of Facts } \\
\hline $\begin{array}{l}\text { What do I see? Hear? Smell? Touch? What } \\
\text { is the teacher doing? What are the students } \\
\text { doing? Verbal communication. }\end{array}$ & $\begin{array}{l}\text { What do the facts mean? What judgments } \\
\text { or interpretations can be made of what is } \\
\text { happening? Non-verbal communication. } \\
\text { What are my emotional responses? }\end{array}$ \\
\hline & \\
& \\
\hline What types of interventions are students being placed? & \\
\hline
\end{tabular}

*Go back each night and completely fill in this document and add more details as necessary. 


\section{Appendix $F$}

Focus Group Questions for Aspen Scheduling Committee Members (Teachers)

Thanks to each of you for visiting with me today. I truly appreciate you taking the time away from your families, significant others, etc. to support the evaluation of Aspen Time today. Your dedication to continuous improvement of your school shows by being present today. The purpose of this case study is to explore the implementation of our Response to Intervention (RTI) system: Aspen Time. This study will also look at the barriers to implementation of RTI at the high school level in addition to how different stakeholders view Aspen Time. This study will help clarify the scheduling committee's future work in program design and implementation of RTI at Aspen High School.

Today we are hosting a focus group to understand your views of Aspen Time. In front of you, there is an informed consent letter detailing the information regarding my study. I would like to specifically point out the section on participation in that if you decide not to participate, you will not be penalized in any way. You can also decide to stop at any time without penalty. If you do not wish to answer any of the questions, you may simply ask that you be skipped or just sit quietly. You may withdraw your data at the end of the study if you so choose too. Please look over this form and if you agree to participate, please sign the form and we will collect them at the end of today's session.

1. Could you please tell me a little about yourself (name, degrees, years in school district, licensures, how long you have taught) and your current role in education?

REMIND FOCUS GROUP ABOUT PURPOSE OF STUDY...As a simple reminder, we will be exploring the absence or presence of essential elements of RTI, the barriers to implementation and finally gathering stake holder's thoughts regarding the implementation of Aspen Time at Aspen High School.

2. What is your general understanding of Aspen Time?

a. Describe your role before/during/after the Aspen Time intervention daily period.

3. How are students assigned to Aspen Time?

4. What instructional strategies have you used during Aspen Time when working with students?

a. Are these strategies different than what you use during the regular class period?

b. Please tell me your reasons for using the same or different strategies than those used during the regular period.

5. Describe what a typical Aspen Time intervention period looks like in your classroom. 
6. What are the benefits or challenges with students who are not assigned to teachers during Aspen Time?

7. What do you think are the drawbacks or challenges of Aspen Time?

8. What do you think are the benefits of Aspen Time?

9. Do you have any additional thoughts on Aspen Time or is there anything that I have not asked that you feel is important for me to know? 


\section{Appendix $G$}

\section{Focus Group Questions for Aspen Leadership Team}

Thanks to each of you for visiting with me today. I truly appreciate you taking the time away from your families, significant others, etc. to support the evaluation of Aspen Time today. Your dedication to continuous improvement of your school shows by being present today. The purpose of this case study is to explore the implementation of our Response to Intervention (RTI) system: Aspen Time. This study will also look at the barriers to implementation of RTI at the high school level in addition to how different stakeholders view Aspen Time. This study will help clarify the scheduling committee's future work in program design and implementation of RTI at Aspen High School.

Today we are hosting a focus group to understand your views of Aspen Time. In front of you, there is an informed consent letter detailing the information regarding my study. I would like to specifically point out the section on participation in that if you decide not to participate, you will not be penalized in any way. You can also decide to stop at any time without penalty. If you do not wish to answer any of the questions, you may simply ask that you be skipped or just sit quietly. You may withdraw your data at the end of the study if you so choose too. Please look over this form and if you agree to participate, please sign the form and we will collect them at the end of today's session.

1. Could you please tell me a little about yourself (name, degrees, years in school district, licensures, how long you have taught) and your current role in education?

REMIND FOCUS GROUP ABOUT PURPOSE OF STUDY...As a simple reminder, we will be exploring the absence or presence of essential elements of RTI, the barriers to implementation and finally gathering stake holder's thoughts regarding the implementation of Aspen Time at Aspen High School.

2. What is your general understanding of Aspen Time?

a. Describe your role before/during/after the Aspen Time intervention daily period.

3. How are students assigned to Aspen Time?

4. Describe the intervention teams at Aspen. How do these teams coincide with Aspen Time?

5. What instructional strategies are being used during Aspen Time when teachers work with students?

a. Are these strategies different than what are used during the regular class period?

a. Please tell me your reasons for using the same or different strategies than those used during the regular period. 
6. What are the benefits or challenges with students who are not assigned to teachers during Aspen Time?

7. What do you think are the drawbacks or challenges of Aspen Time?

8. What do you think are the benefits of Aspen Time?

9. Do you have any additional thoughts on Aspen Time or is there anything that I have not asked that you feel is important for me to know? 


\section{Appendix $H$}

\section{Informed Consent Form}

Identification of Researcher: This research study is being conducted by Andrew McCarthy, a doctoral student in the University of Missouri's comprehensive statewide Ed.D. program

Project Title: A Case Study of Implementing Response to Intervention in High School

Purpose of the Study: The purpose of this case study is to explore to what degree the essential elements of RTI as defined by the literature are implemented in the Aspen Time program developed at Aspen High School. In this case, this study will help clarify the Aspen scheduling committee's future work in program design and implementation.

Request for Participation: I am asking to interview you to help me gather information for a study concerning Aspen Time at Aspen High School. I want to determine if the four elements of a successful RTI program are evident at Aspen. More specifically, the answers to your questions will help me determine if the four elements above are evident (if not, what are the barriers) and how they are being implemented in the classroom. Participation in this study is voluntary. You do not have to participate in this study. If you decide not to participate, you will not be penalized in any way. You can also decide to stop at any time without penalty. If you do not wish to answer any of the questions, you may simply skip them. You may also withdraw your data at the end of the study.

Exclusions: You must be considered an administrator or faculty member at Aspen High School to participate in this research study.

Conflict of Interest: Your responses to the questions asked in this study will have no impact on your final, end of the year summative evaluation with Character Public Schools, should this apply to you.

Description of Research Method: This study asks for your participation in either an indepth interview lasting approximately 15-30 minutes or a focus group lasting approximately one hour. The interview/focus group will ask you various questions about what is taking place during the Aspen Time period. Feel free to ask for clarification on any question at any point during the interview/focus group. Also, you will have the opportunity to ask any questions you may have regarding the topic at the conclusion of the interview/focus group.

Privacy: All of the information I collect will be kept confidential and pseudonyms will be used to identify the different participants. The interview/focus group will use an audio recording and will only be reviewed by the interviewer. The recording will be kept in a 
secure, locked location in the interviewer's home. If transcribed, all documents will also be kept in a secure, password protected electronic file.

Explanation of Risks: The risks associated with participating in this study are similar to the risks of everyday life.

Explanation of Benefits: You will receive no payment for taking part in this study. Once I have completed the research study I will send you a copy of my findings should you ask for one. It will be a document compiling my interpreted findings from the individuals I interviewed and the documents I analyzed.

Questions: If you have any questions about this study, please contact Andrew McCarthy. He can be reached at adme59@mail.missouri.edu. His advisor for this research study is Dr. Lisa Dorner and she can be reached atdornerl@missouri.edu.

If you have any questions regarding your rights as a participant in this research and/or concerns about the study, or if you feel under any pressure to enroll or to continue to participate in this study, you may contact the University of Missouri Campus Institutional Review Board (which is a group of people who review the research studies to protect participants' rights) at (573) 882-9585 or umcresearchcirb@missouri.edu.

A copy of this Informed Consent form will be given to you before you participate in the research.

Signatures: I have read this consent form and my questions have been answered. My signature below means that I do want to be in the study. I know that I can remove myself from the study at any time without any problems.

Subject Printed Name:

Subject Signature: Date: 


\section{Appendix I}

Triangulation of Data Based on Study Questions

\begin{tabular}{|c|c|c|c|c|c|c|}
\hline \multirow[b]{2}{*}{$\begin{array}{l}\text { Research } \\
\text { Question }\end{array}$} & \multirow[b]{2}{*}{$\begin{array}{l}\text { Collection } \\
\text { Method }\end{array}$} & \multicolumn{4}{|c|}{ Four Essential Elements } & \multirow[b]{2}{*}{ Other } \\
\hline & & $\begin{array}{c}\text { Formation } \\
\text { of Teams }\end{array}$ & $\begin{array}{l}\text { Universal } \\
\text { Screening }\end{array}$ & $\begin{array}{l}\text { Continuous } \\
\text { Monitoring }\end{array}$ & $\begin{array}{l}\text { Evidence- } \\
\text { Based } \\
\text { Interventions }\end{array}$ & \\
\hline \multirow{3}{*}{$\begin{array}{l}\text { To what } \\
\text { degree was } \\
\text { each element } \\
\text { evident? }\end{array}$} & $\begin{array}{l}\text { Document } \\
\text { Review }\end{array}$ & & & & & \\
\hline & $\begin{array}{c}\text { Personal } \\
\text { Knowledge }\end{array}$ & & & & & \\
\hline & $\begin{array}{c}\text { Fieldnotes } \\
\text { (classroom \& } \\
\text { SST } \\
\text { observations) }\end{array}$ & & & & & \\
\hline $\begin{array}{l}\text { How was } \\
\text { Aspen Time } \\
\text { implemented } \\
\text { from various } \\
\text { perspectives? }\end{array}$ & $\begin{array}{l}\text { Focus } \\
\text { Groups }\end{array}$ & & & & & \\
\hline
\end{tabular}




\section{Appendix $J$}

Triangulation - Absence of Element, Barriers to Implementation

\begin{tabular}{|c|c|c|c|c|c|}
\hline & $\begin{array}{c}\text { Scheduling/ } \\
\text { Structure }\end{array}$ & $\begin{array}{c}\text { Curriculum } \\
\text { Issues }\end{array}$ & Fidelity & $\begin{array}{c}\text { Staff } \\
\text { Capacity/ PD }\end{array}$ & Other \\
\hline $\begin{array}{c}\text { Formation of } \\
\text { Teams }\end{array}$ & & & & & \\
\hline $\begin{array}{c}\text { Universal } \\
\text { Screening }\end{array}$ & & & & & \\
\hline $\begin{array}{c}\text { Continuous } \\
\text { Monitoring }\end{array}$ & & & & & \\
\hline $\begin{array}{c}\text { Evidence- } \\
\text { Based } \\
\text { Interventions }\end{array}$ & & & & & \\
\hline
\end{tabular}




\section{Appendix $K$}

Triangulation of Data Based on Barriers in Secondary RTI Implementation

\begin{tabular}{|c|c|c|c|}
\hline Category & Researcher & Barrier & Coded in Research \\
\hline \multirow{4}{*}{$\begin{array}{l}\text { Scheduling/ } \\
\text { Structure }\end{array}$} & $\begin{array}{l}\text { Johnson, Smith and } \\
\text { Harris (2009) }\end{array}$ & $\begin{array}{l}\text { Structure of the } \\
\text { school day - } \\
\text { secondary more } \\
\text { than one teacher }\end{array}$ & \\
\hline & $\begin{array}{l}\text { Johnson, Smith and } \\
\text { Harris (2009) } \\
\text { Pyle \& Vaughn } \\
(2012) \\
\text { O'Connor \& } \\
\text { Freeman (2012) }\end{array}$ & $\begin{array}{l}\text { Time within the } \\
\text { school day to } \\
\text { provide } \\
\text { intervention at tiers } \\
\text { two and three }\end{array}$ & \\
\hline & Mellard (2009a) & $\begin{array}{l}\text { Structure of the } \\
\text { school day - } \\
\text { moving to multiple } \\
\text { classrooms in } \\
\text { secondary }\end{array}$ & \\
\hline & $\begin{array}{l}\text { Mellard (2009b) } \\
\text { Sansosti, Goss, \& } \\
\text { Noltemeyer (2011) }\end{array}$ & $\begin{array}{l}\text { Student schedules } \\
\text { prohibit scheduling } \\
\text { of time in day for } \\
\text { intervention }\end{array}$ & \\
\hline \multirow{4}{*}{$\begin{array}{l}\text { Curriculum } \\
\text { Issues }\end{array}$} & $\begin{array}{l}\text { Pyle \& Vaughn } \\
(2012)\end{array}$ & $\begin{array}{l}\text { Secondary } \\
\text { intervention is } \\
\text { content recovery v. } \\
\text { elementary is early } \\
\text { intervention }\end{array}$ & \\
\hline & $\begin{array}{l}\text { Pyle \& Vaughn } \\
(2012)\end{array}$ & $\begin{array}{l}\text { Demands on } \\
\text { curriculum - } \\
\text { vocab., writing } \\
\text { prompts, discuss } \\
\text { abstract ideas in } \\
\text { secondary }\end{array}$ & \\
\hline & $\begin{array}{l}\text { Sansosti, Goss, \& } \\
\text { Noltemeyer (2011) }\end{array}$ & $\begin{array}{l}\text { Student schedules } \\
\text { prohibit scheduling } \\
\text { of time in day for } \\
\text { intervention }\end{array}$ & \\
\hline & $\begin{array}{l}\text { Johnson, Smith and } \\
\text { Harris (2009) }\end{array}$ & $\begin{array}{l}\text { Creation of siloed } \\
\text { teachers who don't } \\
\text { work } \\
\text { collaboratively or }\end{array}$ & \\
\hline
\end{tabular}




\begin{tabular}{|c|c|c|c|}
\hline & & $\begin{array}{l}\text { teach one unique } \\
\text { course }\end{array}$ & \\
\hline \multirow{4}{*}{ Fidelity } & Mellard (2009b) & $\begin{array}{l}\text { Fidelity of } \\
\text { implementation - } \\
\text { professional } \\
\text { development time } \\
\text { for teachers }\end{array}$ & \\
\hline & $\begin{array}{l}\text { Mellard \& Johnson } \\
\text { (2009) }\end{array}$ & $\begin{array}{l}\text { Fidelity of } \\
\text { implementation - } \\
\text { professional } \\
\text { development time } \\
\text { for teachers }\end{array}$ & \\
\hline & $\begin{array}{l}\text { Sansosti, Goss, \& } \\
\text { Noltemeyer (2011) }\end{array}$ & $\begin{array}{l}\text { Sensemaking - } \\
\text { site-specific issues } \\
\text { with } \\
\text { implementation }\end{array}$ & \\
\hline & $\begin{array}{l}\text { Spillane, Reiser, \& } \\
\text { Reimer (2002) }\end{array}$ & $\begin{array}{l}\text { Sensemaking-- } \\
\text { implementation } \\
\text { issues with RTI } \\
\text { based on prior } \\
\text { knowledge }\end{array}$ & \\
\hline \multirow{5}{*}{$\begin{array}{l}\text { Staff } \\
\text { Capacity/ } \\
\text { PD }\end{array}$} & $\begin{array}{l}\text { O'Connor \& } \\
\text { Freeman (2012) }\end{array}$ & $\begin{array}{l}\text { Building staff } \\
\text { capacity and belief } \\
\text { every child can } \\
\text { learn }\end{array}$ & \\
\hline & $\begin{array}{l}\text { Pyle \& Vaughn } \\
\text { (2012) }\end{array}$ & $\begin{array}{l}\text { Teachers working } \\
\text { collaboratively for } \\
\text { all students' needs }\end{array}$ & \\
\hline & $\begin{array}{l}\text { O'Connor \& } \\
\text { Freeman (2012) }\end{array}$ & $\begin{array}{l}\text { More training at } \\
\text { collegiate level }\end{array}$ & \\
\hline & $\begin{array}{l}\text { Sansosti, Goss, \& } \\
\text { Noltemeyer (2011) }\end{array}$ & $\begin{array}{l}\text { RTI practices } \\
\text { taught in college } \\
\text { programs }\end{array}$ & \\
\hline & $\begin{array}{l}\text { Johnson, Smith and } \\
\text { Harris (2009) }\end{array}$ & $\begin{array}{l}\text { More professional } \\
\text { development for } \\
\text { teachers }\end{array}$ & \\
\hline
\end{tabular}


VITA

Andrew D. McCarthy is a proud graduate of Odessa High School, Odessa, MO. After graduating high school, Andrew attended the University of Missouri-Columbia where he received his BEd, Secondary Social Studies; MEd, Curriculum and Instruction; EdS in K-12 Administration; and EdD in Pre K-12 Administration. Dr. McCarthy serves as a high school assistant principal in Columbia Public Schools. He is married to Rachel M. Henderson McCarthy, an assistant principal who also serves in Columbia Public Schools. Andrew and Rachel have four children, a daughter named Eliyah M. McCarthy, and three sons, Brookson J. McCarthy, David N. McCarthy, and Samuel E. McCarthy. 